\title{
The Role of Nuclear Thermal-Hydraulics in the Licensing of Atucha-II: the LBLOCA
}

\author{
Oscar Mazzantini' ${ }^{1}$, Giorgio Galassi ${ }^{2}$ and Francesco D'Auria ${ }^{2, *}$ \\ NA-SA; mazzantini@na-sa.com.ar \\ 2 University of Pisa: g.galass@ing.unipi.it \\ * Corresponding author. University of Pisa: f.dauria@ing.unipi.it; Tel.: (+39-050-2210-359)
}

\begin{abstract}
The paper deals with the safety evaluation and the embedded licensing process of the Atucha-II 800 Mwe Pressurized Heavy Water Reactor (PHWR) in Argentina. Atucha-II was designed by Kraftwerk Union (KWU) during the $60^{\prime}$ s, the related construction was started/stopped in the 90's and restarted on 2006, and was connected to the electrical grid in 2014. Because of market policies, the KWU designer could not be directly involved in the licensing process during the first decade of the 2000 millennium: a licensing suited safety evaluation was performed by the Nucleoeléctrica Argentina (NA-SA), utility owner of the Atucha-II, with support of external experts group. A designer-independent assessment was performed having access to the installed systems and components other than the relevant design documents. Large core size (related to Pressurized Water Reactor - PWR - producing the same thermal power), presence in the core of natural uranium and heavy water fluids, i.e. the coolant and the moderator driven by two circulation loops with different average temperatures, characterize the system design. In those conditions, during the early phase of a depressurization transient, the 'hot' coolant vaporizes and the colder moderator remains in the liquid phase: a positive void coefficient is created. The relevance of the Large Break Loss of Coolant Accident (LBLOCA) in safety assessment is discussed with emphasis given to the system design features, the approach pursued in the analysis and the key results. Break opening time and time of occurrence of the safety boron injection affect, during the early period of the transient, the propagation of (negative) pressure wave, the fluid flashing, the heat transfer and the neutron flux: a fission power excursion is expected to occur. The analysis of a complex three-dimensional situation, considering the unavoidable uncertainties associated with the computation, demonstrates that safety limits are preserved.
\end{abstract}

Keywords: Atucha-II; PHWR; Channel type reactor; Positive void coefficient; LBLOCA; BEPU approach

\section{Introduction}

Nuclear Reactor Safety (NRS) may be defined as the connection between the protection of the environment and the humans against the ionizing radiations massively produced and stored in the core of Nuclear Power Plants, IAEA, 2000.

Accident Analysis (AA) constitutes a key part of NRS: triggering and system availability for transients events are assumed with a given probability within the Design Basis Accident (DBA) boundary and response of the concerned reactor is evaluated with the purpose of demonstrating the available safety margins, IAEA, 2002. However, deterministic analyses have to cover pre-determined events independent of probabilities.

The Loss of Coolant Accident (LOCA) is an element of the DBA set of accidents, OECD/NEA/CSNI, 1989; in the case of Pressurized Water Reactors (PWR), the LOCA term implies a group of accidents primarily characterized by different break area and location. In most situations, 
the Large Break LOCA (LBLOCA), which is strictly connected with the reactor design (chapter 2), is originated by the Double Ended Guillotine Break (DEGB) in one Cold Leg (CL) close to the Reactor Pressure Vessel (RPV).

Licensing constitutes the legal part of NRS or the connection between results from safety analyses and threshold limits set by regulators, e.g. USNRC, 2005: any licensing analysis includes a safety evaluation performed according to hypotheses and procedures consistent with the regulatory process.

A wide literature exists for LBLOCA in PWR see e.g. D'Auria \& Galassi, 2017, and Ylonen A., 2008. A cross-link between design features of reactors, accident scenarios, phenomena and parameters relevant to phenomena, is established; LOCA related topics can be distinguished into six broad categories which are briefly discussed hereafter including main findings: 1) the dynamic effects; 2) the core cooling and the Peak Cladding Temperature (PCT);3) the nuclear fuel behavior; 4) the containment performance; 5) the long term cooling; 6) the licensing aspects and the application of the Best Estimate Plus Uncertainty (BEPU) approach.

The dynamic effects are originated by the break opening and consequent connection between space-regions at different pressures, or primary system and containment at 15 and $0.1 \mathrm{MPa}$, respectively. The fluid depressurization wave and the stored energy in the metal structure of the piping generate loads upon primary system internals (primarily inside RPV), e.g. Vigni et al., 1978, and D' Auria \& Vigni, 1989, and containment (see below). The amplitude of pressure wave generated at the break depends upon the break opening time (as discussed with more detail in section 3.1); consequent load effects arise in about $1 \mathrm{~s}$ since the break opening occurrence owing to the sonic speed propagation of the wave.

The core cooling has been at the center of attention of nuclear thermal-hydraulics since the 50 's of the XX century. Related to LBLOCA well known terms are summarized as blowdown, refill, reflood, Departure from Nuclear Boiling (DNB), PCT, Two-Phase Critical Flow (TPCF) and design/actuation of Emergency Core Cooling Systems (ECCS), see e.g. Aksan et al., 2018, Petruzzi \& D'Auria, 2005, and OECD/NEA/CSNI, 1989.

The fuel behavior needs specific consideration during LOCA because of a three-fold solicitation of the clad after the mentioned pressure wave load: (a) high temperature following the DNB occurrence with reduced mechanical strength, (b) large pressure differential when inside fission gas pressure remains nearly constant and external system pressure decreases following the system depressurization, and (c) fast chemical reaction with water and consequent oxidization and embrittlement. Clad ballooning and burst, other than hydrogen production may result originating concerns in relation to core cooling and release of fission products into the coolant, OECD/NEA, 2009. Additional fuel weaknesses have been characterized during the last decade leading to concerns, e.g. D'Auria et al., 2018, (see also D'Auria et al., 2019) in relation to capability of the fuel to satisfy the criteria set for the ECCS design, USAEC, 1971, and USNRC, 2018.

The containment constitutes the ultimate heavy barrier to the release of fission products installed to protect humans and environment in case of failures of other safety barriers. Pressure and temperature loads following LOCA constitute design targets for the containment, OECD/NEA/CSNI, 1999. Dynamic loads acting on the containment can be classified as jet thrust and primary system restraints, e.g. Vigni \& D'Auria, 1979, pipe whip, e.g. Reid et al., 2011, and missile, Ranjan et al., 2014.

The demonstration of the long term cooling capability is part of early requirements for water cooled nuclear reactors, USAEC, 1971. Recent findings and consideration of the licensing rule can be found in Ullah Amin et al., 2017. The presence of LOCA generated debris on the pool constitutes a concern in nuclear reactor safety, e.g. Park et al., 2011,

The licensing aspects and the BEPU imply the application of a computer code, e.g. Relap, RELAP5/MOD3, 1998, and of a regulation, e.g. USNRC, 2005, (already cited) see also USNRC, 1978, and USNRC, 2007, to the analysis of any accident scenario including LBLOCA. Then, the application of a computer code implies the development and the qualification of the code, e.g. D'Auria \& Galassi, 1998, as well as of the nodalization, e.g. Bonuccelli et al., 1993, and the code-user or analyst, e.g. Ashley et al., 1998. Addressing the scaling issue, e.g. OECD/NEA/CSNI, 2017, coupling of codes, 
e.g. OECD/NEA, 2004, see also Bousbia-Salah et al., 2004, and uncertainty evaluation, e.g. IAEA, 2008, constitute essential elements of the BEPU approach which also needs a formal procedure, e.g. D'Auria et al., 2012, see also Galetti \& D'Auria, 2004, and Kang, 2016.

The peculiarities associated with the use of heavy water as moderator, i.e. Pressurized Heavy Water Reactors (PHWR) strongly affect the LOCA scenario. Two main types of reactors can be classified as PHWR: the Canadian Deuterium-Uranium (CANDU) and the Atucha reactors (I and II units). Heavy water is used in order to allow natural uranium as fuel; cylindrical channel boxes separate coolant and moderator: in the case of CANDU, horizontal pressurized fuel channel separate the coolant from the nearly-at-atmospheric-pressure heavy water moderator; in the case of Atucha, vertical fuel channels are installed inside the RPV which keeps nearly at the same pressure the moderator and the coolant. In both cases average moderator temperature is lower than coolant temperature (much lower in the case of CANDU). LOCA accident generates a fission power peak in both PHWR types, e.g. see Kastanya et al., 2013, in the case of CANDU and Pecchia et al., 2015, and Mazzantini et al., 2018, in the case of the Atucha-II PHWR: coolant vaporization, with moderator remaining in single phase liquid during the early period of blowdown, causes a positive void reactivity feedback, e.g. Gonzales-Gonzales et al., 2014. In all cases suitable safety margins for the concerned reactors have been predicted.

Attempts have been made to re-define the role of the LOCA within the overall safety evaluation of water cooled reactors, also providing insights into the latest developments in the area of analyses, licensing trends and computational capabilities, OECD/NEA/CSNI, 2003, documenting a Workshop held in Zurich. Rather, the following sentence is reported from the summary of the workshop, Thadani \& Laaksonen J., 2003: “... None of the participants suggested that the probability of a LBLOCA could be so high that it represents a significant contribution to the overall risk."

So what remains to be investigated in the area of LBLOCA in either PWR or PHWR? Or, what can be the innovation to justify a 'new' publication dealing with LBLOCA? An answer to those questions is provided by the following topics which constitute the objective for the paper:

- Outlining the connection between LBLOCA and the primary system layout in both PWR and PHWR.

- Considering safety margins associated with positive void coefficient in PHWR.

- Discussing how recent research and technology achievements can be used to assess the safety of reactors designed half-a-century before (i.e. the adoption of the current BEPU approach).

- Demonstrating the importance-of and the capability-to-evaluate:

- Three-dimensional thermal-hydraulic phenomena in the core.

- Mechanical loads upon structures (inside and outside the vessel) generated by pressure wave propagation.

- Coupling between thermal-hydraulics and neutron physics.

- Nuclear fuel performance and deterministic connection with radioactive releases.

- Long term cooling including the containment role.

\section{The PWR and the Atucha-II PHWR}

The history and the bases of the PWR design are shortly revisited hereafter focusing on the safety and the origin of the LBLOCA issue, namely the logical chain: 
Following half a century of discoveries in nuclear physics, the demonstration of sustainability of the fission reaction by E. Fermi (Dec. $2^{\text {nd }}, 1942$ ) constitutes a fundamental landmark for mankind: this is equivalent to the discovery of fire, achieving the ability to produce carbon steel products (the "Iron Age"), the discovery of thermal engine, or the proposition of the " $E=m c^{2}$ " formula from A. Einstein. The war period (WWII) plus the situation that groups of scientists in opponent Countries were working to pursue the same objective (i.e. a powerful bomb), overshadowed the importance of the discovery associated with the Fermi Pile. The unfortunate nuclear weapon explosions in 1945 did not contribute to valorize the potential strategic role of that discovery; rather, the weapon argument continues nowadays to obscure the significance of that discovery.

At this historical moment in the aftermath of 1942, i.e. the end of the WWII, Admiral Rickover entered the scene of the nuclear era. He looks like a sculptor who modeled the raw science material, or the graphite pile, and created a wonderful statue, or the power producing PWR: the first nuclear-powered engine and the first atomic-powered submarine, the USS Nautilus, launched in 1954. All key design features of the submarine PWR are reflected in forthcoming PWR used for electricity production. An attempt is made hereafter to summarize those peculiarities.

In the submarine PWR, the core constituted by cylindrical fuel rods was conceived and the water was chosen as working fluid, e.g. acting simultaneously as coolant for the nuclear fuel and moderator for the energetic fission neutrons. The water was selected considering half-dozen different fluids as coolants (or even solids as moderators): this brought to the difficult-to-manage constraint of low thermal efficiency, with the (big) advantage of knowing the physical properties and the chemical interactions with other materials in the core. The selection of water fixed a roadmap for the high pressure and for the consideration of the Reactor Pressure Vessel (RPV) as the key component for the system design.

Other peculiarities of the submarine-resulting PWR loop can be stated as follows (see Fig. 1):

1) Avoid saturated boiling in the core to preserve the uniformity of neutron flux as much as possible.

2) Introduce steam generators to allow boiling and steam production in order to move a turbine.

3) Mutual position between core and steam generators in such a way that natural circulation can remove the decay power should main coolant pumps go out of order.

4) Piping connection with the pressure vessel at an elevation above the core and with a size (pipe diameter) to allow core cooling following the unfortunate event of pipe break.

The design of PWR incidentally included technological facets which made difficult its replicas; key ones are the pressure vessel itself with thick walls unsuited even for heavy industry, the sophisticate control rod drive mechanisms including related precision requirements and the need for fuel (or natural uranium) enrichment.

The key geometric and layout features of concerned Reactor Coolant System (RCS) were first decided (then planned and designed) in the 50's of the last century; later on, till current year, those features were accepted by coming generations of designers and technologists. Design ensuring safety constitutes a requirement: five related aspects connected with the LBLOCA are emphasized below.

1) Elevation of Cold Leg (CL) axis [related to the bottom of the Reactor Pressure Vessel (RPV) or, more precisely, to the elevations of the Top and Bottom of Active Fuel (TAF and BAF)].

2) Diameter of the CL pipe.

3) Mutual elevation between core and Steam Generators (SG) and overall pressure drop in SG: the elevation has a limited role in the early phase of a LBLOCA (it largely affects other LOCA situations); otherwise, the SG pressure drop may largely affect the system performance in case of LBLOCA.

4) Pressurizer role.

5) Presence of containment.

Sketches for the RPV and RCS of a PWR are given in Fig. 1. The relative position of CL axis and the bottom of the RPV and the TAF, ' $E$ ' and ' $F$ ' dimensions, item 1), left of Fig. 1, is such to allow 
cooling of the core following guillotine break of the same CL pipe: the location of CL at the bottom of the RPV (this is convenient to reduce the pressure drops in primary system) causes loss of the injected emergency cooling liquid by gravity and the consequent impossibility to cool the core. Any larger size for CL pipe, (D), item 2), left of Fig. 1, is convenient from the view point of minimizing the loop pressure drops during normal operation; however, an upper limit for the diameter is fixed to demonstrate fulfilling of Emergency Core Cooling System (ECCS) design criteria including pressure wave propagation from break location, mechanical load of internals, rod surface temperature excursion (maximum value and slope in a time diagram) during the early blowdown phase.

The layout of primary circuit is determined by the mutual position between core and SG, item 3): when the worst LOCA conditions (e.g. as far as core cooling is concerned) are determined for DEGB in CL close to RPV, a design effort is needed to prevent the occurrence of stagnation point in the core thus affecting the hydraulic diameter of the SG. Flow reversal in core region cannot be avoided in case of DEGB-LOCA: fluid from PRZ, item 4), should discharge toward the core contributing to early core cooling rather than toward the SG. Containment, item 5), shall withstand mechanical (pipe whip, jet thrust, missiles) and thermodynamic (pressure and temperature) loads following LBLOCA and prevent radioactivity releases to the environment according to regulation.
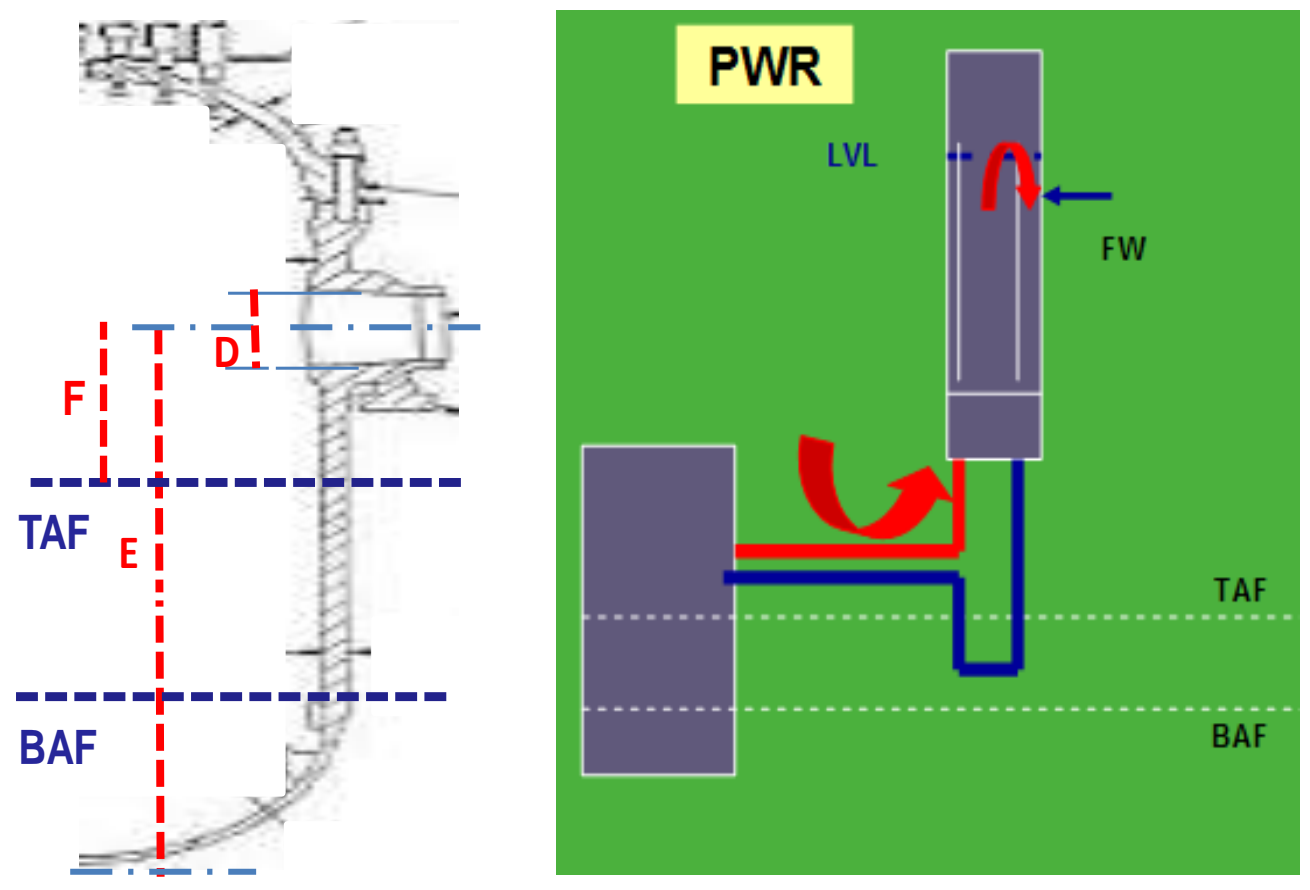

Figure 1. Sketch of PWR system. Left: RPV longitudinal section. Right: Primary Loop, without PRZ.

Design targets of Engineered Safety Features (ESF), including ECCS, ensure acceptable radiation releases such that the containment, item 5), is not needed in principle (i.e. a properly vented building could be enough to protect the environment). However, early designers of PWR added the containment barrier to account for unforeseen deficiencies of the design process.

\subsubsection{The Leak before Break (LBB) Theorem}

LBB is based upon the experimental observation that detectable fluid leakage from a large diameter pressure pipe is expected before disruptive LOCA including double ended break, see e.g., Heckmann \& Sievers, 2018, and Bourga et al., 2015. The LBB has a wide range of applicability in nuclear technology, e.g. it can be used as an argument to justify the elimination of pipe whip restraints and, definitely, for early detection of pipe rupture.

From a literature overview, including two mentioned papers, we synthesize the LBB theorem as follows: "The LBB is a detected fluid leakage including supporting analytical studies and is used as an early alarm to scram the reactor; this may exclude the consideration of Large Break Loss of Coolant Accident 
(LBLOCA) from the list of events to be considered in safety analyses of individual NPP." The first sentence of the theorem can be easily endorsed; however, the last sentence is not acceptable within the present context: seismic events and unforeseen thermal stress induced corrosion erosion processes may cause a bypass of the LBB process, or a large break is not necessarily preceded by a small leakage. Specific Atucha-II related activity, Zhang et al., 2013, is discussed in other parts of this paper.

\subsubsection{PWR and PHWR}

The acronym PHWR is adopted in the literature to indicate any pressurized reactor where heavy water is used; within the PHWR class, one may distinguish the CANDU, the 'Indian' CANDU-type' and the KWU Atucha (i.e. Atucha-I and Atucha-II) NPP. The use of heavy water as moderator combined with natural uranium as fuel and the different thermal-hydraulic conditions of moderator and coolant (more details given below in relation to the Atucha-II PHWR), characterize those reactors. Following LOCA in PHWR the coolant vaporizes before the moderator and induces a fission power excursion, e.g. Prosek et al., 2004. This is the effect of the so-called positive void coefficient: therefore, decrease in coolant capabilities to remove the heat generated by fission is associated to an increase of thermal power. However, the consequent fission power excursion may last a few tenths of a second with total energy generated being a small fraction of core energy during $10 \mathrm{~s}$ of the transient, as discussed in section 4.3.2.

\subsubsection{Summary Remarks}

LOCA and LBLOCA constitute transient events or accidents directly connected with the design of PWR (and Atucha-II type of PHWR). The consideration of those events as part of the mandatory list of DBA is challenged by the LBB theorem discussed above and, more subtly, by recently discovered nuclear fuel weakness (as mentioned in Introduction), see the review by D'Auria et al., 2019. Those weaknesses leading to fuel failures primarily happen for high burn-up fuel (not of concern for PHWR) and do not exclude low burn-up fuel conditions. The consequence is that current licensing thresholds may not be fulfilled: this unavoidably introduces a challenge either to regulations (requirement not fulfilled) or to the operation of current NPP at full power (need to dramatically reduce the nominal power).

Summary-conclusions from the discussion above are: (a) design related motivations to keep LBLOCA as a key accident in safety analyses have been re-stated; (b) a relaxation in the application of current licensing criteria and the (obvious) full consideration of the role of containment are needed for licensing, D'Auria et al., 2019.

\subsection{The Atucha-II Peculiarities}

The central nuclear Atucha II (CNA-II) is a two-loop, 745-MWe, pressurized heavy water reactor (PHWR) nuclear power plant (NPP), operating in Lima, Argentina. The reactor is cooled and moderated by heavy water, see sketches in Figures 2 and 3 and summary data in Table 1, Bonelli et al., 2014, and Mazzantini et al., 2018.

The core consists of 451 vertical natural uranium fuel assemblies located in the same number of coolant channels. The coolant channels are surrounded by the moderating heavy water, which is enclosed in the moderator (MOD) tank. For fission reactivity reasons the moderator is maintained at lower temperature than the reactor coolant. This is accomplished by the MOD system, which extracts the moderating water from the MOD tank, cools it in the MOD coolers and feeds it back to the MOD tank. 


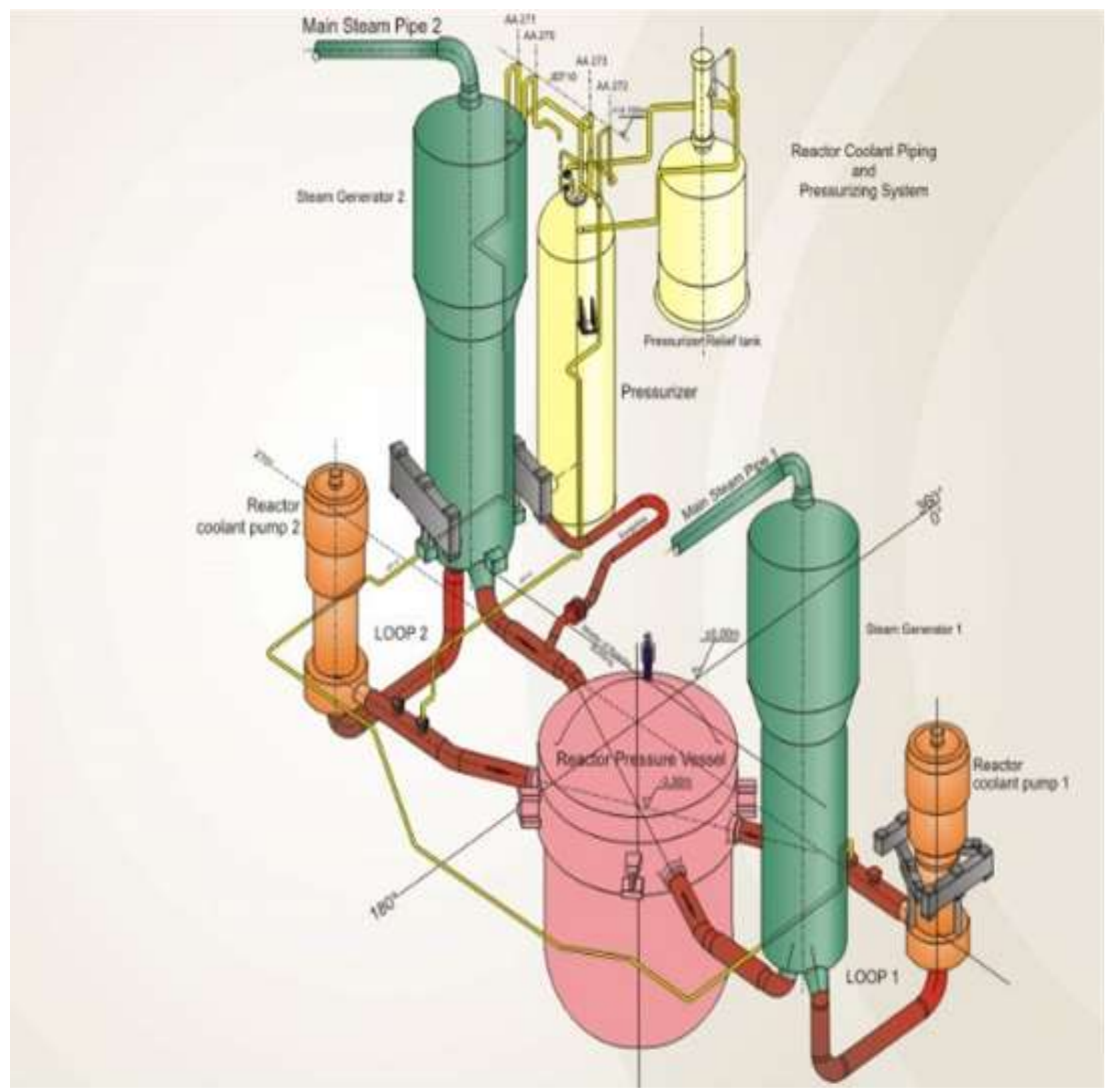

Figure 2. Sketch of the primary system, reactor cooling, of Atucha-II.

During full-load operation, $95 \%$ of the total thermal power is generated in the fuel, and the remaining $5 \%$ in the MOD, because of the neutron moderation. Additionally, approximately $5 \%$ of the thermal power is transferred from the coolant to the MOD through the coolant channels walls, due to the temperature difference between the systems.

The heat removed from the MOD is used for preheating the steam generators (SG) feed water. The reactor coolant system and the MOD system are connected by pressure equalization openings of the moderator tank closure head. Therefore, the pressure differences in the core between the primary coolant and MOD systems are comparatively small, which results in the thin walls for the coolant channels. This allows attaining a high burn-up. Furthermore, the connection between the reactor coolant system and the MOD system permits the use of common auxiliary systems to maintain the necessary water quality. 


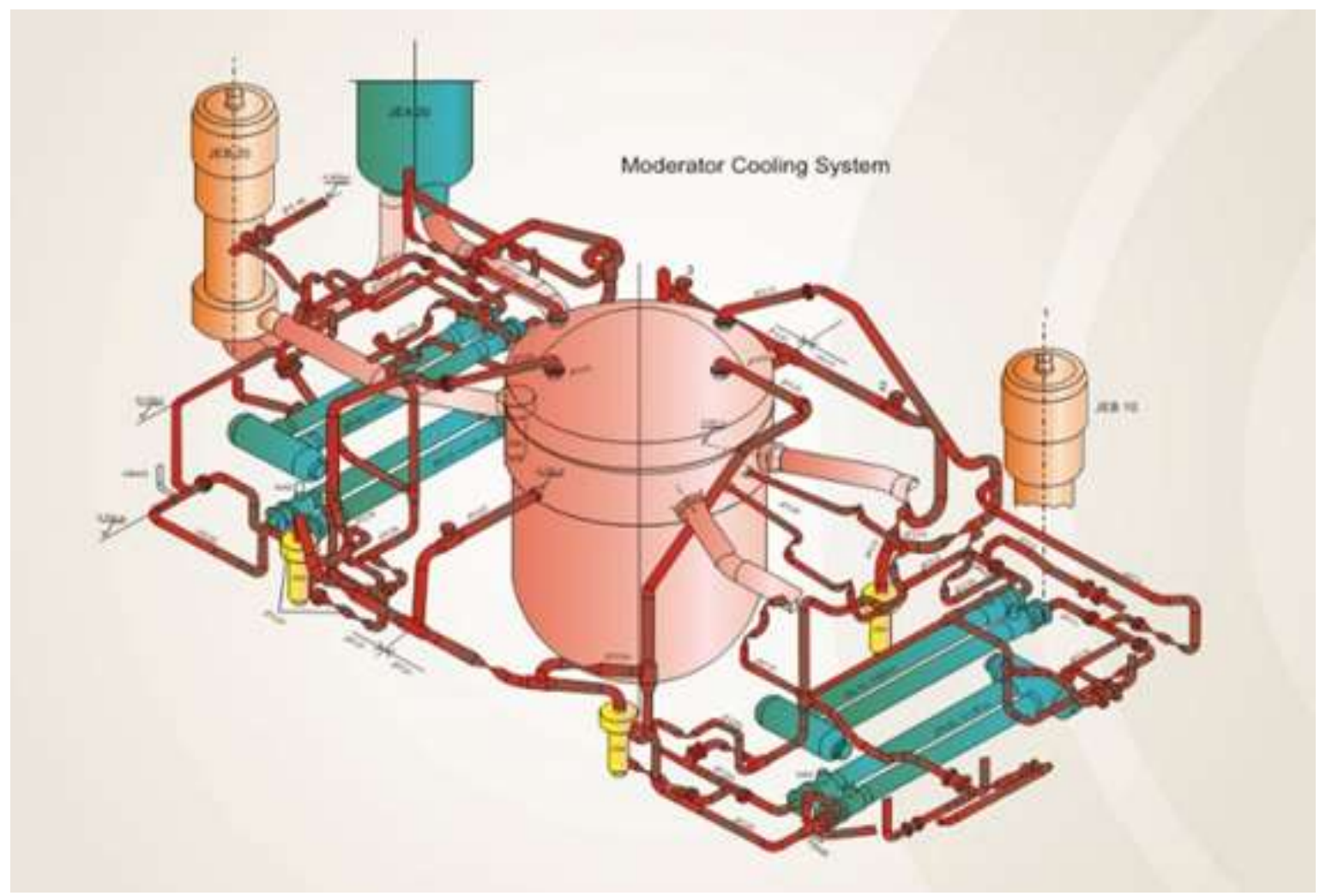

Figure 3. Sketch of the primary and moderator cooling systems for Atucha-II.

The primary system is structured similarly to a PWR (light water reactor) and consists of two identical loops, each comprising a steam generator, a reactor coolant pump, and the interconnecting piping, as well as one common pressurizer.

The MOD system consists of four identical loops operating in parallel. Each loop comprises MOD cooler, pumps, and the interconnecting lines with valves. The moderator system performs various functions depending on the reactor-operating mode. During normal operation the moderator system maintains the moderator at a lower temperature than that of the reactor coolant. The moderator leaves the top of the moderator tank, flows to the moderator pumps, pumped there through the moderator coolers, and flows back to the bottom of the moderator tank. The heat transferred in the moderator coolers is used to preheat the steam generator feed water. For residual heat removal, the moderator system is switched over to the residual heat removal position by means of the moderator valves. Under this operation mode, the moderator is extracted from the bottom of the moderator tank by the moderator pumps and fed into the cold/hot legs of the reactor coolant loops. During emergency core cooling, the moderator system serves as a high-pressure core cooling system. The emergency core cooling function is similar to that of the residual heat removal. The residual heat removal chain connected to the moderator coolers during emergency core cooling is the same as during residual heat removal in nominal operation.

\subsubsection{System Complexity}

Having the aim to provide an insight into the comparison between PWR and PHWR, a summary of technological complexities for the two systems can be found in Table 2.

The adoption of natural uranium as fuel constitutes an advantage (or a lack of complexity) for the PHWR which otherwise needs the costly heavy water as moderator. The continuous (daily) fuel replacement and the consequent need for fuel loading and un-loading machine constitute a complexity for the PHWR. The difficulty to prevent mixing between heavy and light water (thus losing the high valued heavy water) imposes heavy water as a coolant for PHWR. The need to keep 
moderation function imposes (relatively) low temperature for the moderator and therefore a 344 separate loop.

Table 1. Atucha-II PHWR overall data.

\begin{tabular}{|c|c|c|}
\hline QUANTITY & VALUE & NOTES \\
\hline Net power generation & 745 Mwe & \\
\hline Thermal power & 2160 Mwth & Including core and moderator cooling \\
\hline $\mathrm{N}$ of cooling channels & $451(-)$ & $\begin{array}{l}37 \text { fuel rods of natural uranium - cylindrical } \\
\text { channels }\end{array}$ \\
\hline Coolant and Moderator & $\mathrm{D} 2 \mathrm{O}$ & \\
\hline Power to steam generators & 1954.5 Mwth & \multirow{2}{*}{$\begin{array}{l}\text { Thermal power transferred to the 'steam cycle' } \\
2174.5 \text { Mwth (including main coolant pump } \\
\text { power). }\end{array}$} \\
\hline Power to moderator coolant & 220 Mwth & \\
\hline $\begin{array}{l}\text { No of coolant / moderator } \\
\text { circuits }\end{array}$ & $2 / 4$ & 2 HEX per SG to cool the moderator \\
\hline $\begin{array}{l}\text { Circulation flow, core / } \\
\text { moderator }\end{array}$ & $10300 / 890 \mathrm{~kg} / \mathrm{s}$ & Equivalent to $\approx 28 / 2 \mathrm{~kg} / \mathrm{s}$ per channel \\
\hline Pressure at vessel inlet/outlet & $12.25 / 11.53 \mathrm{MPa}$ & For both coolant and moderator \\
\hline Coolant temperature & $280 / 311^{\circ} \mathrm{C}$ & Vessel inlet / outlet ( $\rightarrow$ about $10 \mathrm{~K}$ sub-cooling) \\
\hline Moderator temperature & $189 / 204^{\circ} \mathrm{C}$ & $\begin{array}{l}\text { Vessel inlet /outlet (selected operational } \\
\text { condition) }\end{array}$ \\
\hline $\begin{array}{ll}\text { Average } & \text { moderator } \\
\text { temperature } & \end{array}$ & $170 / 220^{\circ} \mathrm{C}$ & $\begin{array}{l}\text { Normal/maximum value (design expected } \\
\text { range) }\end{array}$ \\
\hline $\begin{array}{l}\text { Pressure at steam generator } \\
\text { outlet }\end{array}$ & $5.49 \mathrm{MPa}$ & \\
\hline Total steam flow & $956 \mathrm{~kg} / \mathrm{s}$ & \\
\hline Power density \& max LHGR & $\begin{array}{l}12 \mathrm{kw} / \mathrm{l} \& 45 \\
\mathrm{kw} / \mathrm{m}\end{array}$ & (power density in PWR is $100 \mathrm{kw} / \mathrm{l}$ ) \\
\hline SIP \& ACC injection ports & 4 & Two in each CL and HL \\
\hline $\begin{array}{l}\text { Containment pressure / } \\
\text { volume }\end{array}$ & $0.7 \mathrm{bar} / 50 \mathrm{E} 3 \mathrm{~m}^{3}$ & Spherical pressure boundary design values \\
\hline
\end{tabular}

Control Rod Drive Mechanism (CRDM) in PHWR is designed having lower mechanical precision requirements than in the case of PWR. This advantage (for PHWR) is counterbalanced by the need of having a fast boron injection system capable of injecting boron into the moderator in less than one second following a demand (e.g. to deal with positive void coefficient after LBLOCA).

In relation to both PWR and PHWR, a Reactor Pressure Vessel (RPV) is needed (internal diameter about 4.5 and $7.0 \mathrm{~m}$, respectively): the RPV size is larger in PHWR per unit power owing to the lower power density in the core (about 12 and $100 \mathrm{kw} / \mathrm{l}$, respectively); however wall thicknesses are comparable for RPV in PWR and PHWR owing the lower nominal pressure in PHWR than in PWR. 
Table 2. Summary of PWR and PHWR system complexities.

\begin{tabular}{|l|l|l|l|l|}
\hline No & $\begin{array}{l}\text { SYSTEM } \\
\text { COMPLEXITY }\end{array}$ & PWR & $\begin{array}{l}\text { PHWR } \\
\text { (Atucha-II) }\end{array}$ & $\begin{array}{l}\text { NOTES } \\
\text { (complexity connected with, e.g.) }\end{array}$ \\
\hline 1 & RPV & X & X & Wall thickness \\
\hline 2 & CRDM & X & & Precision \\
\hline 3 & Fuel Enrichment & X & & Enrichment \\
\hline 4 & Heavy Water & & X & Availability and cost \\
\hline 5 & Boron Injection System & & X & Time of actuation following demand \\
\hline 6 & Load/Unload machine & & X & \multirow{2}{*}{ Design function } \\
\hline 7 & Moderator loop & & X & \\
\hline 8 & I\&C & X & X & \\
\hline
\end{tabular}

\section{The LBLOCA Elements (PWR \& PHWR)}

Several LOCA-related documents are available from literature (and web): the difficulty to provide innovative information has already been recognized. Nevertheless, the consideration all together of aspects related to (a) pressure wave propagation, (b) fluid-dynamics, (c) heat transfer, (d) chemical reaction, (e)mechanical loads, (f) neutron physics,(g) nuclear fuel performance, (h) containment, and (i) sump recirculation (including debris), may imply an innovation.

The application of complex codes is needed to discuss items (a) to (i): this requires the demonstration of capabilities for the numerical tools and the qualification (or V\&V) for the generated calculation results, e.g. D'Auria \& Galassi, 1998; unavoidable uncertainty evaluation is also involved, IAEA, 2008. Physicals aspects reflecting current understanding and assuming the availability of suitable computational tools are discussed in sections 3.1 to 3.6 (general level) and 4.1, 4.2 (Atucha-II specific).

Sensitivity studies are needed in advance, i.e. preliminarily to 'final deterministic analyses', in order to characterize the boundary conditions for LOCA (as well as for any other transient part of DBA) which cause the largest challenge to safety margins. Examples of targets for preliminary sensitivity studies are (search for):

- break location (along the primary loop piping) which causes the largest PCT;

- break location which causes the highest containment pressure;

- break size at a given location, which results in the highest PCT;

- break location which results in the highest load on RPV internals or on containment structures distinguishing between pressure wave (impulse type of load) and fluid-dynamic (static type of load) origin;

- configuration of ECCS (e.g. when two out of four accumulators are assumed to actuate, selection of the least effective ones) which causes the highest PCT;

- break size and location which result in the highest Fission Power Peak (FPP) when positive void coefficient is part of the core design.

Typical outcomes from preliminary sensitivity studies performed in relation to Atucha-II LOCA (discussed in section 4) are given in Figs. 4 and 5.
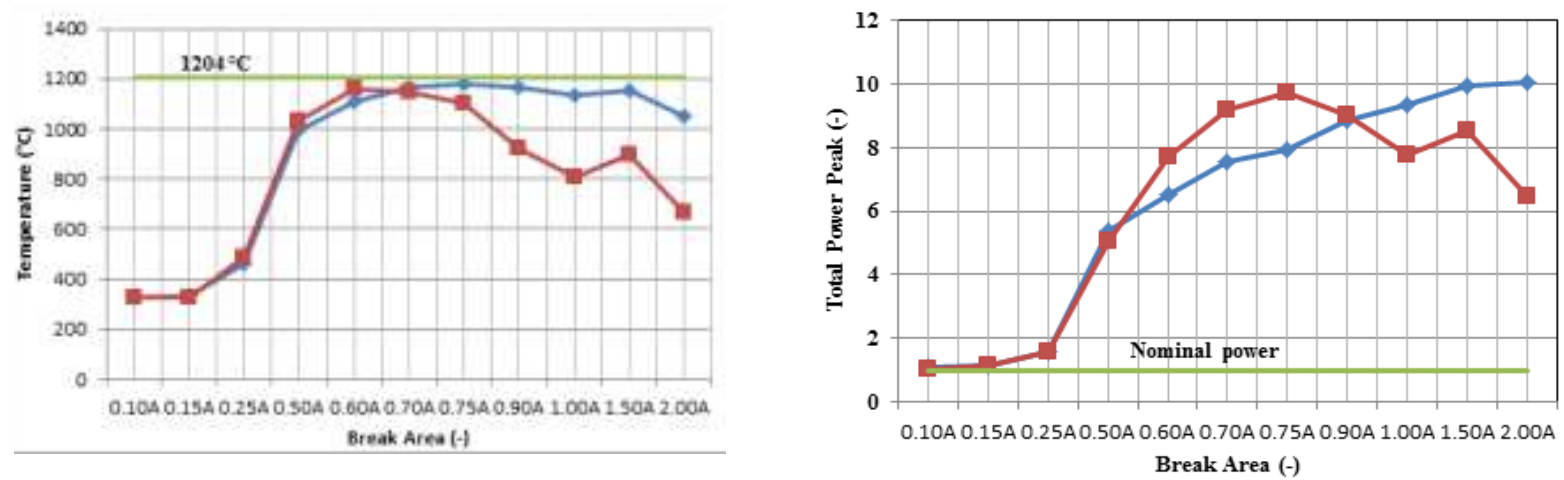

Figure 4. Sensitivity studies from Atucha-II LBLOCA: PCT (left) and FPP (right) vs break area; for each diagram two curves obtained from different (qualified) nodalizations. 

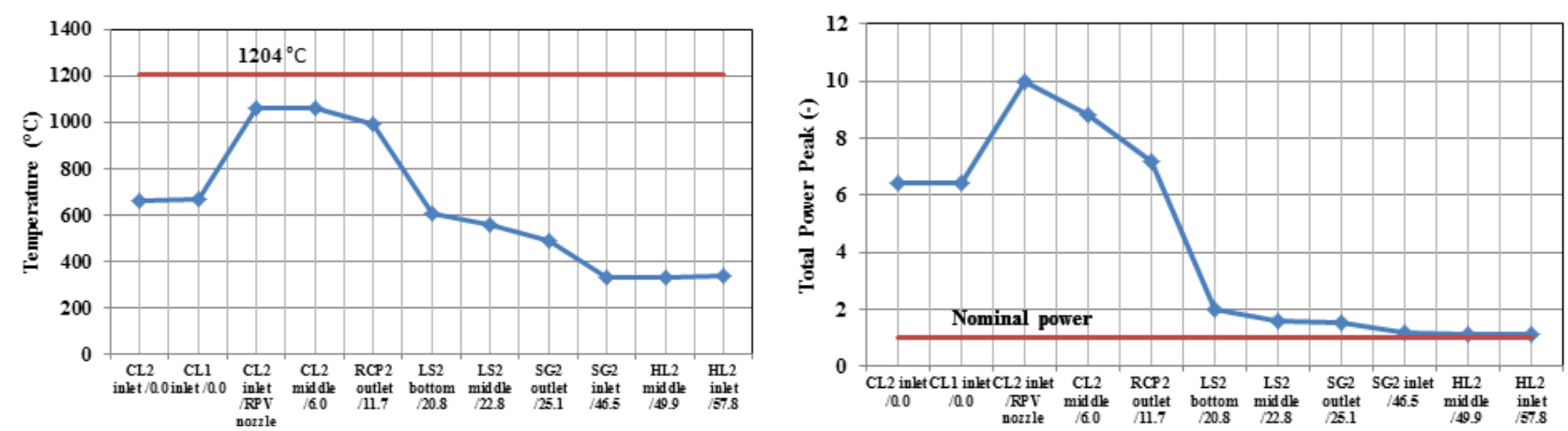

Figure 5. Sensitivity studies from Atucha-II LBLOCA: PCT (left) and FPP (right) vs break location [in the horizontal axis: break location expressed as the distance from RPV-CL connection (m)].

The following can be deduced from the analysis of the diagrams:

$>$ A range of break sizes for PCT must be considered (starting from $0.4 \mathrm{~A}$ up to $2 \mathrm{~A}$ where $\mathrm{A}$ is the cold leg cross section area and 2A = DEGB);

$>$ The worst break size as far as FPP is concerned is $2 \mathrm{~A}$;

$>$ The worst break location (either PCT or FPP) is in the cold leg at the outlet of the RPV.

The evaluation of other challenges (not shown here) considering above bullet items confirms the importance of the DEGB. However, a larger number of 'final deterministic analyses' (i.e. in addition to the DEGB LBLOCA) are needed to systematically consider the worst situation for each concerned safety margin (not further discussed here).

\subsection{The Early Blowdown - the 1't Period: the (Fast) Dynamic Effects}

Considered topics are relevant to both PWR and PHWR with noticeable exception of 'fission power excursion' and 'fast boron injection' which apply to PHWR (time duration is a few seconds).

\subsubsection{Break Opening Time (BOT)}

Intuitively BOT affects the depressurization wave formation at the break, namely its amplitude, and, consequently generated loads. Fracture mechanics, corrosion-erosion, presence of weld, geometric or material discontinuities, material plasticity, local stress-strain status, detectable defect and compressibility of the pressurized fluid constitute (a minimum set of) elements affecting the BOT. Attempts to estimate BOT are discussed in the literature, e.g. Baum, 1984, and Bhandari \& Leroux, 1993. Namely, a theoretical approach is proposed by Baum (also reported by Ylonen, 2008) ending-up with the formula, see diagram in Fig. 6:

$$
A=\frac{2 P_{0} \mu_{P} t^{3}}{3 m}+\frac{P_{0} \mathrm{~L} t^{2}}{m}
$$

where, $A=$ the actual flow area, $t=$ time, $P_{0}=$ initial internal pressure, $L=$ initial defect length, $m=$ mass per unit area of the pipe wall and $\mu_{p}=\left(\sigma_{y} / \rho_{s}\right)^{1 / 2}=$ ductile fracture propagation velocity [with $\sigma_{y s}=$ yield stress at prevailing strain and $\rho_{s}=$ density of pipe material].

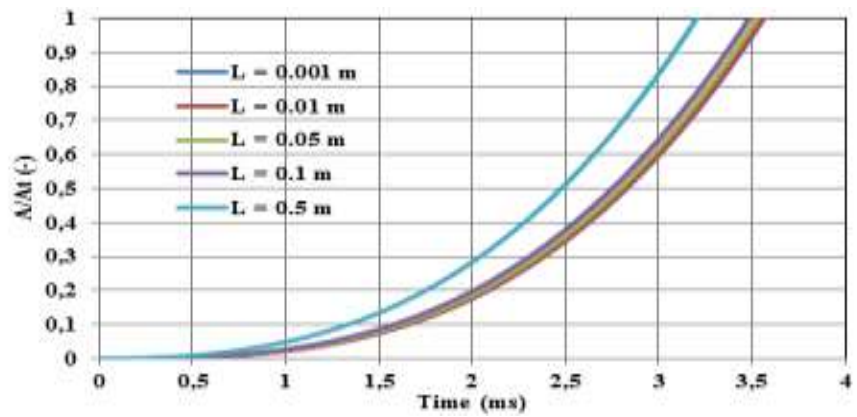

Figure 6. Break flow area versus BOT for different initial defect length [L], derived from Baum, 1984. 


\subsubsection{Depressurization Wave Propagation}

Following the start of rupture occurrence (or break opening), a (negative) pressure wave

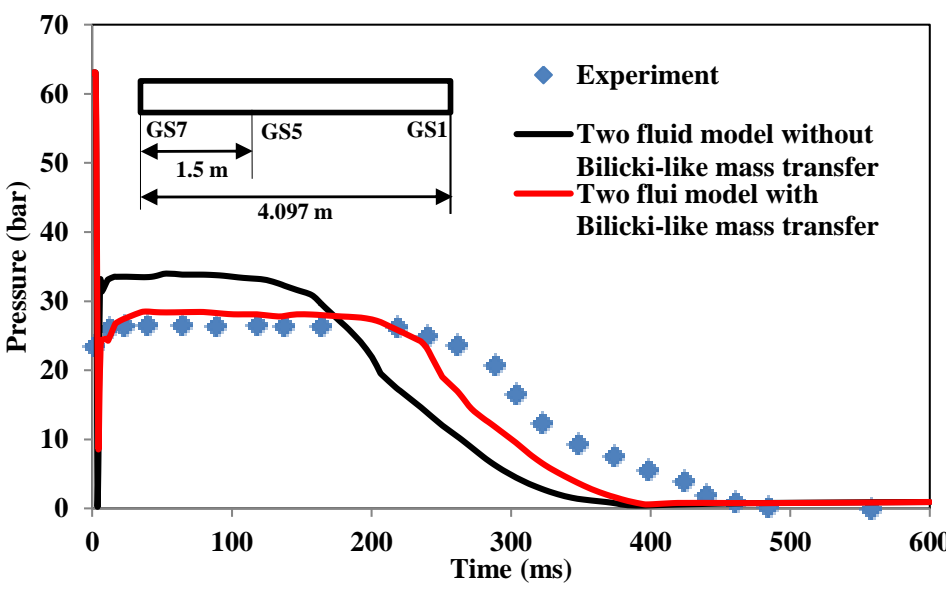

451
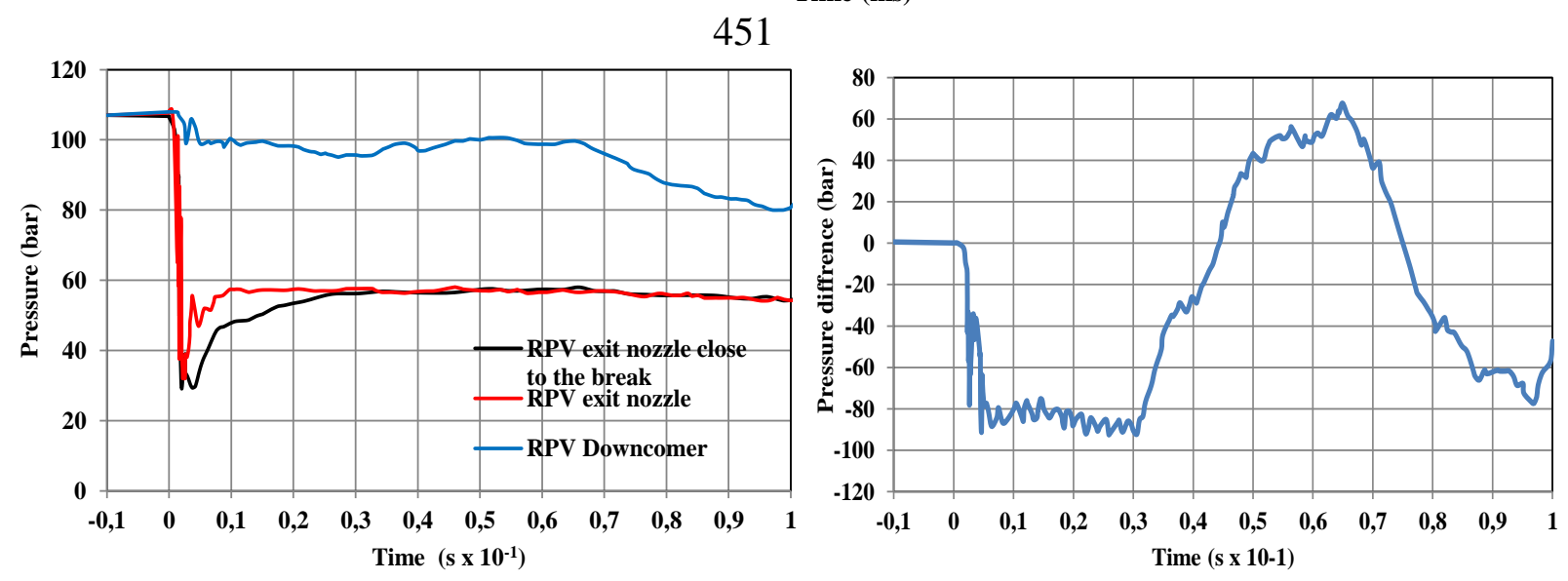
(sometimes called a rarefaction wave) propagates from the break towards the RPV and in the opposite direction, towards the Main Coolant Pump, in the case of a LOCA in a PWR. Selected experimental and data and in one case results of calculation are given in Fig. 7: Edwards, Edwards \& O'Brien, 1970, and HDR, Wolf, 1982, experiments are given together with results of calculations performed by Lochon et al., 2017, in the case of Edwards experiment (see also discussion related to Fig. 9 below). BOT is estimated for a large pipe in the conditions of cold legs in a PWR: about $100 \mathrm{~m}$-s BOT is expected, however lower values cannot be excluded.

In the case of licensing analyses, where the evaluation of pressure wave effect is excluded, typical value used for BOT corresponds to one time-step of the code-calculation (time step has a typical value in the range $1-10 \mathrm{~m}-\mathrm{s}$ ). Additional details are given in section 4.3 .1 related to Atucha-II calculations.

Figure 7. Pressure wave propagation. Upper diagram: comparison between measured and calculated data for Edwards pipe experiment (Edwards \& O'Brien, 1970, and Lochon et al., 2017), GS7 location. Lower diagrams are related to HDR tests (Wolf, 1982): left: absolute pressure in exit nozzle and in RPV downcomer; right: pressure difference between outside and inside the barrel [Poutside - Pinside].

The following can be derived from the analysis of the figure, assuming a BOT in both cases of the order of 2-5 m-s, with rupture occurring in special membranes properly designed:

$\checkmark$ The pressure wave moves (starting from the break) at a velocity close to the sound speed.

$\checkmark$ The Amplitude of the Pressure Wave is a complex function of (a) BOT including time derivative (APW larger for smaller BOT), (B) sub-cooling of the fluid (APW larger for high 


\subsubsection{Two-Phase Jet, Jet-Impingement and Thrust}

subcooling), (c) size of the system compared with break area (APW smaller for larger sizes), (d) compressibility of the fluid (e.g. APW decreasing when passing in the pressurized reservoir from subcooled liquid to two-phase mixture), (e) system geometry (e.g. dimensions of a nozzle connected with a reservoir, and presence of internals).

$\checkmark \quad$ The pressure wave induces impulse and cyclic loads (soliciting fluid-structure interactions) upon internals as can be inferred from the bottom right diagram.

$\checkmark$ Occurrence of a double critical section for TPCF (or two TPCF locations) can be derived from the bottom left figure.

$\checkmark$ Current (Lochon et al., 2017) 'low' predictive capabilities of pressure wave models, following fast depressurization, can be seen from the upper diagram. This is true, notwithstanding good predictive capabilities demonstrated in different situations, e.g. case of pressure wave originated by closure of turbine inlet valve, Bousbia Salah et al., 2004.

Break formation implies fluid jet formation and interaction with surroundings. The jet can be a cylinder of the same diameters of the exit pipe when high subcooled flow is concerned, e.g. ambient temperature liquid flowing out of a reservoirs pressurized by gas. In the case of RPV at thermal-hydraulic conditions of a nuclear reactor a conic or a paraboloid jet forms depending upon void fraction at pipe outlet: from low to high void fraction the bounding jet shape with the jet axis as center-line, moves from paraboloid to cone, see e.g. D'Auria \& Vigni, 1981, and Celata et al., 1986; the last authors also measured the pressure inside the jet.

Hereafter the attention is focused to the load caused by the jet acting upon both any hypothetic structure outside the RPV and upon the vessel supports. The load (F) can be expressed as:

$$
F=K P_{0} A
$$

where $P_{0}=$ reservoir pressure; $A=$ break flow area; $K=$ coefficient discussed below for various cases.

In the case of a jet impinging upon a flat plate orthogonal to the jet axis, a $\mathrm{K}$ value in the range $1.0-1.2$ is measured at a distance between the plate and the exit area cross section plane in the order of a few pipe diameters, Vigni \& D'Auria, 1979, and Yano et al., 1982. The value is affected (other than by the thermal-hydraulic conditions inside the reservoir, namely by the void fraction at the break section) by the distance of the plate from the break; the value $\mathrm{K}=2$ can be characterized as an upper limit for $\mathrm{K}$.

The thrust upon RPV supporting frame shall be considered as the sum of the 'jet reaction force' and the spring type mechanical force associated with the mechanical energy stored into the piping material; in the case of a RPV ending up with the jet exiting nozzle, the spring force depends upon the nozzle length and flow area, the wall thicknesses and the size of the possible flange at the pipe end. The measured value for $\mathrm{K}$ has been measured in the range 1.0 - 2.0, Vigni \& D'Auria, 1979, and D'Auria \& Vigni, 1981, (see also Kurihara et al., 1987), with a maximum theoretical value K=4. Impulse type of load occurs during the first few $\mathrm{m}$-s after break opening and are consistent with $\mathrm{K}$ values larger than about 1.2.

\subsubsection{Pipe Whip and Break-Generated-Missiles}

Pipe whip and missile generation are associated with break opening: related phenomenology occurs at a time scale in the orders of $0.1-1.0 \mathrm{~s}$.

Without entering into details like ovalisation of a pipe or complex elastic-plastic formulations Reid et al., 2011, and experimental data Kurihara et al., 1987, the pipe whip investigations end up with the design of suitable restraints or in the demonstration that pipe movements do not impact the integrity of safety components and safety functions.

Current status and issues related to missiles are discussed by Ranjan et al., 2014: ensuring the resistance for structures and components hit by missiles constitute typical objectives for the analyses. In relation to both cases of pipe whip and generated-missiles, assuming suitable safety demonstration according with mentioned targets, there is no further impact with LBLOCA evolution and no further discussion hereafter. 


\subsubsection{Load on RPV Internals}

The depressurization wave generated at the break enters (namely in the case of a PWR) the annular space between the reactor vessel and the core barrel, then it travels down to the lower internals as it wraps around the barrel. This is illustrated in Fig. 8 taken by Krieg et al., 1977, and later on (widely spread picture) by Hosford et al., 1981 (USNRC NUREG-0609). The depressurization wave, depending upon its amplitude and the sub-cooling of the encountered fluid, may generate voids with a delay of the order of m-s after its passage. This causes complex Fluid Structure Interaction (FSI), Mahmoodi et al., 2019, see also Vigni et al., 1978, for experimental data in simple geometry blowdown. Following the definition of FSI, mutual interaction occurs among moving of fluid, void formation and motion of internals (see also Fig. 8).
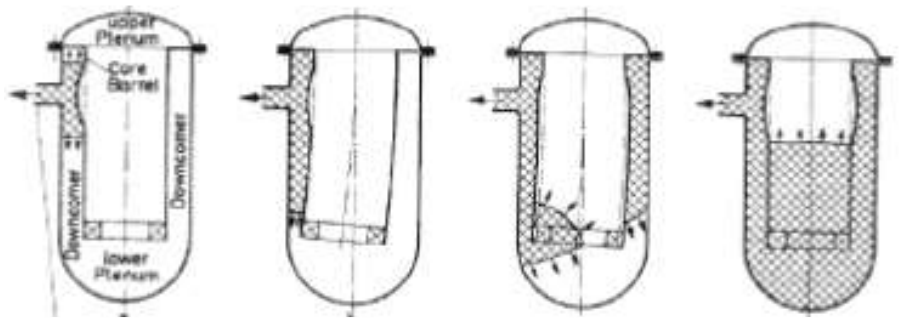

Figure 8. Propagation of depressurization wave from the break (shadowed region is at low pressure), Krieg et al., 1977.

The capability to withstand blowdown loads by the Control Rod Drive Mechanisms (CRDM) in the upper plenum of a PWR is discussed and demonstrated as far as possible, by Krieg et al., 1982.

\subsubsection{Flashing in RPV}

The effect of a depressurization wave is to create voids (vaporization due to depressurization in the phenomena list, Aksan et al., 2018) in a subcooled liquid, provided an amplitude such to create a pressure lower than the pressure corresponding to the local saturation temperature. The delay in void formation can be estimated as in the order of milliseconds, see e.g. Nouri-Borujerdi \& Ghazani, 2018; in some situations measured delays between pressure decrease and void formation can be as low as a fraction of one m-s as reported by Faucher et al., 2000. An effect of neutron flux upon nucleation and void formation during blowdown is reported in the literature, e.g. Kendoush, 1989.

A correlation between pressure wave and void fraction / vaporization (and vaporization rate) resulting from flashing can be deduced from the Edwards \& O'Brien, 1970, experimental data, Fig. 9: the consideration of data in Fig. 7 (upper diagram) allows observing how void formation (flashing) contributes in keeping the system pressure nearly constant during the period $10-280 \mathrm{~m}$-s.

Flashing in core region causes lack of moderation and immediate termination (consistently with the arrival of the pressure wave from the break) of the fission reaction. Flashing in lower and upper plenum at different times interact with core flashing and flow reversal as discussed in next section.
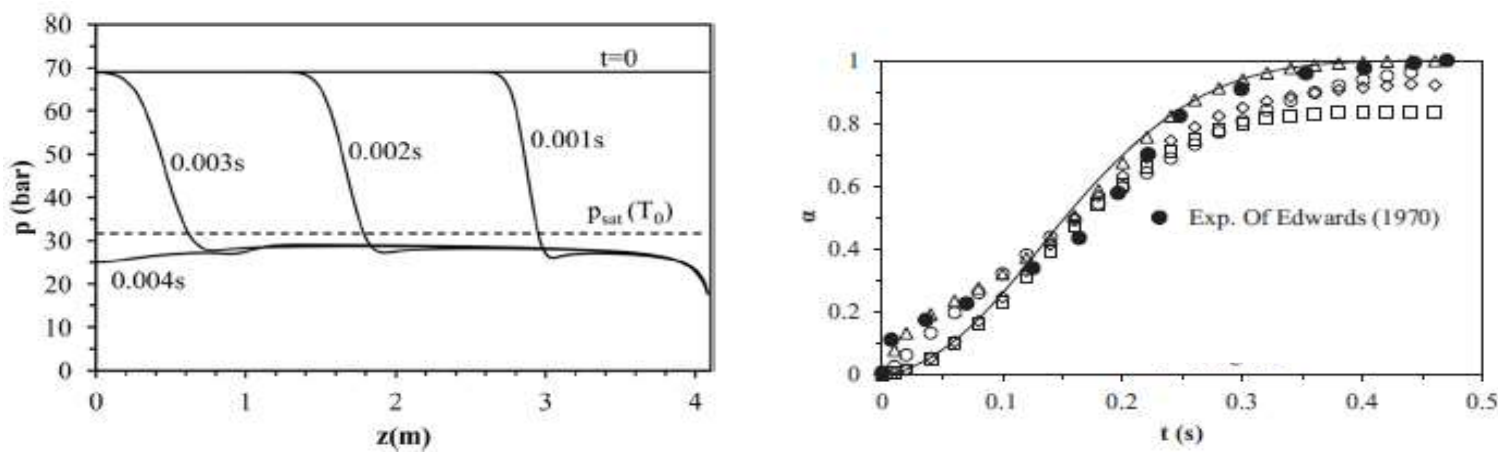

Figure 9. Propagation of depressurization wave and void formation, Edwards \& O'Brien, 1970, test

551 as reported by Nouri-Borujerdi \& Ghazani, 2018, together with results of prediction models. 


\subsubsection{Flow Reversal in Core Region}

The change in flow direction from nominal conditions is characterized as flow reversal and may occur at any point in the core: flashing and flow stagnation associated with pressure wave propagation together with flow inertia and $\mathrm{MCP}$ operation, determine flow reversal. This happens during both the $1^{\text {st }}$ and the $2^{\text {nd }}$ LOCA period, typically leading to flow-rate oscillation primarily during the $2^{\text {nd }}$ period.

The origin of the flow reversal is the 'pressure sink' (negative term) which establishes at the break and is not (sufficiently) balanced by the initial flow inertia and by the flow momentum coming from the operation of the pumps in the intact loops (positive terms). Flow reversal is reported to occur during a calculated LBLOCA transient at $3 \mathrm{~s}$ after the break occurrence, D'Auria \& Galassi, 2017; more details are given in Section 4.2.3.

\subsubsection{Neutron Physics and Fission: Reactivity Coefficients and Power Excursion}

PWR case: all neutron fission reactivity coefficients are solicited during LOCA. However the arrival into the core of the depressurization wave generated at the break a few $\mathrm{m}$-s after the occurrence, creates enough void such to stop the fission reaction; in other terms decay heat becomes the only source of energy in the core independently upon the actuation of scram rods which also are immediately called into operation. This is also valid when high boron concentration, at the beginning of core life, causes a positive moderator temperature coefficient: the effect of void formation (in case of LBLOCA) overpasses the effect of expelling a (highly) neutron absorbing moderator from the core region.

PHWR case: the moderator and coolant are at different temperature during nominal operating condition; therefore the depicted scenario for PWR does not apply. Early coolant voiding following LBLOCA deprives the core of a neutron absorbent material and a fission power excursion is unavoidable. Furthermore, the rate of increase in reactor power in a heavy water moderated reactor is inherently limited by its relatively long prompt neutron lifetime (about 40 times longer than that in a light water moderated reactor), so that the reactor period is much longer and the rate of rise in power and enthalpy is much slower, Popov \& Snell, 2012.

A typical fission power excursion calculated for CANDU reactors with different assumptions adopted for deriving the void coefficient is reported in Fig. 10, Kastanya et al., 2013.

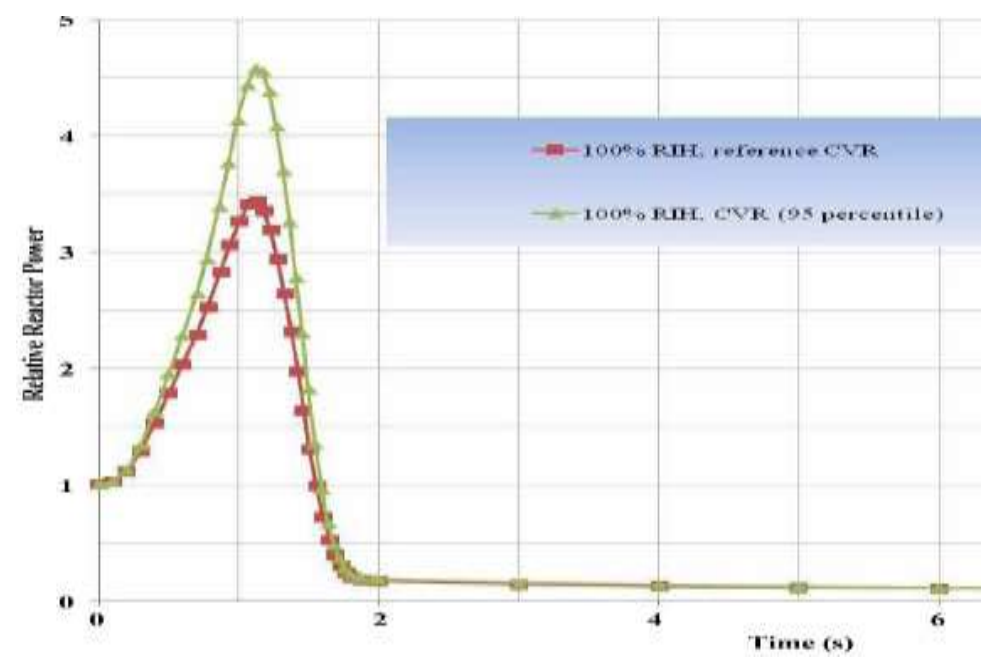

Figure 10. Fission power excursion during LBLOCA in CANDU, Kastanya et al., 2013.

\subsubsection{Boron Injection}

In the case of the Atucha-II a special Boron Injection System is installed which is capable of fast injection of boric acid suitable to limit the power excursion expected as a consequence of the positive void reactivity coefficient, e.g. Moretti et al., 2018. More details are given in sections 4.2 and 4.3.2. 
A picture has been given in section 3.1 of key phenomena occurring soon after the break opening (a few seconds) following LOCA in PWR and PHWR, i.e. pressure wave dominated effects. What happens during a few tens of seconds till the intervention of accumulators is discussed hereafter: i.e. emphasis given to core heat transfer and fast depressurizing two-phase mixture evolutions.

\subsubsection{The TPCF}

TPCF has a strong impact upon overall system performance, namely core cooling, during a PWR LOCA. A synthesis of TPCF related ideas and modeling is well beyond the framework of the present paper; nevertheless a few statements are provided below to connect with sections 3.1 to 3.6:

a) TPCF is a recognized 'leading phenomenon' in case of LOCA, see e.g. Aksan, 2017.

b) Break flowrate (or TPCF) directly affects depressurization rate, pressure distribution in the loop, mass and energy lost form the break and containment pressurization.

c) TPCF is strongly affected by geometry other than by fluid conditions that establish at the break: sharp edges, crack shapes, L/D ratio in nozzle, valve geometry (e.g. fluid discharge valves) strongly affect the phenomenon and multiple TPCF section may occur simultaneously, or TPCF location may move during a transient.

d) Notwithstanding experimental researches and modelling efforts since the 60's of previous century, predictive capabilities for TPCF need improvement: discrepancies between measured and calculated values can be as large as 30\% of the measured value; current model validation procedures appear inadequate specifically in the case of TPCF, as discussed by D’Auria \& Lanfredini, 2018.

e) Nucleation sites: the impact of nucleation sites in predicting bubble size is discussed by Nigmatulin et al. 1987.

f) Attention currently drawn by the 'TPCF issue' can be derived by Jo et al., 2018, and Hamouda et al., 2018, who point out the importance of considering two pressures in modeling [Models that do not account for the pressure differential across the vapor-liquid interface will significantly under-predict the rate of vapor growth]

\subsubsection{The Flow Stagnation}

Depending upon the MCP and overall flow inertia in the primary loop, flow stagnation (or nearly zero fluid velocities) may occur during the $1^{\text {st }}$ and the $2^{\text {nd }}$ period: in the former case, the pressure wave formation at the break and the propagation in two opposite direction may generate a potential flow stagnation in the loop location where the two pressure waves come across; in the latter case two-phase (primarily) pressure drop balance along the two sides of the loop caused by the break, generate the flow stagnation. The flow stagnation, or better the flow stagnation region; (a) has a dynamic nature and may continuously migrate as a function of time; (b) implies very low fluid velocities and therefore very low heat transfer coefficients.

A suitable design/repartition of pressure drops along the primary loop may ensure that flow stagnation does not occur in the core; large pressure drops in primary side of steam generator may facilitate stagnation region inside the U-tubes. This ensures more fluid in the core following upper plenum flashing and pressurizer draining in case of LBLOCA.

\subsubsection{CHF Occurrence, Pellet Stored Thermal Energy and the $\left(1^{\text {st }}\right)$ PCT}

Background considerations given for TPCF apply here: CHF is a widely studied phenomenon topic of textbooks, e.g. Collier, 1975, and highly impacting LBLOCA. A few notes are provided below:

1) Accurate knowledge of CHF is needed in order to establish safety margins during nominal core operation: this allows achieving high linear power which directly impacts (see below) the occurrence of CHF following LOCA.

2) Nuclear fuel designers and suppliers adopt specific experiment-derived correlations for CHF suitable to optimize fuel performance and to demonstrate safety margins. 
3) Spacer grids (number and types) other than fuel bundle equivalent diameter and local thermal-hydraulic parameter values, e.g. Aksan et al., 2001, affect the CHF occurrence in nominal and transient conditions.

4) Notwithstanding the large number of ('more or less') empirical correlations to determine $\mathrm{CHF}$, the most widely used approach, namely for transient analyses, is based upon the so-called Groeneveld and Kirillov look-up tables, Groeneveld et al., 1996, which directly make reference to several ten thousands experimental data points.

5) Following LBLOCA, CHF may occur either immediately after the break as the result of flashing generated by depressurization wave or a few seconds later due to flow reversal and low fluid velocity: both situations may occur in different regions of the core at different times.

CHF occurrence generates (the 1st) rod surface temperature excursion: slope and values for the

\subsubsection{The early Core Rewet}

Following CHF and the initial rod surface temperature excursion, a turnaround for the temperature (reported as a function of time since the transient start) may occur well before the actuation of accumulators and has been measured in LOFT facility, Brittain \& Aksan, 1990; the turnaround may end-up to a complete local quench, so called early core rewet, or to a (small early) decrease in temperature value, e.g. Queral et al., 2015. Pump characteristics, flashing and droplet entrainment and eventually flow from pressurizer are at the origin of partial or complete early core rewet.

\subsubsection{The Depressurization Rate}

The primary coolant pressure decrease and pressure decrease rate (depressurization characteristics) constitute essential parameters for blowdown and LOCA. Depressurization characteristics affect and are connected with mass loss and time of actuation of accumulators or accumulator design pressure: early actuation of accumulators (or high design pressure) may cause too much of injected mass lost to the break; late actuation of accumulators (or low design pressure) may cause too high rod surface temperature. Therefore, the knowledge of depressurization characteristics is essential (also) before the actuation of accumulators.

Typical average values for depressurization rate from break opening till the concerned time are 1-3 MPa/s, $1 \mathrm{MPa} / \mathrm{s}$ and $0.5 \mathrm{MPa} / \mathrm{s}$, for the $1^{\text {st }}$, the $2^{\text {nd }}$ and the $3^{\text {rd }}$ blowdown period, respectively (sections 3.1 to 3.3), see e.g. Queral et al., 2015, and D'Auria \& Galassi, 2017.

\subsubsection{The Containment Pressure Peak}

Depressurization of primary system corresponds to pressurization of containment, full pressure type in PWR, see e.g. OECD/NEA/CSNI, 1999, and Noori-Kalkhoran et al., 2016. Following pipe whip, jet impingement, thrust on RPV supports and possible missiles during the first LOCA instants, pressure and temperature loads in containment are created by the discharging two-phase flow. Peak pressure is expected during the time interval 10-20 s after break occurrence with a value $0.35-0.55$ $\mathrm{MPa}$, depending upon the reactor unit, the break location and the assumptions about the accident progression including mitigation measures. Hydrogen management is expected inside containment (see also section 3.3).

Containment constitutes the ultimate (robust, not to be overpassed) barrier against the massive release of fission products into the environment. 
The intervention of accumulators, typically at a primary pressure of $4.0 \mathrm{MPa}$ at around $30 \mathrm{~s}$, fixes the time when refill and recovery actions for core cooling start. The minimum mass inventory for the primary system (in the order of $10 \%$ of initial value) occurs.

\subsubsection{The Precursory Cooling, the $2^{\text {nd }} \mathrm{PCT}$ and the Temperature Turnaround}

Attention is focused to nuclear fuel rod cooling after the occurrence of CHF and blowdown temperature rise depending upon heat stored in UO2 pellets and LHGR. Film boiling and radiation heat transfer are concerned. Precursory cooling occurs prior to the arrival of the rewetting front and is due to entrained droplets originated by continuous flashing and possibly by accumulator injected liquid or, later on and with the same modalities, by LPIS actuation, Svanholm et al., 1995, and Chatzikyriakou et al., 2010. The entrained droplet may evaporate into the steam and act as a heat sink or may directly cool the clad by impinging. The last authors estimate that the heat extracted by those droplets directly impinging rods to be "about 1/10 of the heat extracted by single-phase vapor under typical reflood conditions".

Precursory cooling, i.e. a film boiling heat transfer regime, causes a reduction in the slope of rod surface temperature rise or even a negative slope for the same quantity following the $2^{\text {nd }} \mathrm{PCT}$; in the last case, the rod surface temperature turnaround occurs and local thermal-hydraulic parameter values are suited for rewet or Return to Nucleate Boiling (RNB) are discussed in section 3.4.

\subsubsection{The $\mathrm{H}_{2}$ Production}

The production of $\mathrm{H}_{2}$ constitutes a well-known and widely studied phenomenon associated with rod surface temperature excursion, e.g. Shiozawa et al., 1982, see also the fundamental work by Urbanic \& Heidrick, 1978. The impact of the chemical reaction upon the LBLOCA evolution, which also implies addition of thermal energy into the system, becomes more and more important when clad temperatures overpass $600-800{ }^{\circ} \mathrm{C}$. Acceptability thresholds in ECCS design, USAEC, 1971, and countermeasures in containment, OECD/NEA/CSNI, 1999, are established to deal with $\mathrm{H}_{2}$ production.

As in previous cases, e.g. TPCF and CHF), it is well beyond the framework for the present paper to provide an outline of $\mathrm{H}_{2}$ production and LOCA related effects.

The interaction between $\mathrm{H}_{2}$ production, heat transfer coefficient including radiation and nuclear fuel performance (presence of crud and oxide, ballooning and burst, clad hydrating, etc.) during a transient (e.g. LBLOCA) needs more investigation.

\subsection{The Reflood and other Thermal-Hydraulic Phenomena}

The injection of borated water by Low Pressure Injection System (LPIS) starts when primary loop pressure reaches around $2 \mathrm{MPa}$. Massive amounts of coolant become available for core cooling, break flow decreases because of the low pressure difference between primary loop and containment and conditions for cooling of the core in forced circulation or nuclear boiling regimes are restored. Typically, the reflood process occurs during this period including quench front progression till the top of active fuel (actually two quench fronts are generated, see below; during the same period the equalization of pressures between primary loop and containment is established, thus terminating the blowdown.

\subsubsection{Quench Front Progression}

LPIS capability to quench the core after unavoidable dry-out occurrence during LBLOCA must be demonstrated, although reflood conditions may occur early during the transient depending upon the concerned reactor unit and the hypotheses adopted for the accident scenario. Recalling the following nomenclature to depict reflood may be of some interest: overpassing of Quench Front (QF) at a given axial location implies the occurrence of rewet and the Return to Nucleate Boiling (RNB) for that location; the temperature at the assigned location before the arrival of the QF may 
correspond to the Minimum Film Boiling (MFB). A picture of reflood phenomenology and related predictive capabilities can be derived from Fig. 11, Valette et al., 2011, and Reventos et al., 2008.

The phenomenology of QF progression in a typical PWR equipped with U-tubes steam generators, without hot leg injection, can be deduced from the left diagram in Fig. 11; the following notes apply:

- Bottom-up progression of the QF results from the bottom rising line: this is consistent with the increasing core collapsed level consequent to the LPIS injection in downcomer and prior refill of the lower plenum.

- Simultaneous occurrence of top-down QF progression occurs (top-down descending line): this is due to liquid transportation from the bottom-up QF in the form of droplets or even liquid slugs (in this case underlying the occurrence of Inverted Annular Film Boiling - IAFB - heat transfer and fluid flow regime).

The experimental data (red crosses in the diagram at about 220 seconds) show simultaneous reflood occurrence which is not predicted by the calculation: similar phenomenon was also detected
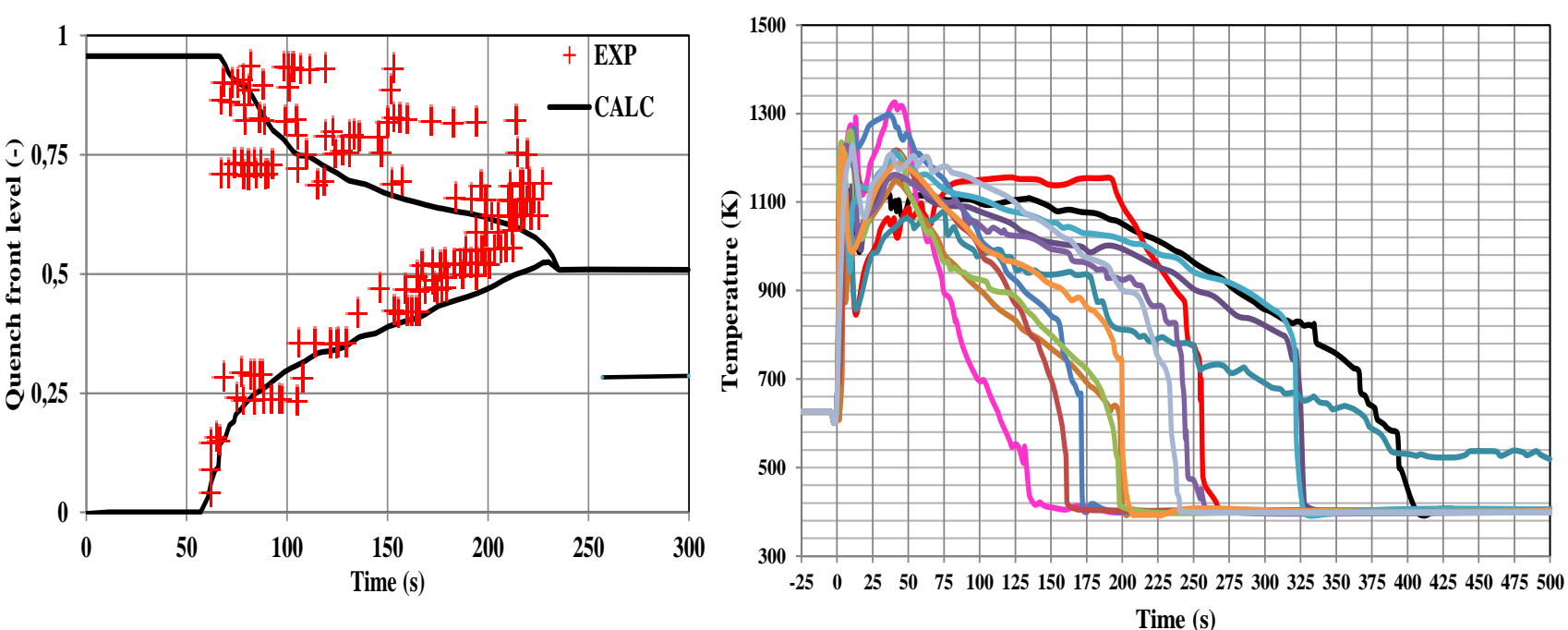

Figure 11. Quench front progression (left, Valette et al., 2011) and reflood predictive capabilities (right, Reventos et al., 2008: application of different codes to LBLOCA analysis in PWR).

The right diagram shows the spread of data calculated by various codes for LBLOCA reflood: each line corresponds to a different calculation made by different code users; Zion (virtual or never operated) PWR unit is concerned. PCT (namely what has been called blowdown PCT) is calculated with a reasonable agreement by various code users; however, precursory cooling conditions for rewet and time of rewet occurrence show large discrepancies among the various calculations.

\subsubsection{Other Thermal-Hydraulic Phenomena}

Thermal-hydraulic phenomena in addition to those discussed in the present paper are relevant in case of LBLOCA in PWR (and PHWR) during each of the considered periods, as discussed by Aksan, 2017, D'Auria \& Galassi 2017, and Aksan et al., 2018. A more comprehensive list of phenomena includes: ECCS bypass, steam binding, CCFL in different locations, pressure drop at geometric discontinuities, broken MCP fluid-dynamic resistance with free or locked rotor, two phase MCP (broken and intact loops) performance, condensation at ECC port, downcomer liquid penetration, mixing in different locations of primary loop, containment thermal-hydraulics. Those phenomena are indirectly embedded into the issues discussed in the paper and related predictive capabilities shall be associated with any computational tool (or numerical code) adopted for performing LOCA analyses. 
The nuclear fuel constitutes the main target and motivation for the analysis of thermal-hydraulic phenomena during LBLOCA: a dynamic interaction happens between the fuel pins and the coolant. This is relevant during each identified period. After reflood no further mechanisms for fuel damage are expected: therefore nuclear fuel performance during LBLOCA is depicted hereafter by considering a list of physical processes causing degradation or rupture of fuel pins, namely occurring at high temperature and low coolant pressure:

- $\mathrm{H}_{2}$ production following the Zircaloy-water chemical reaction discussed in section 3.3.

- Ballooning of a few or of several rods, Ammirabile \& Walker, 2014: this causes obstruction to the coolant channels and interacts with QF progression.

- Burst (following ballooning) and fission gas release, Pontillon et al., 2001: the burst, following fuel fragmentation and relocation (see below) may cause release of long lived solid fission products into the coolant in addition to non-condensable gases.

- Fuel relocation, Kim et al., 2017, into the ballooned region which causes increase in local decay power production. This is preceded, depending upon burn-up, by fuel fragmentation (or even pulverization), Brankov, 2017, see also Bianco et al., 2015.

During the last two decades experimental research brought to better understanding of nuclear fuel weaknesses following in-core operation: high burnup is mainly concerned although "...fragmentation appears to almost always occur, regardless of burnup ..." (reference is made here to the current US licensing limit of $62 \mathrm{MWd/Ton} \mathrm{U),} \mathrm{Raynaud,} \mathrm{2012.} \mathrm{The} \mathrm{weaknesses} \mathrm{can} \mathrm{be} \mathrm{classified} \mathrm{into}$ three broad categories, synthesized by D'Auria et al., 2019: (a) Pellet Clad Mechanical and Chemical Interaction (PCMI and PCCI), noticeably involving fuel swelling and cracking associated with core power ramps and reactivity excursions, e.g. Sartoris et al., 2010; (b) clad-coolant chemical interaction, e.g. including oxide formation, appearance of hydride precipitates and occurrence of spalling and hydride rims, e.g. Kim, 2011, (c) crud (or deposit) formation upon the clad, e.g. Leyse, 2007. The nuclear fuel weaknesses interact with the listed degradation mechanisms in case of LOCA (bullet item above) creating complex fuel failure conditions; see e.g. Rozzia et al., 2012: expected fuel failures oriented USNRC to propose modification in acceptance criteria, USNRC, 2018.

\subsection{The Long Term Cooling - the Sump Recirculation}

Once the core is covered by borated liquid water at a temperature below the saturation value, the pressure in primary loop and in containment is the same and the LPIS is in operation according to design, steady state conditions are reached and the transient (LOCA) period is concluded. However, fission product decay is still producing thermal power in the order of $1 \%$ of initial-nominal reactor power (or about 40 MWth in a 1000 Mwe NPP unit) and LPIS tanks are going to be emptied in some minutes: safe conditions must be ensured during some time without the support of energy sources or human actions outside the NPP site (typically, 8 and 72 hours, for existing and new reactors, respectively). Those conditions are achieved by so called containment sump recirculation: the sump at the bottom of containment is filled with steam water mixture coming from the break and condensed into the containment and LPIS pumps suction is switched from the tanks to the sump. The safety and design issues of concern are:

- Liquid level and temperature in the sump should be consistent with pump Net Positive Suction Head (NPSH).

- Debris formed during LOCA, namely around the break location should not induce pump cavitation, or, in the case of 'small debris', should not accumulate in narrow passages as in the core inlet.

Addressing the first item implies performing coupled primary system / containment analyses, e.g. Mascari et al., 2012. A technological challenge is connected with the latter item; e.g. Lee et al., 2014, and Azam et al., 2018. 
The phenomenological picture provided for LBLOCA shall be integrated into the licensing

\subsubsection{Key Elements of BEPU} process. The application of numerical codes is needed in order to fulfill licensing related regulatory requirements; namely, those codes can be considered as the bridge between individual reactor features, phenomena and requirements.

A suitable description of licensing framework, code development and code application procedures may require textbooks and is well beyond the present framework. Hereafter, a synthesis discussion is provided in relation to:

a) The connection between LBLOCA phenomenology (or physical aspects) and the licensing requirements.

b) The key elements which constitute the Best Estimate Plus Uncertainty (BEPU) approach for code application into the licensing process.

\subsubsection{Cross-Link between Physical Aspects of LBLOCA and Licensing Needs}

ECCS licensing targets, can be found in USAEC, 1971; details needed for demonstrating the acceptability of analyses can be found is USNRC, 2013, (NUREG-0800, continuously updated).

Selected licensing needs are summarized in Table 2 (heading) and cross-linked with the LBLOCA physical aspects identified in sections 3.1 to 3.6 [lines 1 to 20; the words 'physical aspects' are used to distinguish from 'phenomena' used by Aksan et al., 2018]. It can be noticed that: (1) each of the needs is considered by at least one physical aspect; (2) each concerned LBLOCA aspect addresses at least one licensing need; (3) other phenomena (list in section 3.4) line 20, are all relevant in LBLOCA analyses and, without providing details, are assumed contributing to the demonstration of accomplishment of each identified need.

The simplest definition tells that BEPU is an approach for the application of Best Estimate (BE) codes and related (or 'Plus') Uncertainty (PU) to the licensing process for the evaluation of reactor safety, D'Auria, 2018. Other than a code and an uncertainty method, six characterizing elements for BEPU have been identified:

1) The phenomena.

2) The V\&V (Verification and Validation).

3) The scaling.

4) The code coupling.

5) The framework and the requirements for AA part of the Final Safety Analysis Report (FSAR).

6) The qualification of the code users or analysts.

Phenomena, item 1), have been discussed in sections 3.1 to 3.5 and regulatory framework, item 5) has been mentioned in previous paragraph. The Verification and Validation (V\&V), item 2), is expected to be a part of BEPU because of unavoidable approximations embedded into the development of a code, e.g. see D'Auria \& Lanfredini, 2018, for new perspectives in the area. Scaling analysis, item 3), is essential because most of data for validation are available for parameter ranges different from those applicable to reactors, OECD/NEA/CSNI, 2017. Different numerical codes need to be coupled, item 4), in order to perform a BEPU application, IAEA, 2007: the demonstration of qualification of coupling constitutes the concern here (and shall be part of BEPU). Finally, the qualification of analysts in charge of BEPU application, item 6), needs proper consideration, e.g. Ashley et al., 1998. BEPU description is completed by a few dozen additional 'framework elements', as discussed by D'Auria, 2018. 
Table 3. Cross-link between selected LBLOCA phenomena and licensing needs.

\begin{tabular}{|c|c|c|c|c|c|c|c|c|c|}
\hline $\mathbf{N}$ & $\begin{array}{c}\text { [Licensing requirement] } \longrightarrow \\
\qquad\left[\begin{array}{l}\downarrow \\
\text { [LBLOCA physical aspect] }\end{array}\right.\end{array}$ & 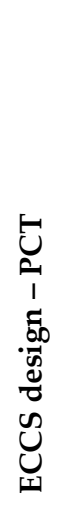 & 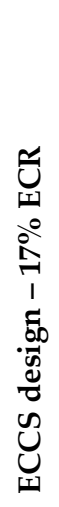 & 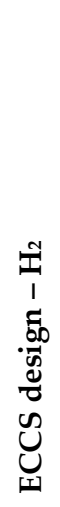 & 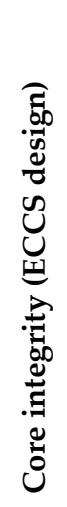 & 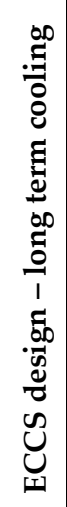 & 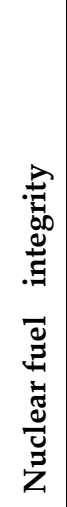 & 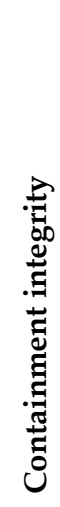 & $\begin{array}{l}\text { Notes } \\
{[X \text { implies that the given }} \\
\text { physical aspect is directly } \\
\text { relevant to demonstrate the } \\
\text { corresponding need }]\end{array}$ \\
\hline 1 & Break Opening Time (BOT) & & & & $\mathrm{X}^{*}$ & & & & \multirow{2}{*}{$\begin{array}{l}\text { * Core integrity not affected by } \\
\text { ECCS design. }\end{array}$} \\
\hline 2 & Depressurization wave & & & & $\mathrm{X}^{*}$ & & & & \\
\hline 3 & Jet impingement \& Thrust & & & & & & & $\mathrm{X}$ & \\
\hline 4 & Pipe Whip \& Missiles & & & & & & & $\mathrm{X}$ & \\
\hline 5 & Loads on internals & & & & $\mathrm{X}^{*}$ & & & & * see note at line1 \\
\hline 6 & Flashing & $x$ & & & & & & & \\
\hline 7 & Core flow reversal & $x$ & & & & & & & \\
\hline 8 & Fission Power Peak & $x$ & & & & & $x$ & & \multirow[t]{2}{*}{ Only in PHWR } \\
\hline 9 & Boron injection & $x$ & & & & & $\mathrm{X}$ & & \\
\hline 10 & TPCF & $\mathrm{X}$ & $\mathrm{X}$ & $\mathrm{X}$ & & & & $x$ & \\
\hline 11 & Flow stagnation & $\mathrm{x}$ & & & & & & & \\
\hline 12 & CHF \& blowdown, $\left(1^{\text {st }}\right)$ PCT & $x$ & & & & & & & \\
\hline 13 & Early core rewet & & $x$ & $x$ & & & & & \\
\hline 14 & Depressurization rate & $x$ & $\mathrm{X}$ & $x$ & & & & & \\
\hline 15 & Containment pressure & & & & & & & $x$ & \\
\hline 16 & $\begin{array}{l}\text { Precursory cooling, }\left(2^{\text {nd }} \text { PCT }\right) \text { and } \\
\text { temperature turnaround }\end{array}$ & $x$ & $x$ & $x$ & & & & & Conditions for reflood \\
\hline 17 & $\mathrm{H}_{2}$ production & & & $x$ & & & & $x$ & \\
\hline 18 & Quench progression \& RNB & & $x$ & $x$ & & & & & \\
\hline 19 & Long term cooling & & & & & $X$ & & $x$ & Sump recirculation \& debris \\
\hline 20 & 'Other' phenomena & $x$ & $x$ & $x$ & $X$ & $X$ & $\mathrm{X}$ & $\mathrm{X}$ & Listed in section 3.4 \\
\hline
\end{tabular}

\section{The ATUCHA-II LBLOCA Safety Evaluation}

In 2006, the Argentinean Government set the financial framework and requested the NA-SA Company to complete the construction of Atucha-II. About ten year before the Siemens (German Company) had delivered all main components of the nuclear reactor on the site and basically completed the technology transfer connected with the PHWR design. The same company was not any more available to resume the construction activities in 2006; then, NA-SA took the decision to bring the reactor in operation without the direct support of the original reactor designer. In this framework University of Pisa was asked to contribute to the Final Safety Analysis Report and, namely to issue the Chapter 15 dealing with accident analysis.

The activity was accomplished by GRNSPG of University of Pisa at the due time, involving a properly established international group of senior consultants. A suitable version of the FSAR was submitted to Argentinean Regulatory Body (ARN) in 2010 (and later on endorsed by the same Body) and the reactor was connected to the electrical grid for continuous operation in 2014.

\subsection{The Framework for the Activity}

Starting from 2006, three main lines of activity were pursued at University of Pisa in relation to Atucha-II:

> LBLOCA analysis and understanding of inherent design features, D'Auria et al., 2008. 
Formulation of a BEPU approach (approved by Regulatory Body), Muellner et al., 2008.

It shall be noticed in advance that the understanding of the system design features and the confirmation of available safety margins was possible only with BEPU and utilizing techniques and research findings not available at the time of the design of the Atucha-II PHWR.

Hereafter, achievements from the LBLOCA analysis are outlined: reported data are not necessarily part of the licensing documentation, GRNSPG, 2010; rather, results from safety evaluations and supporting studies for the FSAR are reported and discussed; the technological framework established in section 3 is considered to this aim.

The BEPU approach had a key role for the issuing of FSAR Chapter 15. However a number of related papers have been already published: reference to those papers is provided in section 4.4 together with a list of performed key activities.

\subsection{Background analysis and challenges}

Two statements summarize the start of Atucha-II LBLOCA activities at University of Pisa: $<[A]$ All design documents and information (noticeably including access to components and systems as built) from the technology transfer (i.e. from the original designer to the utility in Argentina) related to Atucha-II are available $>$.

$<[B]$ A positive void reactivity coefficient is expected to produce a fission power excursion after LOCA: safety margins need to be (evaluated independently from designer and) confirmed $>$.

The former statement implied a few million pages documents possibly needed to understand the project details; the latter should be taken considering that in the aftermath of the power excursion in Chernobyl, (i.e. for 2 decades at the time of the start of activities) no reactor in the world was put in operation with a positive void coefficient. Therefore the Atucha-II project, or a stimulating endeavor, started.

Two intrinsic challenges for the project are directly derived from the PHWR description (section 2.1): the use of $\mathrm{D}_{2} \mathrm{O}$ as coolant/moderator and the features of the moderator system imposed preliminary investigation to confirm the applicability of adopted computational tools. Errors in experiments where operational fluid is $\mathrm{H}_{2} \mathrm{O}$ and $\mathrm{D}_{2} \mathrm{O}$ were compared (former challenge); modeling of a dozen RPV bypass flow paths was needed (latter challenge) to simulate two parallel loops, PS and moderator, at different temperatures and driven by separate pumps ending up at the same pressure into the RPV.

A list of ten additional (selected) challenges which needed to be considered prior to start of safety margins calculation is [note-1, adopted abbreviations are: $B A=$ Break Area; BIT $=$ Boron Injection Time; $B O T=$ Break Opening Time; $B P=$ Break Position (along the loop); $C C F L=$ Counter Current Flow Limitation; $\quad C L=$ Col Leg; FA = Fuel Assembly; FPP = Fission Power Peak; $G / P=$ Mass flowrate divided by power produced in each FA; HL = Hot Leg; $L P=$ Lower Plenum; $M C P=$ Main Coolant Pump; $P C T=$ Peak Clad Temperature; RPV = Reactor Pressure Vessel; note 2: FPP may not coincide with Total Power Peak (TPP) where all contributions to core power are included, e.g. decay power]:

[1] LP modeling.

[2] PCT vs (BA and BP).

[3] FPP vs (BA and BP).

[4] FPP vs (BOT and BIT).

[5] (PCT and FPP) vs ECCS configuration.

[6] (PCT and FPP) vs core life.

[7] Initial void content, MCP operation and single failure.

[8] BA based on the as-built CL nozzle connection and RPV.

[9] CCFL in HL.

[10] G/P in each FA (nominal operation).

[1] The Atucha-II RPV-LP is filled by blocks of inert material in order to decrease the amount of expensive heavy water. The LP function to create a uniform upper oriented flow towards the core (case of PWR) is taken by a plate formed by rhomboidal boxes, sketch given in Fig. 12 (left and center): each box has vertical holes connecting with fuel channels and horizontal flow passages 
(arrows in the center sketch) to uniform the pressure at core inlet. Results to demonstrate
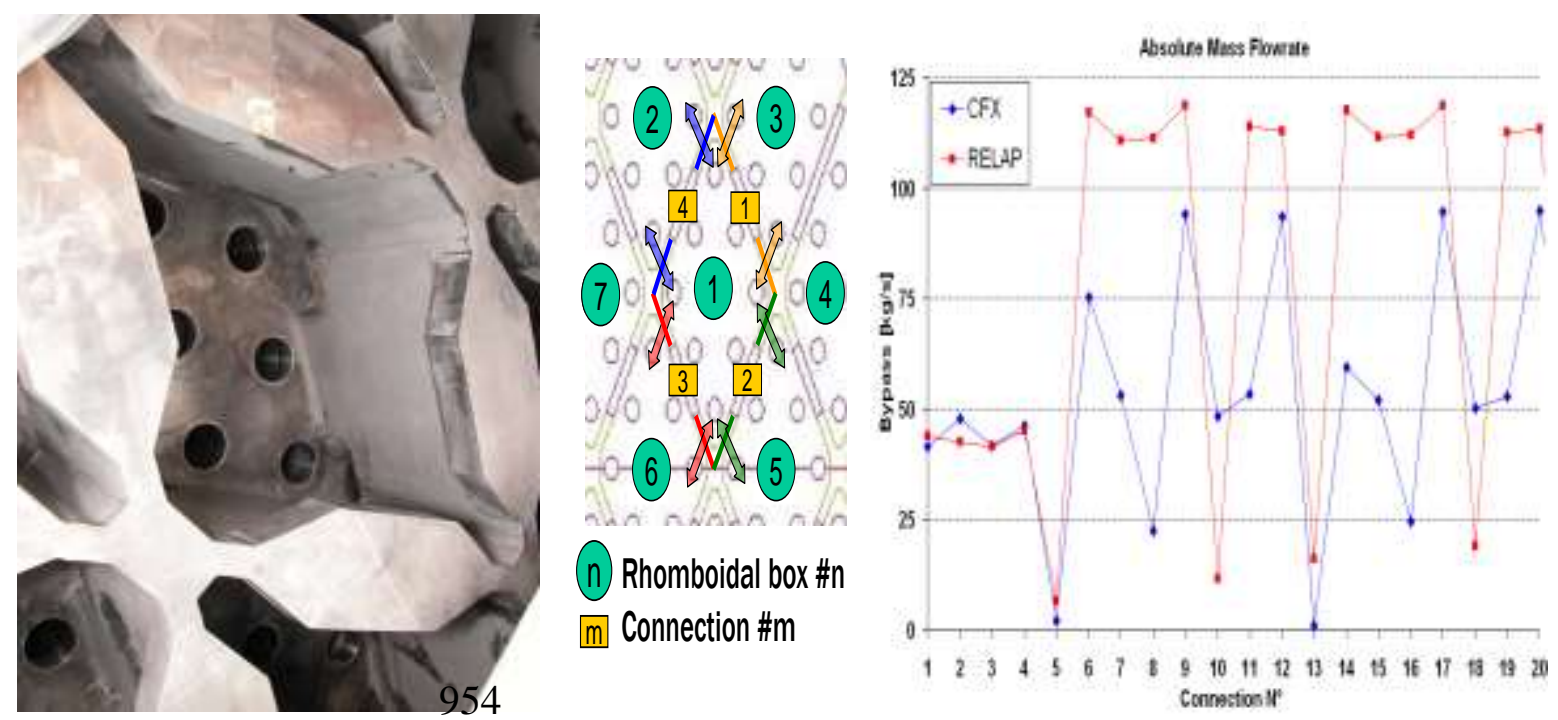

Figure 12. Left: view from the bottom of one rhomboidal box core support plate. Center: identification of box and of horizontal 'bypass' paths; Right: detail of qualification results for the system code model.

[2] Break area and position affect PCT in Atucha-II in a similar way as in PWR, as shown (sample results) in left side of Figs. 4 and 5, respectively. The difference is that, in the current situation, the FPP has also an impact upon PCT (further discussion below).

[3] FPP expected in case of PHWR LBLOCA is affected by parameters different from those influencing PCT: a specific sensitivity study was needed with sample results shown in right sides of Figs. 4 and 5, respectively related to BA and BP dependencies.

[4] BOT has negligible impact on PCT in case of PWR where fission power shifts to decay power immediately after the break occurrence; this is not the case of PHWR where void formations in the core, affected by BOT, determine a FPP. Therefore, the Fast Boron Injection System was added to the Atucha-II design: the actuation of the system is characterized by the BIT parameter. BIT is defined as the time when the first droplet of highly borated liquid reaches the moderator: at that moment the 'same droplet' had already interacted with the intrinsic neutron reflector at core top affecting fission power generation.

Selected results obtained by a simplified nodalization (nodalization discussion in section 4.4.2) are summarized in Fig. 13.

The support analyses (not necessarily characterized by reported data) demonstrated that:

- BOT values $\geq 1 \mathrm{~s}$ suppress any FPP.

- BIT values $\leq 0.3 \mathrm{~s}$ suppress any FPP; otherwise BIT values $\geq 1.0 \mathrm{~s}$ are ineffective in reducing FPP.

- The largest values for PCT and FPP are obtained for a BA (slightly) lower than the maximum attainable area (i.e. the DEGB of the $\mathrm{CL}$ ): early and increased core flow reversal (and connected core cooling) contributes to this outcome (see also Figs 4 and 5).

The importance of BIT suggested the construction of a 'scale 1' test facility, called BITF (= Boron Injection Test Facility), Moretti et al., 2018: performed experiments brought to an improvement of the system and confirmed the design parameters adopted in licensing analyses.

[5] The lack of symmetry of the Atucha-II system, the availability of four trains (each one having $50 \%$ capability of core cooling) per ECCS (noticeably accumulator and LPIS) and the licensing need to exclude the most effective train brought to a complex analysis. The worst conditions for the LBLOCA had to be identified by combining the selected ECCS configuration with BA and BP. 

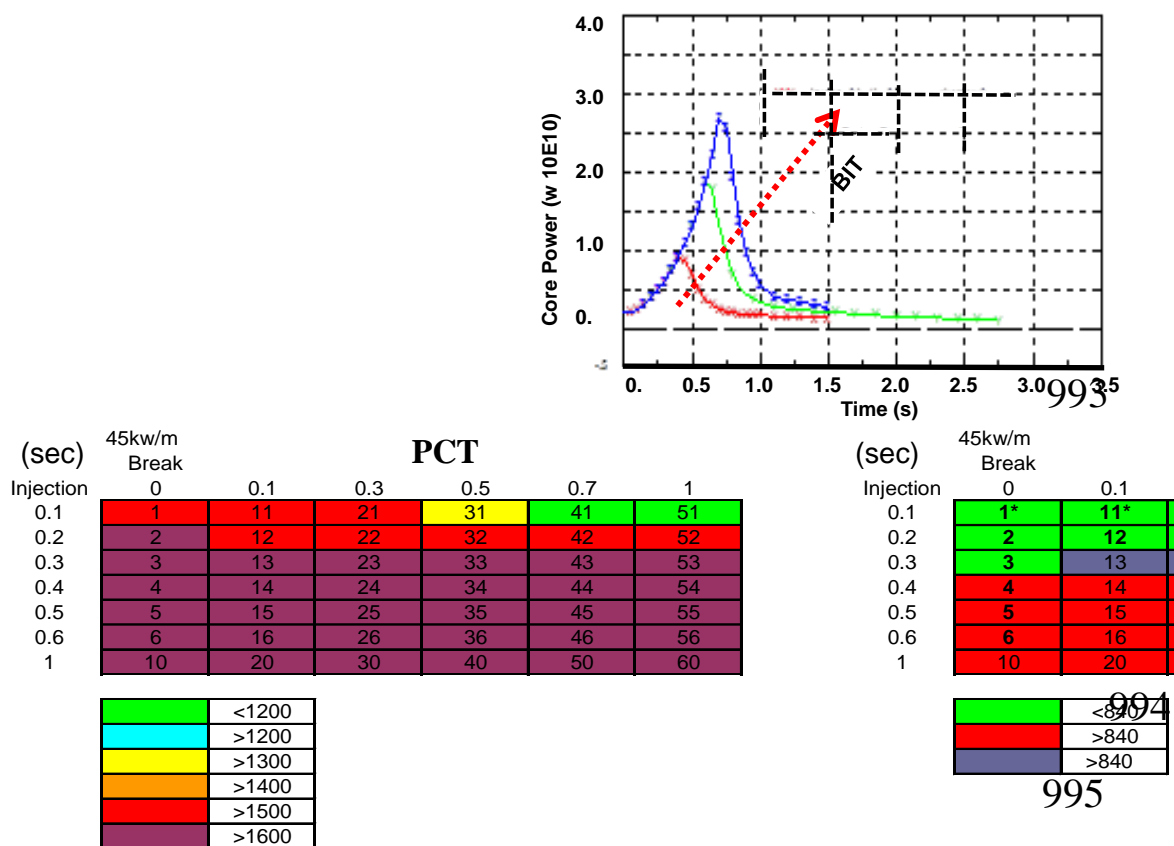

Figure 13. Top: FPP calculated for different BIT (0.4, 0.6 and $0.7 \mathrm{~s}$ from bottom to top). Bottom: relationship between BIT, BOT, PCT [ $\left.{ }^{\circ} \mathrm{C}\right]$ and FPP (energy to the fuel, $[\mathrm{Cal} / \mathrm{g}]$ ) at LHGR limit value.

[6] Daily changes of fuel characterize the operation of natural uranium PHWR; this implies change in core power distribution, average burn-up and, consequently, fuel material properties during the core life. Noticeably, maximum LHGR and void coefficient change during the core life. A specific core-life analysis led to identify an equilibrium cycle the worst LBLOCA conditions.

[7] Several "settings", other than those already discussed, have to be justified for a suitable LBLOCA licensing analysis, like initial pressurizer level, steam generator pressure and initial core power. Assumptions for (a) fluid sub-cooling and sub-cooled void content in individual channels at the time of the LBLOCA start, (b) the operation of MCP, and (c) the worst single failure in active components, in addition to the failure of one ECCS train, constituted examples of formidable targets for investigations which had to be completed prior to the start of an acceptable licensing study. In relation to the item (a), for an equilibrium core condition, the following was found:

- Fluid temperature sub-cooling at core outlet in the range $(0-25) \mathrm{K}$ and average value of $10 \mathrm{~K}$;

- Sub-cooled voids are present (void fraction up to 0.4 ) at the outlet in $(10-20) \%$ of core channels;

- High average void contents at LBLOCA start may imply lower contribution of voids to FPP.

[8] The reference geometric configuration for the connection region between the RPV and the CL is shown in the left sketch of Fig. 14, together with the actual (as built) configuration in Atucha-II. Let's consider: $\mathrm{G}^{\mathrm{ref}}=$ (initial value of critical flow-rate adopted in final (licensing) analysis consistent with the left sketch; Gcathare $=$ (initial value of) critical flow-rate derived from modeling the sketch on the right by Cathare code; Ggas ${ }^{\text {fdd-left }}$ and Ggas $^{\text {cfd-right }}=$ left and right values of (stationary) critical gas flow obtained by CFD calculations assuming an infinite reservoir upstream the break.

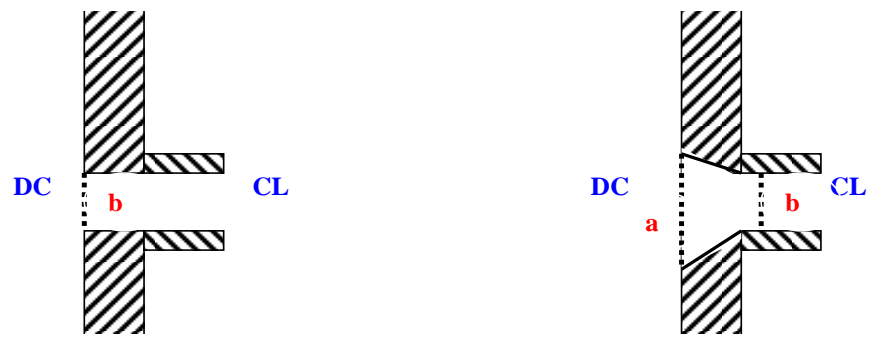

Figure 14. Sketch for CL to RPV connecting nozzle. Left: typical PWR. Right: Atucha-II PHWR.

Starting from the ratio $\mathrm{a} / \mathrm{b}=1.52$ (Fig. 14), the following results were obtained: 
Flowrate values related to the right sketch in Fig. 14 were not considered in final (licensing) analyses because (a) they bring to reduction in PCT and FPP (see Fig. 4); (b) lack of experimental data prevented the possibility to demonstrate a suitable qualification for the obtained results.

[9] The capability to predict delivery into the upper plenum of the ECCS liquid injected in HL (related phenomenon called CCFL in HL) is difficult due to the momentum of ECC water directed towards the upper plenum [Damerell \& Simons (Eds.), 1993]. CCFL in hot leg under reflux condenser conditions is described by Glaeser \& Karwat, 1993, for example. This implies

$$
\left(\mathrm{Jg}^{*}\right)^{0.5} \approx 0.7 \text {, }
$$

where $\mathrm{Jg}_{\mathrm{g}}^{*}$ is the non-dimensional value of vapor superficial velocity at the concerned (HL nozzle in this case) CCFL location. Recent available documents (i.e. published after the completion of Atucha-II licensing) confirm the above statement; see e.g. Fig. 15, Deendarlianto et al., 2012, where data predicted by Chun \& Yu, 2000, are reported too (Chun \& Yu data are obtained by an empirical correlation qualified by an experimental data-set measured in a pipe with a diameter about 10 times smaller than the HL of Atucha-II).

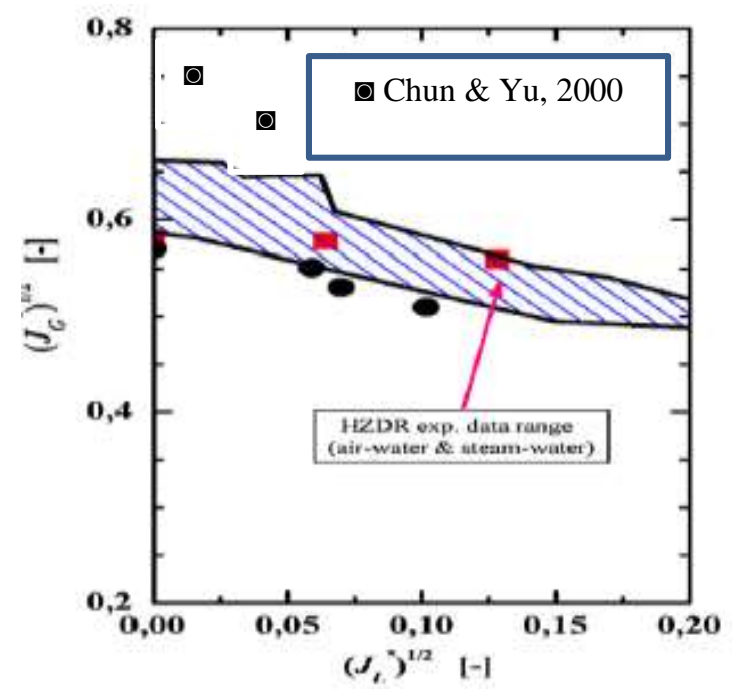

Figure 15. CCFL data relevant to the Atucha-II LBLOCA at the HL-RPV connection.

The status of knowledge for CCFL (namely at the HL-RPV connection) after the completion of the Atucha-II licensing can be summarized, according to Deendarlianto et al., 2012, as "... presently we have no physical measure to capture the important parameters of CCFL. ..., if we change the test liquid temperature, the physical properties of the liquid also change which accordingly affects the interfacial heat transfer between gas and liquid." Insights about the steps undertaken to optimize the CCFL modelling capabilities for the Atucha-II application are provided in section 4.4.2

[10] The ratio mass flowrate / power generated (G/P) in each FA is given in Fig. 16. In a typical operational condition this ratio has a complex distribution and numerical values across the core in the range 4 to 7 (concerned units) can be noted. Selected key aspects of LBLOCA which are affected are:

- Early void generation is different in different FA.

- Flow reversal occurrence is expected at different times.

- Energy stored in fuel pins is affected in addition to LHGR (different fluid temperature at pin surface)

- FPP is expected at different times.

- PCT in individual FA is largely affected by G/P because of all of above. 


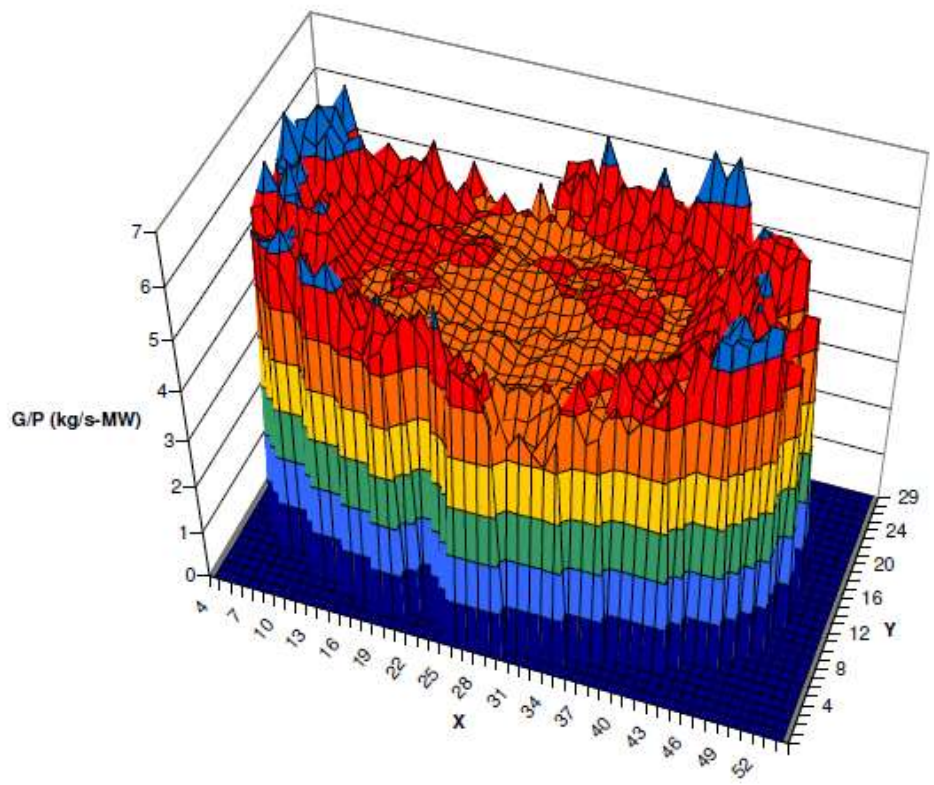

\subsection{The key results}

LBLOCA calculations for Atucha-II were performed based on the available background information (chapter 3) with main attention for challenges (selected ones in section 4.2). A

1101 qualitative and quantitative picture of results can be drawn from Fig. 17 and Table 4, respectively.

1102

The reported values, as indicated in the note under the $4^{\text {th }}$ column in Table 4 , do not coincide

1103

1104

1105

1106

1107

1108

1109

1110

1111

1112

1113

1114

1115

1116

1117

1118

1119 with the proprietary licensing data. Rather, those values relate to safety supporting calculations and provide a 'meaningful' picture of the transient scenario.

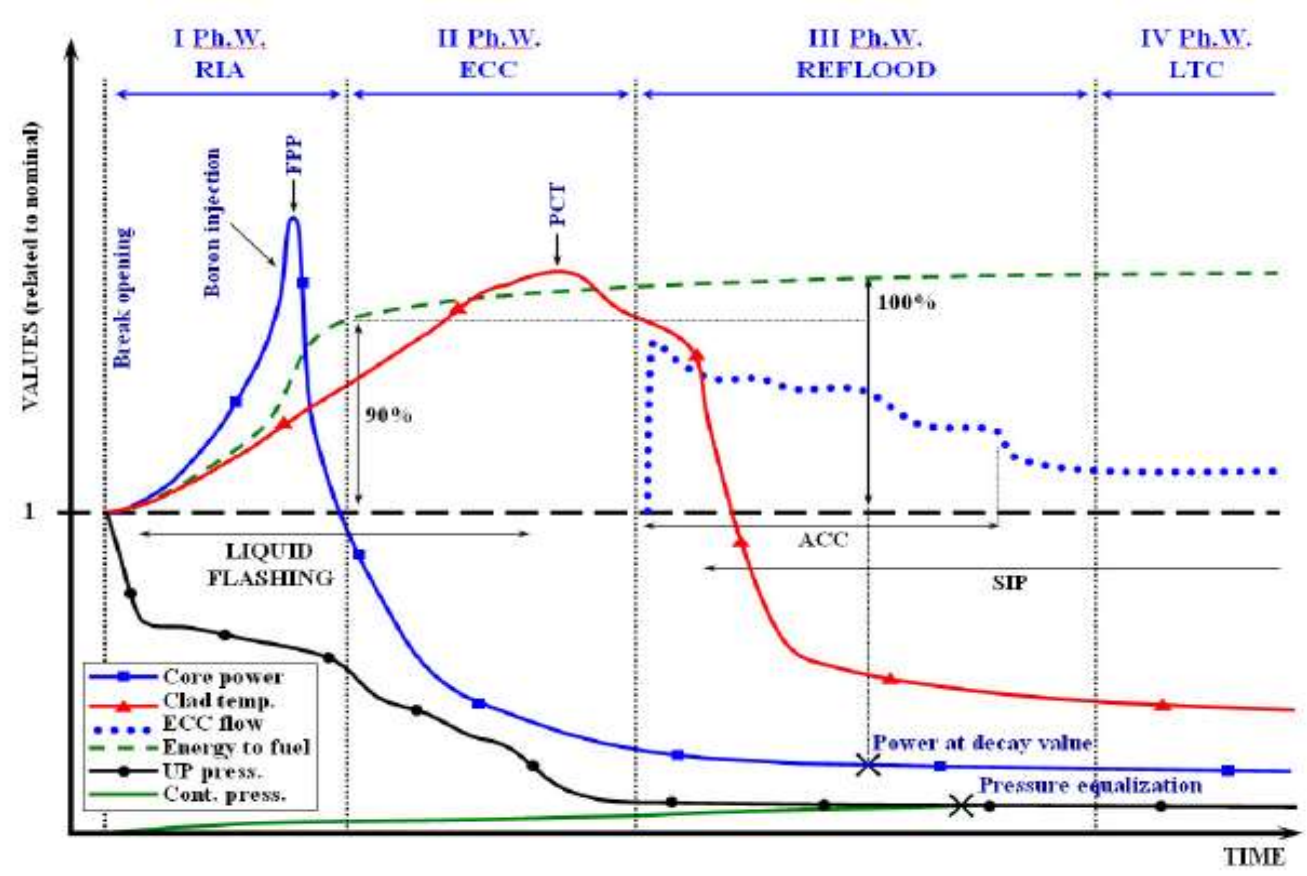

Figure 17. A picture of the LBLOCA scenario predicted for Atucha-II. 
Table 4. An overview of Atucha-II LBLOCA: sequence of events and phenomena.

\begin{tabular}{|c|c|c|c|c|c|}
\hline \multirow[b]{2}{*}{$\mathrm{N}$} & \multirow[b]{2}{*}{$\begin{array}{l}\text { Phenomenon, Event or } \\
\text { LBLOCA Aspect }\end{array}$} & \multirow[b]{2}{*}{ Unit } & \multicolumn{2}{|c|}{ Value } & \multirow[b]{2}{*}{ Notes } \\
\hline & & & \begin{tabular}{c|} 
Licens \\
ing
\end{tabular} & Safety & \\
\hline 1 & Break occurrence & $\mathrm{s}$ & \multirow{4}{*}{ 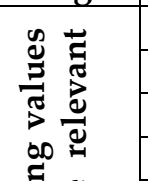 } & 0 . & \\
\hline 2 & BOT & $\mathrm{m}-\mathrm{s}$ & & 1. -30 . & \\
\hline 3 & Load on RPV support & Ton & & $<1500$ & \multirow{3}{*}{$\begin{array}{l}\text { No or limited (acceptable) damage to } \\
\text { containment structures and to RPV } \\
\text { support }\end{array}$} \\
\hline 4 & Jet impingement load & Ton & & $<1100$ & \\
\hline 5 & Reactor cavity pressurization & $\mathrm{MPa}$ & \multirow{8}{*}{ 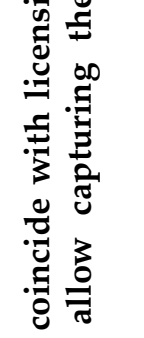 } & 0.8 & \\
\hline 6 & Stress on moderator tank & $\mathrm{MPa}$ & & $<430$ & ASME criteria fulfilled \\
\hline 7 & BIT & $\mathrm{s}$ & & 0.6 & \\
\hline 8 & FPP & Mwth & & 21. & at $\approx 0.6 \mathrm{~s} ; \approx 50 \mathrm{Cal} / \mathrm{g}$ energy \\
\hline 9 & Decay power reached & $\mathrm{s}$ & & 15. & After FPP \\
\hline 10 & Void appearance in the core & $\mathrm{s}$ & & $0.01-1.0$ & Depending upon location \\
\hline 11 & Flow reversal at core inlet & $\mathrm{s}$ & & $0.05-0.1$ & Not occurring in each channel \\
\hline 12 & Flashing in upper plenum & $\mathrm{s}$ & & 2. & Bulk values connecting pressure \\
\hline 13 & Flashing in downcomer / LP & $\mathrm{s}$ & & 13. & decrease and initial temperature \\
\hline 14 & Flashing in moderator & $\mathrm{s}$ & & $35 .-80$. & (range in the case of moderator) \\
\hline 15 & $\mathrm{CHF}$ & $\mathrm{s}$ & రृ & $0.5-1$. & Not occurring in each channel \\
\hline 16 & PCT & $\mathrm{K}$ & 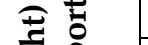 & $<1350$ & At about $5 \mathrm{~s}$; including uncertainty \\
\hline 17 & Containment pressure peak & $\mathrm{MPa}$ & .000 & 0.35 & At about $10 \mathrm{~s}$ \\
\hline 18 & PRZ emptied & $\mathrm{s}$ & & 28. & Pressure equalization with PS \\
\hline 19 & Minimum RPV mass inventory & $\%$ & $=\dot{I}$ & 20. & Excluding the moderator \\
\hline 20 & Accumulator injection start & $\mathrm{s}$ & โี & 15. & \\
\hline 21 & Accumulator emptied & $\mathrm{s}$ & $\exists \geq$ & 150. -170 . & \\
\hline 22 & LPIS injection start & $\mathrm{s}$ & $\Xi \pi$ & 100. & SIP in Fig. 17 \\
\hline 23 & Reflood completed & $S$ & : & 200. & \\
\hline 24 & Collapsed level above core & $\mathrm{S}$ & & 240. & \\
\hline 25 & Equal $p$ in containment and PS & $\mathrm{S}$ & $\Xi \bar{z} \tilde{g}$ & 250. & Pressure equalization \\
\hline 26 & Sump recirculation start & $\mathrm{S}$ & > & 800. & Time of emptying of LPIS tanks \\
\hline 27 & Sump level and temperature & $\mathrm{m} /{ }^{\circ} \mathrm{C}$ & E $\approx$ \& & $>1 /<80$ & At above time \\
\hline 28 & Fraction release of $(\mathrm{Xe \& Kr}) /(\mathrm{I})$ & - & ث己 & 1. $\quad /<0.4$ & \\
\hline 29 & Radiation impact & Sv & 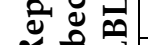 & $<0.1$ & Event duration in LPZ \\
\hline 30 & End of calculated transient & $\mathrm{S}$ & & 1000. & \\
\hline
\end{tabular}

1123

1124

1125

1126

1127

1128

1129

1130

1131

1132

1133

1134

1135

1136

1137

1138

1139

1140

1141

1142

Explanatory notes for Fig. 17 and Table 4 are (additional insights can be found in sections 4.3.1 to 4.3.5):

* Four phenomenological windows (PHW) are established and are characterized by (1st PHW) the FPP occurrence, ( $2^{\text {nd }}$ PHW) the PCT occurrence, ( $3^{\text {rd }}$ PHW) the actuation of ECCS and the reflood, $\left(4^{\text {th }} \mathrm{PHW}\right)$ the long term cooling and the sump recirculation.

* No argument could be used to justify (for regulators), or to substantiate (from a technology viewpoint), a BOT value greater than $1 \mathrm{~m}$-s (line 2 in Table 4): this value was conservatively assumed in the licensing analysis.

* Flashing occurs during the $1^{\text {st }}$ PHW up to the $3^{\text {rd }}$ PHW: however early flashing consequence of pressure wave propagation should be distinguished from depressurization originated flashing.

* The loads generated by two-phase jet are considered in lines 3 to 5 (Table 4); pipe whip was evaluated as uninfluential because of design countermeasures.

- Noticeably, sump level formation and presence of debris are considered during the $4^{\text {th }} \mathrm{PHW}$.

A typical PWR LBLOCA scenario (PRZ, PS and containment pressure, CHF and flow reversal occurrence, rod surface temperature excursion, ECCS actuation and reflood) constitutes the outcome for the Atucha-II PHWR prediction. Key difference related to a PWR is the occurrence of the FPP and the need for fast boron injection: the FPP has an impact over PCT and the integrity of fuel which needed specific investigation. Emphasis is given in sections 4.3.1 to 4.3.5 to peculiar aspects of 
Atucha-II PHWR LBLOCA; description of established LBLOCA parameters (depressurization rate, reflood phenomenology, etc.) is omitted.

A specific activity was carried out for Atucha-II in order to demonstrate a BOT $>1 \mathrm{~s}$ for DEGB LBLOCA: this would imply a negligible FPP, as already mentioned. To this aim, Zhang et al., 2013, started their work considering that Stress Corrosion Cracking (SCC) is an issue with many PWR plants; therefore, an upper bound SCC growth curve was used to envelope both Primary Water Stress Corrosion cracking (PWSCC) and intergranular stress corrosion cracking (IGSCC). The pipe material in Atucha-II is 20MnMoNi55 (similar to A533B) and at this time is not known to be susceptible to SCC; nevertheless, a high crack growth rate was used so that after 80 years of operation the concerned degradation may occur. This consists of a circumferential through wall crack of $120^{\circ}$; then a hypothetic earthquake was assumed having maximum amplitude of the acceleration wave much higher than the design earthquake. In such a situation it is impossible not to realize that there was a leak, or the LBB concept could be adopted to prevent LBLOCA; furthermore, even in the absence of leak detection (or LBB not 'working'), a through wall crack ended into a $2 \mathrm{~A}$ break in a couple of seconds. This result was used within licensing process; otherwise information below relates to BOT $\approx 1$ m-s.

The (negative) pressure wave propagation from the break towards the RPV can be observed in Fig. 18. The lowest pressure, detected soon after the break occurrence in the CL, has a value below the local saturation value corresponding to the initial temperature (similar situation observed in HDR experiment, Fig. 7). The amplitude decreases when the pressure wave moves from CL to downcomer and to lower plenum; with an approximate delay of $20 \mathrm{~m}-\mathrm{s}$ the wave reaches the bottom of the fuel channels and propagates upwards where about one-half amplitude can be seen. Not shown in the diagram, the moderator pressure remains at the initial value during the reported time span (horizontal axis in Fig. 18).

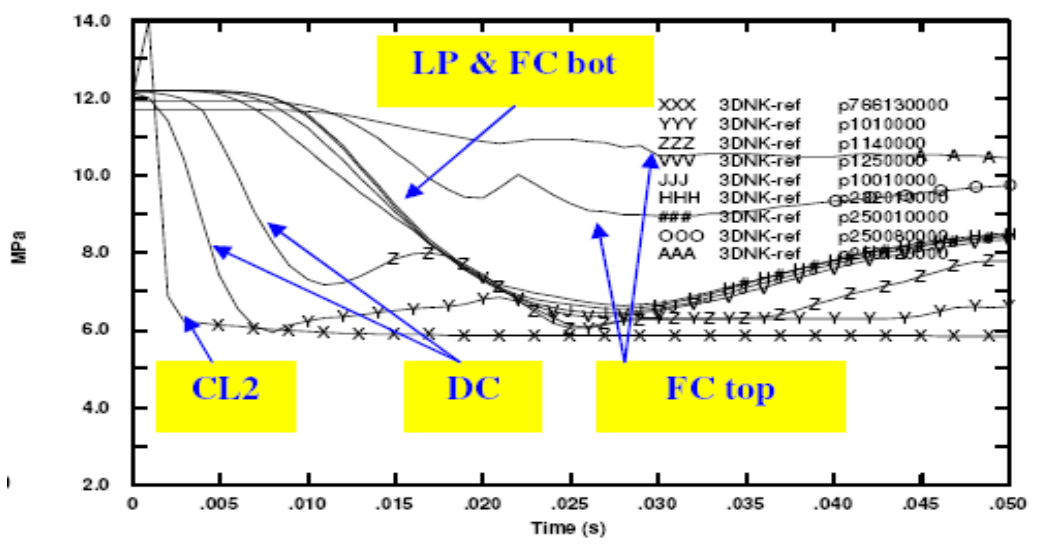

Figure 18. Atucha-II LBLOCA: propagation of depressurization wave from the break.

The wave propagation produces an impulse pressure load acting from the inside to the outside in the case of the moderator tank, Fig. 19 left, and from outside to the inside of fuel channel walls, Fig. 19 right. The location of the maximum stress value can be observed in Fig. 19 at the concerned time.

a) location of channels in the core related to the CL where the break occurs: closer channels are affected earlier;

b) channel orifice: the smaller the flow area at fuel channel inlet the smaller is the pressure wave amplitude into the channel; 
c) distance from channel bottom: upstream pressure wave propagation (and void generation) is affected by distance from channel inlet and flow conditions (see also item below);

d) fluid temperature profile in each channel: subcooling at channel inlet is the same in all channels, however, G/P ratios and total power are different in each channel (see also Fig. 16) and in some channels subcooled void is present at the top (see also challenges [7] and [10] under section 4.3): therefore each channel has, (1) a different feedback in terms of void production, and (2) a different impact upon local and global fission power.
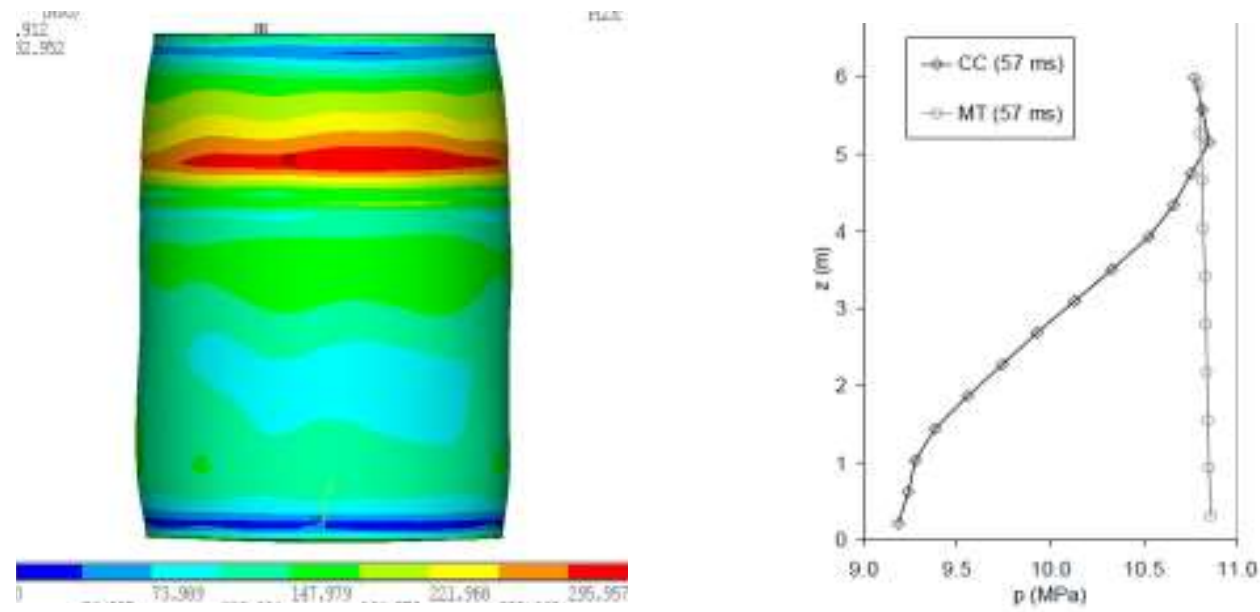

Figure19. Atucha-II LBLOCA at 0.05 s. Left: pictorial view of moderator tank load. Right: pressure difference across one selected fuel channel.

Differences in terms of void generation between two typical channels and among (three selected) axial locations inside each individual channel can be drawn from top of Fig. 20.
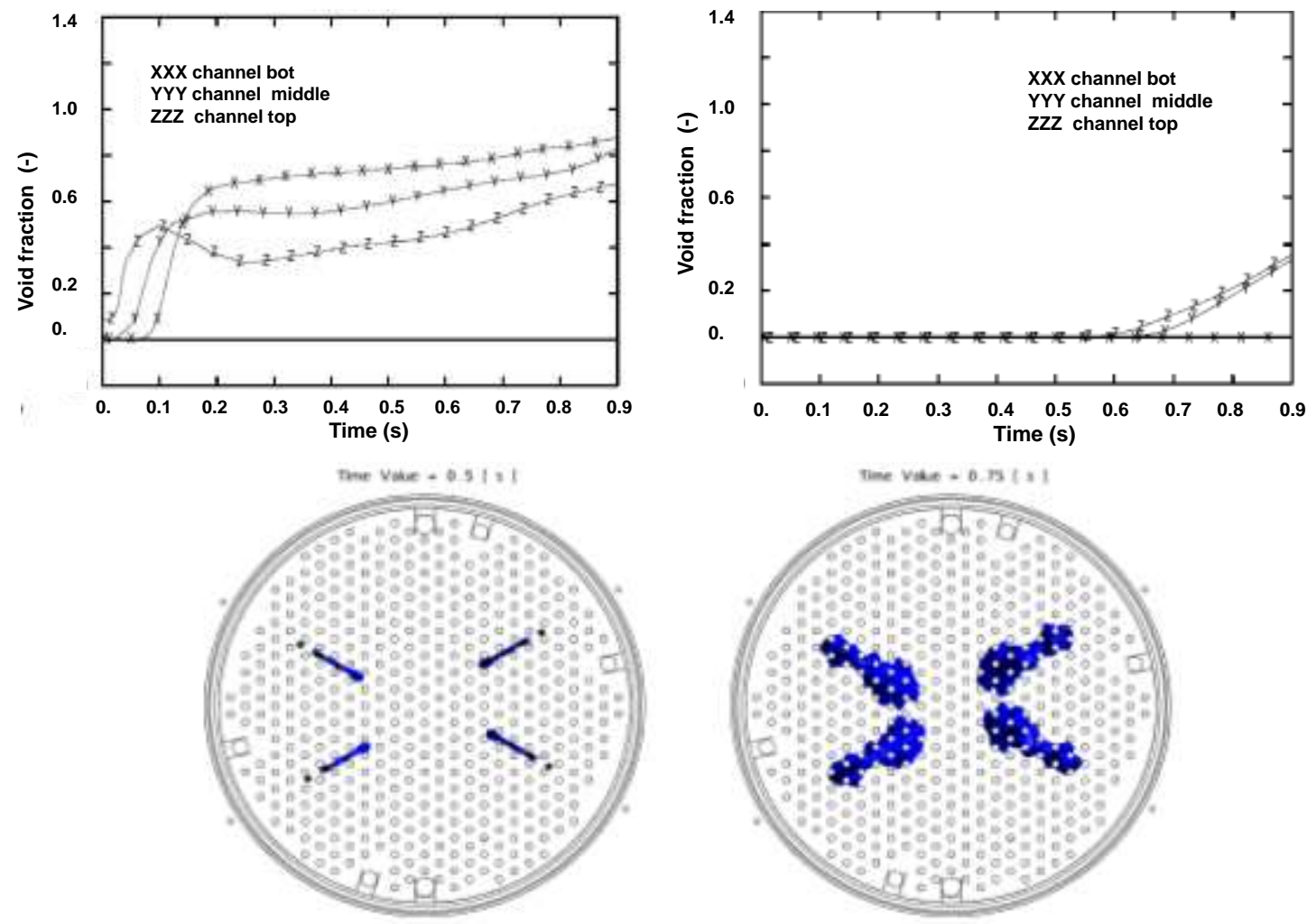

Figure 20. Atucha-II LBLOCA, bases for the evaluation of FPP. Top: void fraction in two different channels at three different elevations originated by propagation of depressurization wave from the break. Bottom: top view of boron cloud formation in the moderator tank. 
The end components of the Boron Injection System consist of four lances which penetrate the moderator tank, each one having several holes and an angle related to the axis of the tank. The arrival time of borated fluid into the moderator tank has been called BIT (see challenge [4] and line 7 in Table 4). In addition to BIT, the diffusion of highly borated fluid into the (still solid, i.e. not yet vaporized liquid in the moderator tank at the concerned time) affects the FPP. A top view picture for boron arrival into the moderator tank and consequent boron cloud formation is provided in the bottom of Fig 20 (left and tight sketches correspond to two different times)

A complex modeling activity was needed to calculate (a) BIT (this took benefit from the already mentioned BITF experiment, Moretti et al., 2018), (b) the borated fluid diffusion (this needed CFD analyses), and (c) the impact of local poisoned moderator upon FPP generated by void formation. A detailed three-dimensional coupled thermal-hydraulics and neutron physics calculation was carried out considering local values for coolant and moderator fluid parameters, primarily temperature and void, and for nuclear fuel, primarily burn-up and pin temperature distribution. Selected results are shown in Fig. 21, also supported by MCNP calculations, Pecchia et al., 2009, and Pecchia et al., 2015. Calculated FPP is about 10 times the nominal power and occurs before $1.0 \mathrm{~s}$ (top left); power distribution at the time of PCT is given in the top right diagram. The time change in axial power profile for individual fuel assemblies can be seen in each of the bottom diagrams; the different behavior power profiles evolutions between two different fuel channels can be noted.

1239

1240
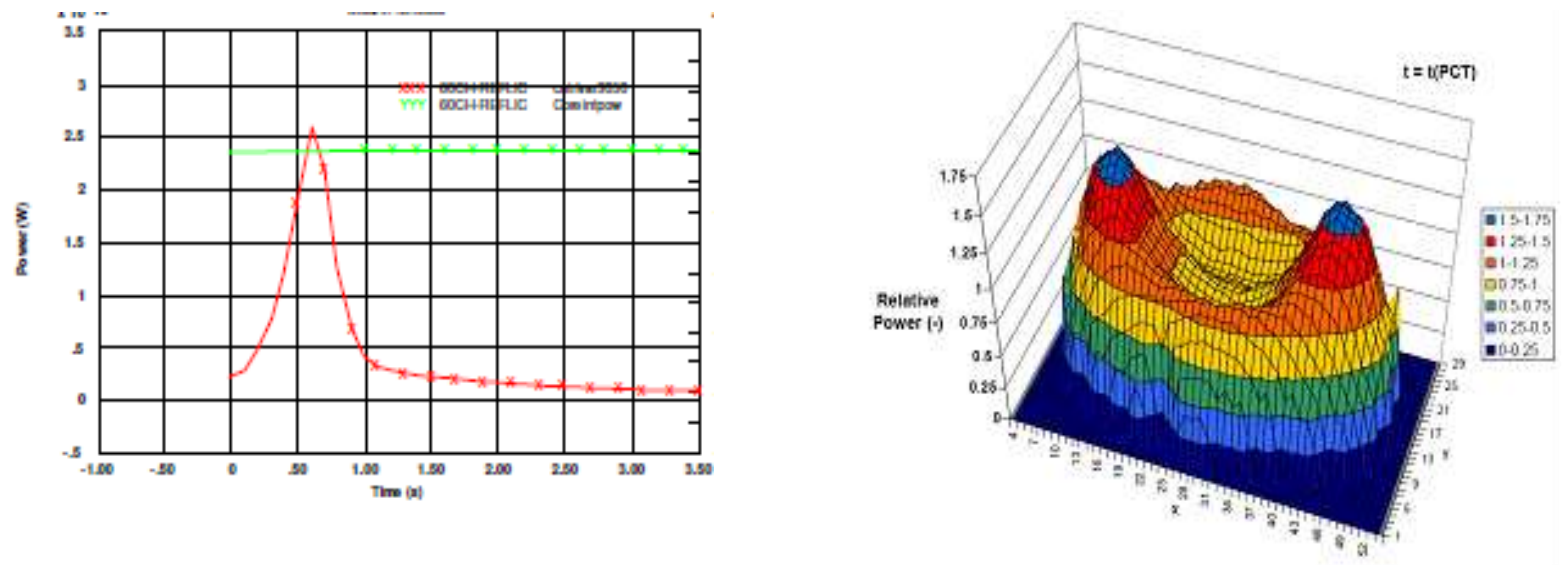

1241
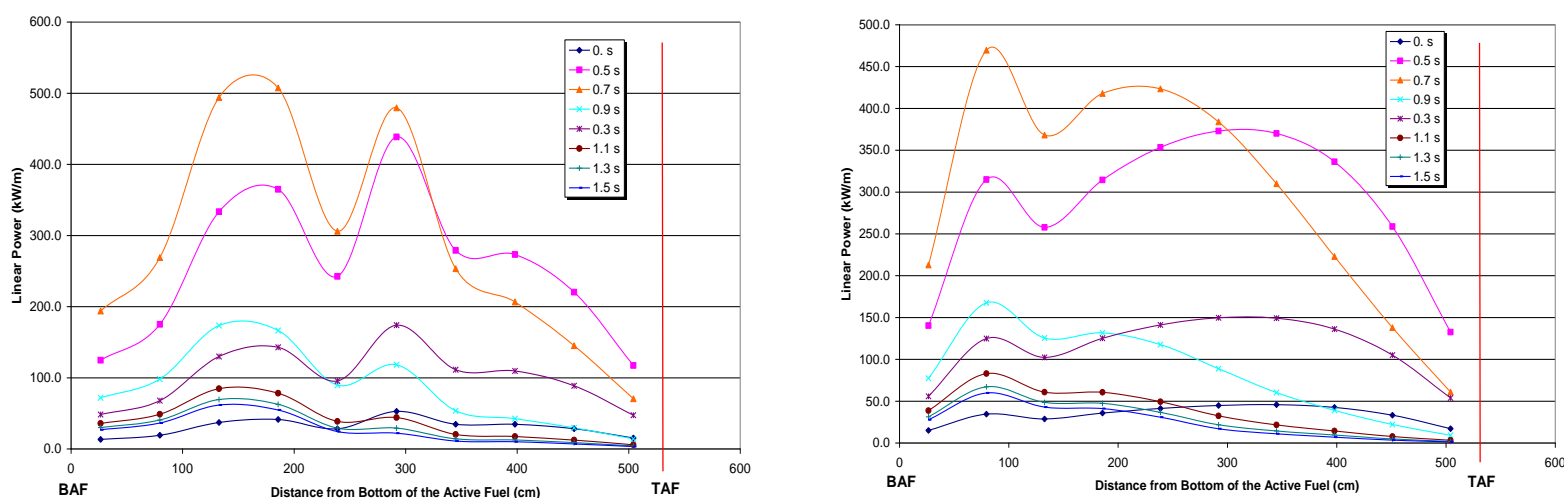

Figure 21. Atucha-II LBLOCA, evaluation of FPP. Top: overall core power. Bottom: power profile during the FPP in different fuel channels.

\subsubsection{The Overall System Performance (PHW 1, 2 and 3)}

\subsubsection{Key Variables}

The qualitative global LBLOCA scenario in Atucha-II PHWR is the same as a typical PWR, as already mentioned: in other terms, from a qualitative viewpoint, the time trends of pressure in RPV, 
of rod surface temperature experiencing CHF, PCT and reflood, are similar. Emphasis is given below to the description of a few selected differences between Atucha-II PHWR and PWR.

1252

1253

1254

1255

1256

1257

1258

1259

1260

1261

1262

1263

1264

1265

1266

1267

1268

1269

1270

1271

1272

1273

1274

1275

1276

1277

1278

1279

1280

1281

1282

1283

1284

1285

1286

1287

1288

1289

1290

1291

1292

1293

1294

1295

1296

1297

1298

1299

1300

\subsubsection{Flow Reversal at Core Inlet}

The low amount of fluid mass in the case of Atucha-II (related to a typical PWR) in lower plenum and the geometric diameter of the core cause, see Fig. 22:

- Early core flow reversal.

- Low influence of lower plenum flashing.

- Differences in flow reversal as far as individual channel locations are concerned.

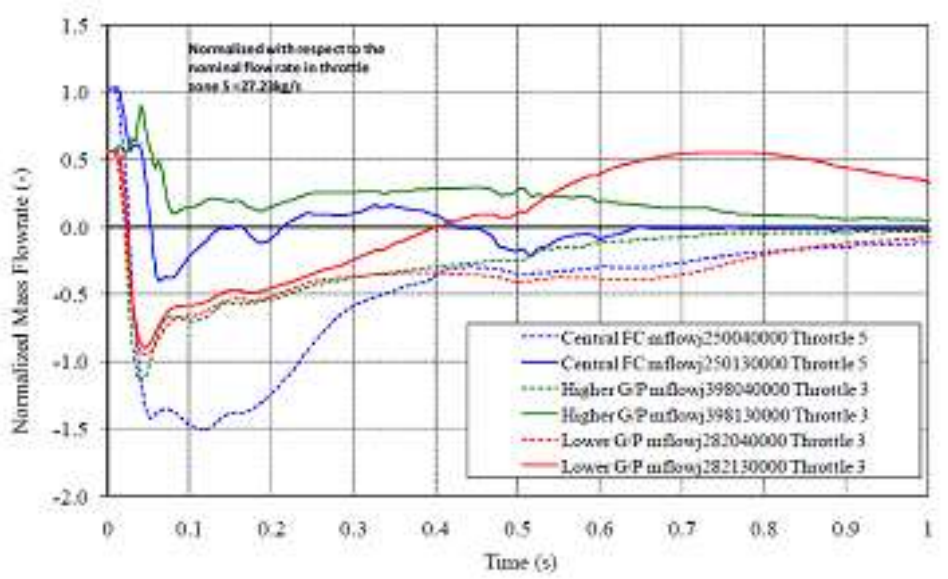

Figure 22. Atucha-II LBLOCA, occurrence of flow reversal at fuel channel inlets.

\subsubsection{The ECCS and the Moderator Performance.}

ECCS consisting of accumulator and LPIS (also called SIP, see Table 1), deliver mass flowrates in both CL and HL. ECCS delivered mass becomes equal to break mass flow roughly at the time of pressure equalization between primary system and containment (Table 4).

The special role of moderator cooling loops should be considered. During nominal operation the four moderator circuits remove about $10 \%$ of core power (see also Table 1). During LBLOCA transient an intrinsic and a design role in cooling the core can be seen from Fig. 23 (PHW 2 and 3) and Fig. 25 (PHW 4, see section 4.3 .5 below).

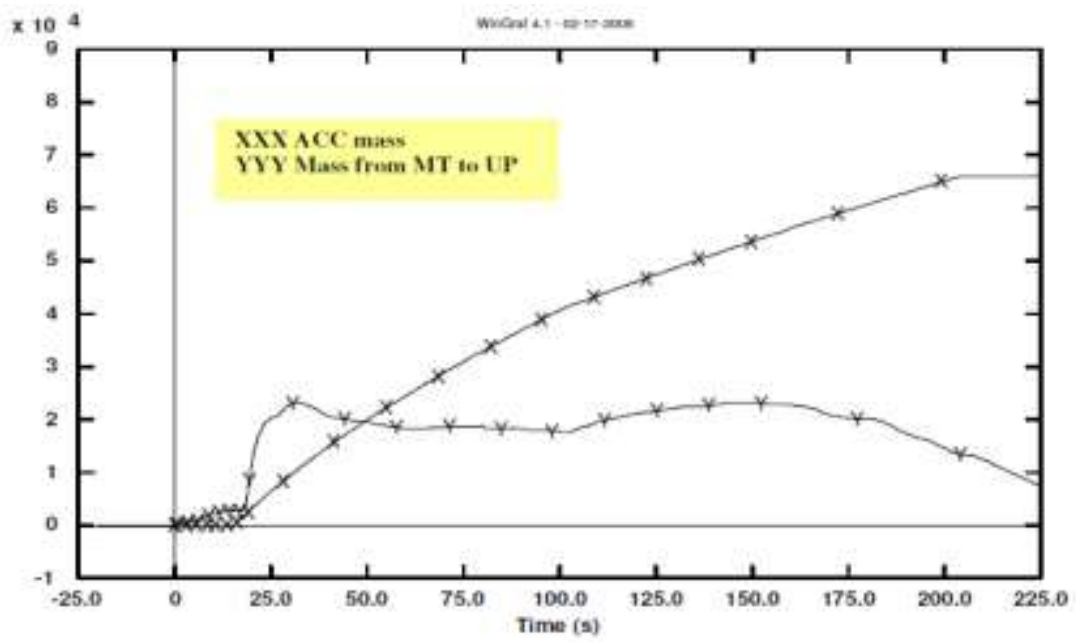

Figure 23. Atucha-II LBLOCA: moderator cooling by liquid delivery in core region (PHW 2 and 3).

The mass flowrate from moderator tank towards the upper parts of fuel channels, which experience a pressure lower than the moderator tank pressure owing to the break in the primary loop, is given in Fig. 23 (vertical axis); a comparison is made in the same figure with the accumulator 
1301 mass delivered from the HL region: an early contribution of moderator liquid to core cooling during 1302 PHW 2 and PHW 3 can be noted.

1303 4.3.4 Nuclear Fuel Performance (PHW 3)

1304 Evaluation of fuel failures constituted an essential part of the LBLOCA analysis because of the need to estimate radioactivity release. A complex pattern for fuel failure was established including ballooning and consequent bursts, Adorni et al., 2011; H2 production and clad fragility were calculated. The result is a fuel failure map, Fig. 24; fuel channels including at least one failed rod are shown in black. The exact number of fuel rod failed was used to calculate radiological release.

1310

1311

1312

1313

1314

1315

1316

1317

1318

1319

1320

1321

1322

1323

1324

1325

1326

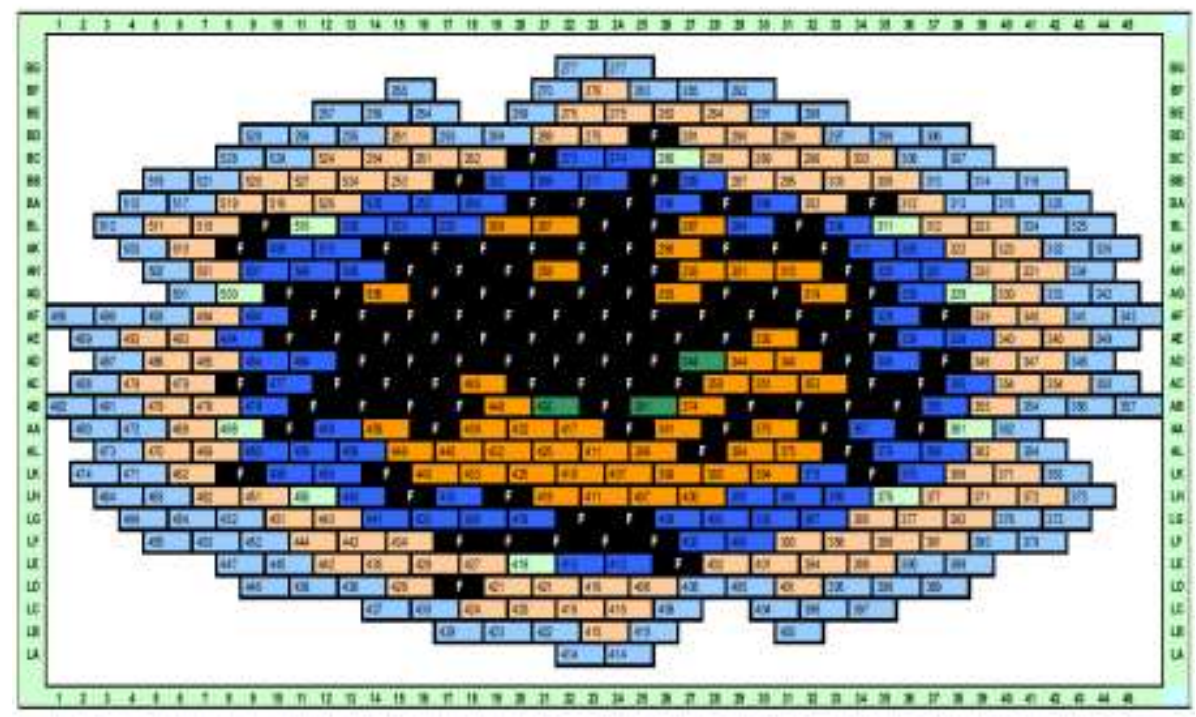

Figure 24. Atucha-II LBLOCA: resulting fuel failure map shown in a core cross-section.

4.3.5. Long Term Cooling, Containment Behavior, Radioactivity in the Environment (PHW 4)

A key question to be answered for LTC analysis is "At what time the calculation must be extended?" The answer needs a phenomena evaluation (i.e. demonstration that core cooling conditions are stable) and a connection with licensing needs. Half-a-hour after the event start was considered a suitable compromise in the case of Atucha-II LBLOCA.

\section{3}

1334

1335

1336

1337

1338

1339

1340

1341

1342

1343

1344

1345

1346

1347

1348

1349

1350

\subsubsection{Moderator Role During LTC}

The moderator cooling loops include heat exchangers which in case of LOCA are connected with outside of containment and are capable of removing thermal power according to Fig. 25.

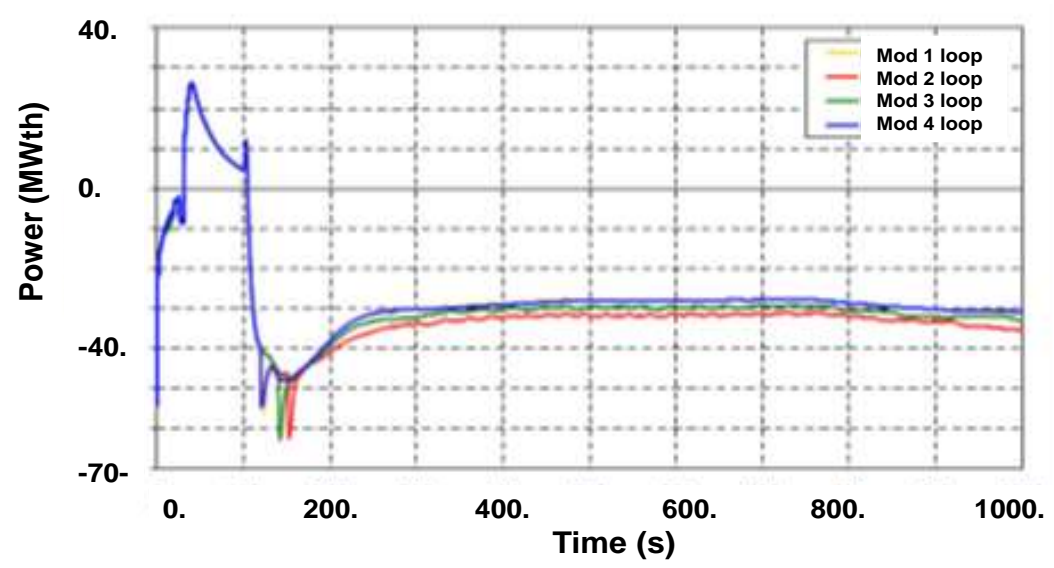

Figure 25. Atucha-II LBLOCA: thermal power removal from core by moderator loops (PHW 4). 
In the case of Atucha-II LBLOCA BEPU analysis both containment and containment annulus (or the region between the pressure 'containment sphere', see Table 1, and the reactor building) were modeled and (fully) coupled to primary cooling and moderator systems. Pressure and fluid temperatures were calculated together with sump level, Fig. 26.

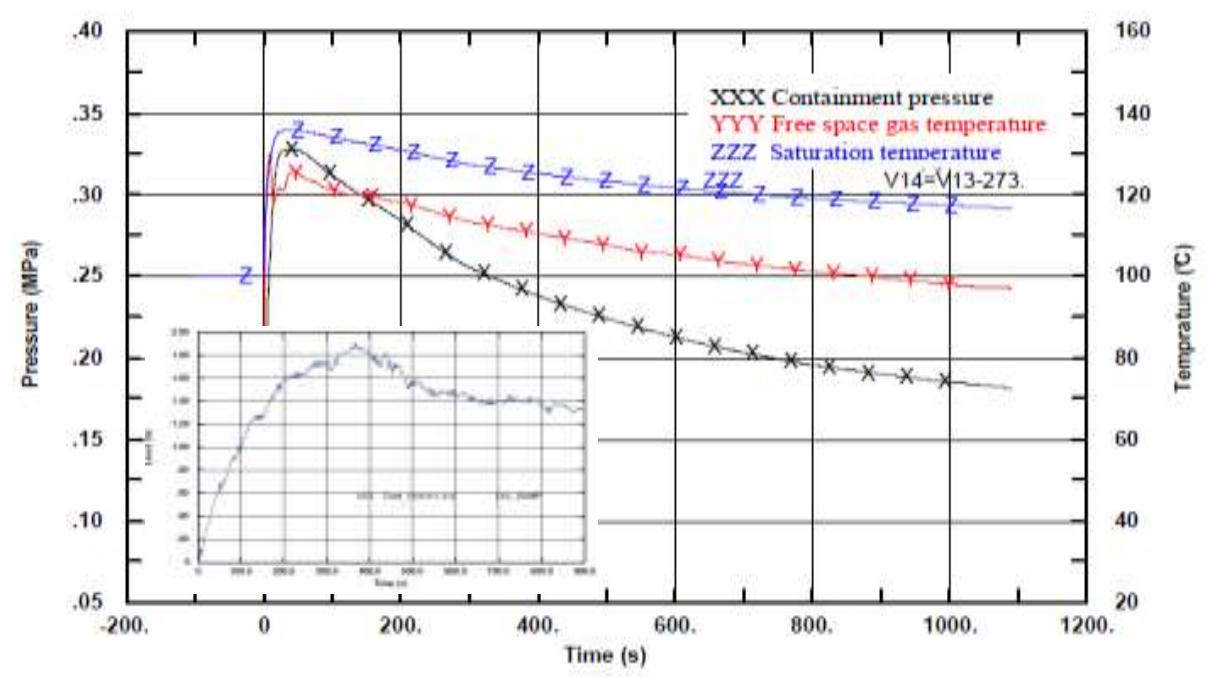

Figure 26. Atucha-II LBLOCA: containment pressure and temperature and sump level.

1374

1375

1376

1377

1378

1379

1380

1381

1382

1383

1384

1385

1386

1387

1388

1389

1390

1391

1392

1393

1394

1395

1396

1397

1398

1399

1400

1401

1402

1403

The sump level (diagram at bottom left of Fig. 26) and the liquid temperature in the sump (not shown in the figure) allowed the demonstration of consistency with the Net Positive Suction Head (NPSH) of pumps used for LTC. Margins to available NPSH for debris effects were considered although, consistently with state of art, properly designed grids were installed in the sump.

\subsubsection{Radioactivity Release}

The main goal for the overall LBLOCA analysis consisted in the calculation of doses external to the reactor building under identified atmospheric conditions at an assigned distance. This implied 'deterministic' calculation of: a) fuel damage (section 4.3.4); b) radioactivity leaking from fuel; c) radioactivity diffusion in the primary loop; d) radioactivity ending into the containment; e) based on containment pressure and leaking test data, radioactivity into the reactor building (or the annular space of containment); f) radioactivity exiting the reactor building; g) doses at the assigned position for the assigned time duration. Indicative results from steps b), c), d) and e) are provided in Fig. 27.

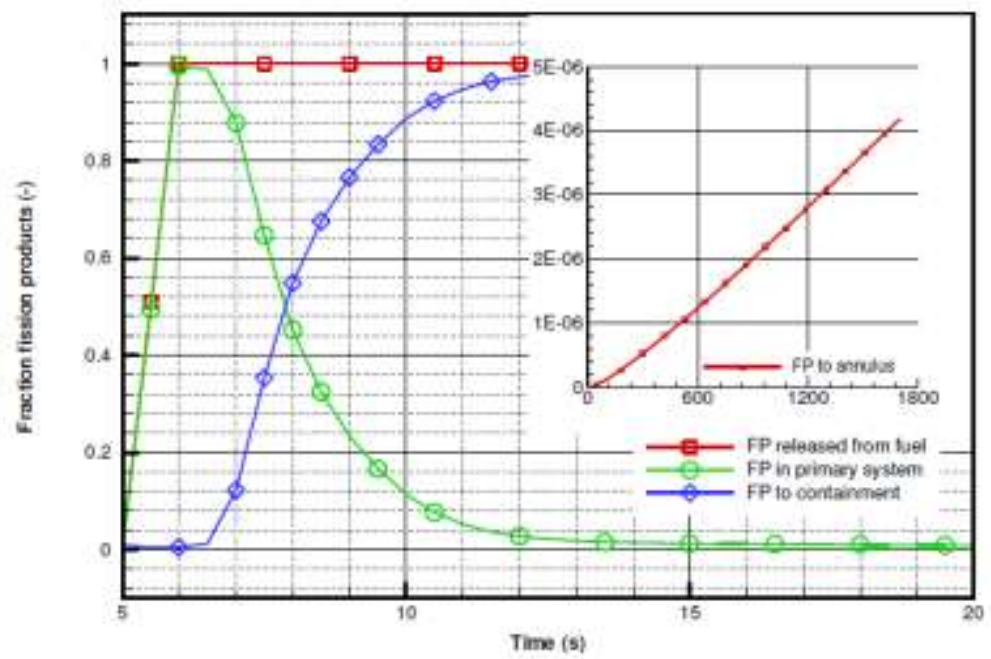

Figure 27. Atucha-II LBLOCA: radiation release from damaged fuel ending into the primary loop, containment and reactor building. 
Distinguishing about several release categories, and considering different transport mechanisms allowed the calculation of the activity expected at the given location external to the reactor building. The additional (regulatory) assumption about persons absorbing the radiation allowed the calculation of doses (overall result given at line 29 in Table 4).

\subsection{The Application of BEPU}

The framework and the role of BEPU can be derived from chapter 1 and section 3.6 above. Atucha-II licensing process brought to a cornerstone in the history of BEPU as it happened, roughly one decade before, with Angra-2 licensing process in Brazil. Namely, both Angra-2 and Atucha-II constituted the first reactor put in operation based on the application of a BEPU approach to LBLOCA and to all the entire spectrum of accidents, respectively.

\subsubsection{The BEPU Approach in Atucha-II Licensing}

The availability and the handling capability for a series of codes (a couple dozen adopted, not listed here) and the availability of an uncertainty method, see D'Auria \& Giannotti, 2000, and Petruzzi \& D'Auria, 2006, constituted prerequisites for BEPU application. This is discussed in the proprietary document Muellner et al., 2008, and synthesized by D'Auria \& Mazzantini, 2009, see also D'Auria et al., 2012. Even a summary description is outside the framework for the present paper; rather the main challenges for BEPU application to Atucha-II licensing are listed below.

$\Rightarrow$ Full BEPU analyses were performed for the entire spectrum of accidents. In some cases, following criteria agreed with the Regulatory Body (i.e. when wide safety margins were calculated), uncertainty analyses were not documented in the Final Safety Analysis Report. For instance, it was checked for each concerned transient analysis (i.e. when uncertainty results are not documented), that uncertainty contribution did not bring to CHF if CHF was not part of the original BE calculation result.

$\Rightarrow$ The LBLOCA challenges (see section 4.2) also constitute BEPU challenges.

$\Rightarrow$ Each design peculiarity of Atucha-II, or the difference between PWR and PHWR (use of $\mathrm{D} 2 \mathrm{O}$, continuous fuel reload, etc.), was at the origin of a challenge for the BEPU approach which had been developed and previously qualified for PWR applications.

$\Rightarrow$ The detailed consideration of I \& C interaction with operation and safety of the reactor, or I \& C modeling, was needed, e.g. starting from the fine movement of control rods to adjust the local neutron flux and going to the control of turbine flow and moderator fluid temperature.

$\Rightarrow$ Adoption of conservatism was of no help (and no support) to justify BEPU results; e.g. use of conservative input for predicting FPP would imply unacceptable results: this actually imposed BEPU as the only way to evaluate Atucha-II safety.

$\Rightarrow$ The licensing connection implied consideration of regulatory documents in both the Countries where the reactor was designed (Germany) and constructed (Argentina); furthermore, USNRC rules (see also below) had to be considered.

$\Rightarrow$ The fundamental (and somewhat philosophical) safety concept of 'single failure' was considered, notwithstanding the Best Estimate (or realistic) nature of the analysis, i.e. connected with physical phenomena evaluation: the difficulty is associated with (not only in case of LBLOCA study) the need to identify the most effective failing component (among several thousand part of I \& C).

$\Rightarrow$ Because of the pioneering (BEPU) approach, an international group of experts was formed under the supervision of the Regulatory Body in Argentina: the BEPU approach, Muellner et al., 2008, and the results from the BEPU application, GRNSPG, 2010, were thoroughly reviewed and generated series of mandatory questions which needed further analyses.

\section{4.4.2. Selected Validation And Uncertainty Steps and Results}

A few BEPU-LBLOCA related topics (i.e. a narrow view over a universe of BEPU supporting activities) are described below in order to provide, as far as possible, an idea of the performed investigations. 
The nodalization, or input deck, is the interface between the numerical code and the reactor design and operation; the nodalization must account for the objective of the analysis although a unique 'general purpose' input deck suitable for all transient analysis was developed. In order to acquire confidence of the results and get suitable quality from the analyses, at least six main nodalizations where developed, here distinguished by the number of radial regions adopted to simulate the Atucha-II core: 1, 2, 36, 60, 280 and 451 core regions were built. The last one implied each individual channel separately modeled, a full three-dimensional model for the RPV and up to ten thousands nodes for the primary system. Convergence of results when increasing number of core channels from 1 to 451 was not achieved, as expected; however, discrepancies among calculations from various input decks were explained and helped in removing errors and constituted a support for the final 'licensing' result.

\subsubsection{Nodalization Qualification, Kv-Scaled Analyses}

1468

1469

1470

1471

1472

1473

1474

1475

1476

1477

1478

1479

1480

Established procedures were used to qualify each developed nodalization (i.e. whatever the number of modeled core channels, see above), Bonuccelli et al., 1993. A noticeable step in the process is the Kv-scaled analysis already introduced in 1995, D'Auria et al., 1995. A step of the procedure implies the comparison between a calculated Atucha-II and a measured Accident Scenario (AS) in any PWR experimental test facility (ITF). Obviously difference are expected and occur between the AS datasets. The activity consists in demonstrating, by performing additional calculations:

- the reason of each difference,

- that geometry and initial conditions are the origin of the difference,

- that phenomena not measured in the ITF do not results from Atucha-II AS.

In recent years it was also shown by OECD/NEA/CSNI, 2017 that the so-called triad method, Ransom et al., 1998, consists of elements part of Kv-scaled procedure. Within the same international document the use of the methods (either $\mathrm{Kv}$-scaled or triad) is recommended for addressing the scaling issue.

\subsubsection{Convergence of Results When Varying Time Steps}

As expected, reducing the time step, whatever the starting nodalization, did not bring to convergence of results, see e.g. Fig. 28; in general terms decreasing of time steps and increasing the number of nodes (or reducing the node size, see also above) for the primary system of Atucha-II did not bring to convergence of results. This put an additional challenge to the application of BEPU and needed a number of sensitivity studies supported, whenever possible, by experimental evidence.

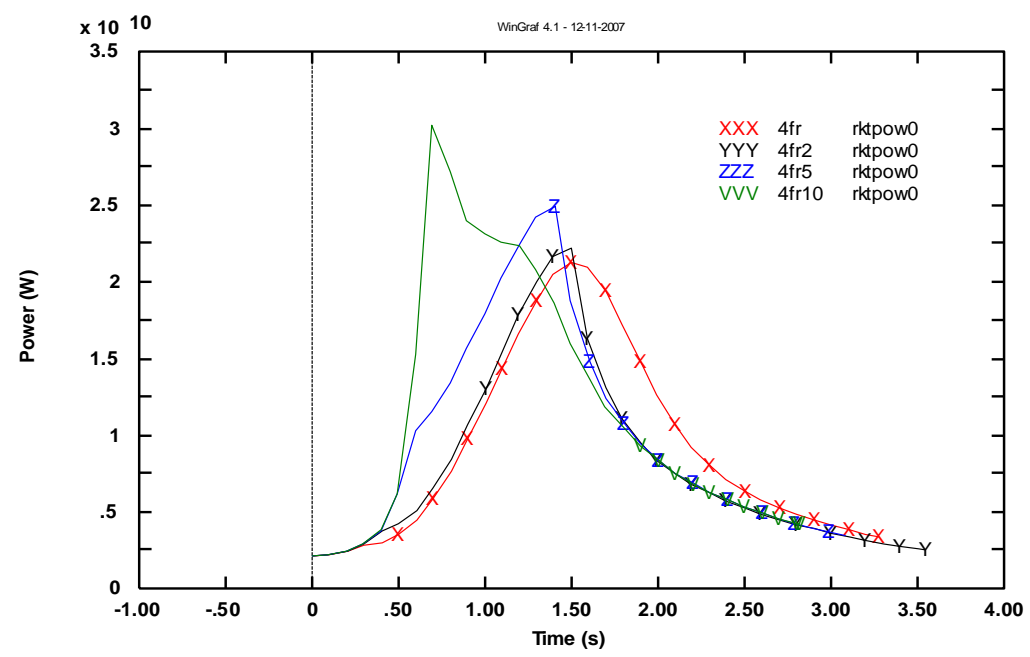

Figure 28. Atucha-II LBLOCA: FPP calculated by different time steps and different nodalizations (the highest peak on the left resulting from the smallest time step). 
Convergence and realism of final results was demonstrated making use of experimental data in the case of thermal-hydraulic parameters: an example can be found in the paper by Lazarte \& Ferreri, 2012, dealing with natural circulation. In the case of neutron flux data and fission power, the calculation results derived from CANDU analyses, see Kastanya et al., 2013 (e.g. duration and amplitude of power peak resulting from void reacivity), were considered.

\subsubsection{Thermal-Hydraulic Code Specific Validation and Applicability}

Question marks were raised at different steps of the BEPU process in relation to the capabilities of adopted codes to reproduce the AS phenomenology expected in Atucha-II. For instance, the challenge [9] in section 4.2 (CCFL in HL) may appear in any PWR; however in the case of the Atucha-II system, the ratio between flow area of HL and the volumetric steam flow produced in the core (originated by decay power) achieves a minimum value, thus generically requesting higher precision of results and higher confidence towards results. The CCFL issue was of primary concern for the $0.1 \mathrm{~A}$ break LOCA analysis. This imposed a pioneering (in the sense of not available before) demonstration of capability for the adopted code version: all experimental data measured in UPTF, were collected to form different regions in a suitable phase space. Applicability of the code and of the adopted nodalization details was confirmed, Fig. 29, and used for the present LBLOCA analysis (for more details of the experimental data base see also the paper Rohatgi \& Glaeser, 2019, in this Special Issue).

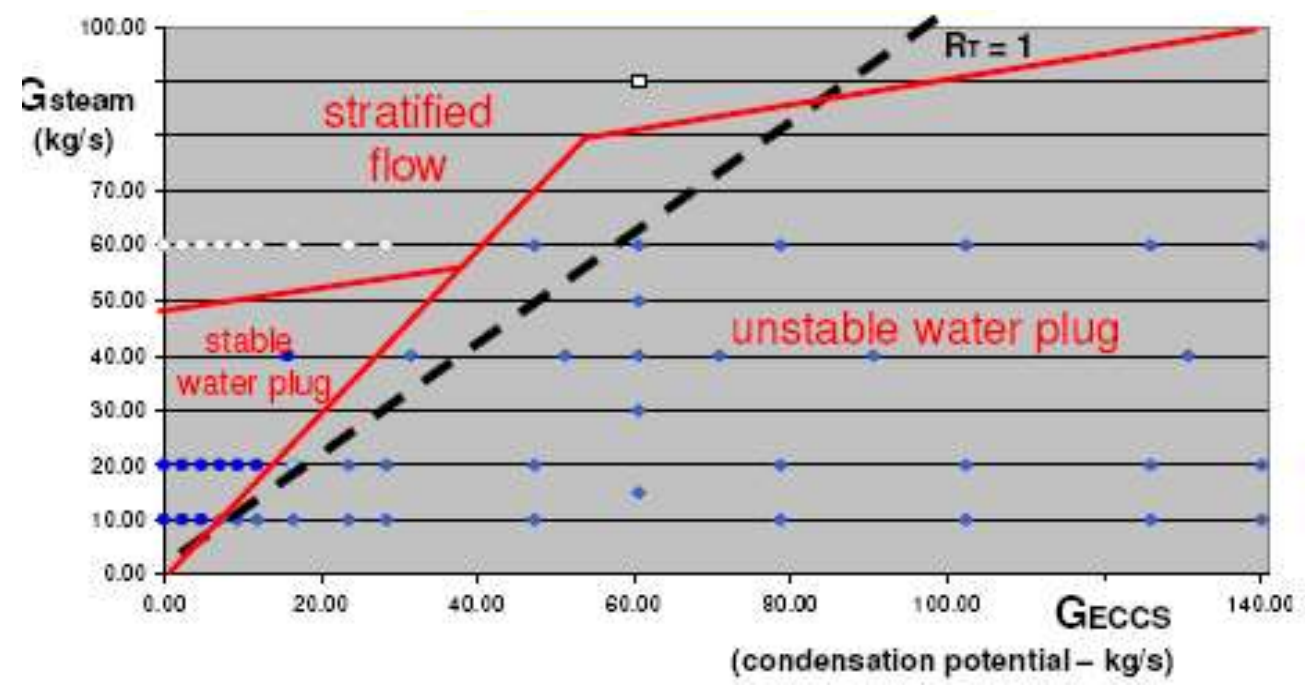

Figure 29. Atucha-II LBLOCA: comparison between measured and calculated CCFL regimes in UPTF.

\subsubsection{Selected Miscellaneous Findings or Outcomes from the BEPU Process}

A few statements below provide further views of the performed BEPU application.

1) Sensitivity analyses were systematically adopted, not only to deal with convergence of results, but also to support uncertainty evaluation.

2) Two uncertainty methods (independent among each other) were used to increase the confidence in establishing safety margins is some situations (e.g. evaluation of FPP).

3) A full three-dimensional model for thermal-hydraulics and neutron physics was needed to demonstrate the safety of the large and low power density (in terms of kw/l) core: different core regions contribute to phenomena (like the FPP) at different times, making unrealistic any more simplified approach (e.g. 0-D, 1-D, etc.).

4) Computational Fluid Dynamics (CFD) and Montecarlo type of numerical codes (MCNP) were strictly needed to perform analyses supporting the application of a coupled 3-D thermal-hydraulic and neutron physics model.

5) About five hundred documents were produced to address any question raised during the BEPU process. 
6) A specific Data Management System was adopted to manage the data resulting from the analysis and for issuing the FSAR (about one thousand sections, all together).

\section{Conclusions}

A brief historical overview is introduced in the paper to connect the thermal-hydraulic design of the Atucha-II PHWR with a PWR. Key complexities of both systems are compared: basically, the CANDU features of using natural uranium and heavy water as moderator are associated in the case of Atucha-II with the presence of the pressure vessel typical of PWR. Then, LBLOCA evolution (in Atucha-II) has several similarities with the widely investigated and well understood LBLOCA in PWR with one significant difference: the fission power excursion which occurs during the early blowdown period which impacts the PCT and the fuel safety margins. A LOCA-RIA transient occurs. This was one main trigger and motivation for the performed activity.

Atucha-II licensing process was completed in 2014 at the time when the reactor unit was connected to the electrical grid. The BEPU approach has been used to issue the Chapter 15 of the FSAR and a wide range investigation was completed to deal with the LBLOCA (or 2A, or $2 \times 100 \%$ A, or DEGB).

The application of BEPU was unavoidable to avoid the use of conservatism: one may state that the modeling of neutron interaction with the materials in the core and the geometric and operating conditions of the reactor brought to the calculation of fission power peak and to demonstration of Atucha-II safety margins: i.e. no conservative or designer suggested parameter value was adopted to achieve such demonstration.

A wide variety of challenges (some of those listed in the paper) had to be addressed; these were solved by searching for the availability of experimental data with the support of sensitivity studies and adopting a couple dozen qualified numerical tools. Actually an important challenge was constituted by inadequacies of computational tools.

The PWR Large Break Loss of Coolant Accident scenario has been revisited in the occasion of summarizing the results from BEPU analysis of LBLOCA in Atucha-II PHWR.

Key findings of technological interest from the performed LBLOCA analysis are:

- The LBLOCA has direct impact upon the overall design of PWR (and PHWR), including the layout of the primary loop: suitable safety analyses shall not ignore the importance of LBLOCA also to avoid loss in credibility towards the technology of (high pressure) water cooled nuclear reactors.

- The nuclear fuel weaknesses which have been recently characterized from measurements of irradiated rods may have a limited impact upon Atucha-II safety evaluations because of the relatively low burn-up which characterizes the operation of PHWR; rather the discovery of fuel weakness may need significant changes in regulations.

- The role of containment as the key barrier to the release of fission products is directly reflected by current Argentinean regulations: fuel failures and radioactivity releases into the containment can be tolerated from the analyses of events part of DBA provided suitable thresholds are fulfilled for the radioactivity into the environment. The philosophy at the basis of the Argentinean regulations, outlined in this paper, can be pursued at the international level.

- The amplitude of the depressurization wave generated at the break is a function of the Break Opening Time (BOT): notwithstanding fundamental research and technological achievements in the area of the LBB an acceptable (regulatory) justification for BOT longer than a few m-s could not be found.

- BOT in the order of $1 \mathrm{~s}$ and/or increase in initial break flow (justified in Atucha-II by the special configuration of the nozzle connecting the CL to the RPV) brings to substantial reduction in the value of FPP: neither of those two circumstances has been considered in the licensing process.

- Loads upon internals and early vaporization in individual fuel channels generated by the pressure wave have been calculated by three dimensional techniques. Acceptable mechanical stresses and subsequent voiding of different core regions bringing to a 


\section{LIST OF ACRONYMS}

A

AA

ACC APW ARN AS BA BAF BEPU BIT

BITF

BOT

BP CANDU

CC CCFL CFD CHF

CL CRDM CVR DBA DC DEGB

smoothed FPP (i.e. compared with the case of simultaneous voiding of the entire core) have been calculated.

- Lack of convergence in either space or time, i.e. results of code calculations do not converge when the time steps and the node sizes are reduced, constitutes a deficiency of current computational tools and a challenge for the (BEPU) analyses. Supporting analyses and experimental data (namely in the area of transient thermal-hydraulics) were considered in order to minimize the impact of lack of convergence; uncertainty evaluation (embedded into the BEPU process) accounted for the expected residual error.

- Procedures adopted within the concerned Atucha-II licensing process, e.g., noticeably, the $\mathrm{Kv}$-scaled calculation to address the scaling issue, were internationally recognized as essential elements of BEPU applications.

- The construction and the operation of the BITF experimental test facility (scale 1:1) to demonstrate the compliance of Boron Injection Time (BIT) with the calculated value shall be seen as a valuable example of the interaction between safety requirements, reactor design and research needs coming from BEPU application.

The Atucha-II licensing by BEPU (entire Chapter 15) constituted at the same time a pioneering effort and a cornerstone in the application of BEPU. This was possible thanks to the availability of Regulators and the thrust towards science, technology and innovation by the utility (plant owner) in Argentina. International community, particularly IAEA, looked positively at the overall initiative. Definitely, the frontier of numerical code application and suitability, not only in the area of hermal-hydraulics, has been progressed by BEPU application in the licensing process of Atucha-II

\section{Acknowledgements} in between University of Pisa and NA-SA. Thanks are due to International Review Group members N. Aksan, C. M. Galassi, M.C. Galassi, M. Giersch, D. Araneo, M. Lanfredini, N. Arnold, M. Adorni, P. Pla, and D. Lazzerini. At $A-S A$ responsible scientists were $M$. Schivo and A. Bonelli.

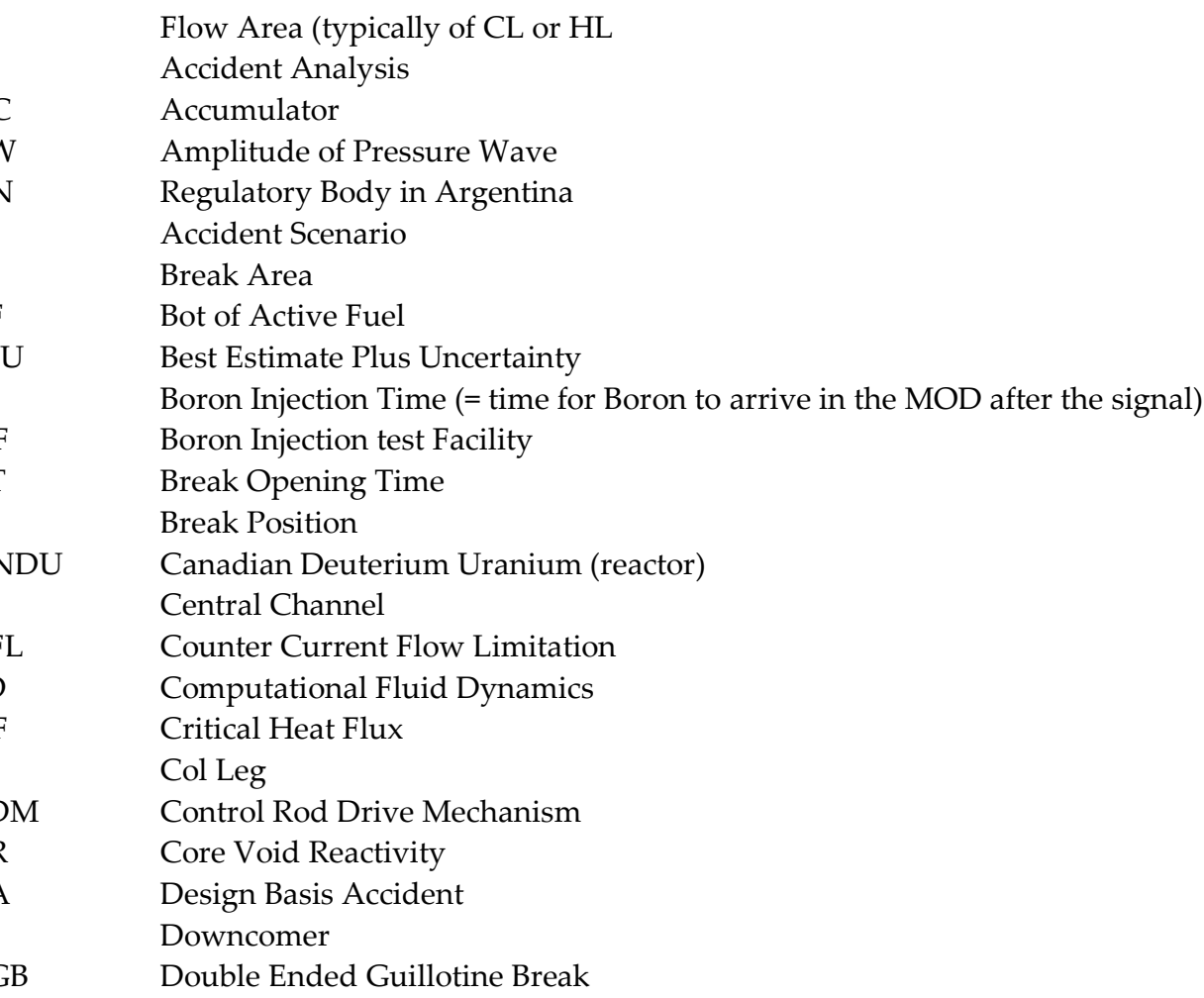




\begin{tabular}{|c|c|c|}
\hline 1667 & DNB & Departure from Nucleate Boiling \\
\hline 1668 & ECC & See ECCS \\
\hline 1669 & ECCS & Emergency Core Cooling System (see also ECC) \\
\hline 1670 & ESF & Engineered Safety Features \\
\hline 1671 & FA & Fuel Assembly \\
\hline 1672 & FC & Fuel Channel \\
\hline 1673 & FPP & Fission Power Peak (lower than TPP) \\
\hline 1674 & FSAR & Final Safety Analysis Report \\
\hline 1675 & FW & Feed Water \\
\hline 1676 & $\mathrm{G} / \mathrm{P}$ & Mass flow-rate divided by power in each FA \\
\hline 1677 & HEX & Heat Exchanger \\
\hline 1678 & HL & Hot Leg \\
\hline 1679 & IGSCC & Inter Granular SCC \\
\hline 1680 & $\mathrm{I} \& \mathrm{C}$ & Instrumentation and Control (system) \\
\hline 1681 & KWU & NPP Designer in Germany \\
\hline 1682 & LBB & Leak Before Break \\
\hline 1683 & LBLOCA & Large Brea LOCA \\
\hline 1684 & LHGR & Linear Heat Generation Rate \\
\hline 1685 & LOCA & Loss of Coolant Accident \\
\hline 1686 & LP & Lower Plenum \\
\hline 1687 & LPIS & Low Pressure injection System (see also SIP) \\
\hline 1688 & LPZ & Low Population Zone \\
\hline 1689 & LTC & Long Term Cooling \\
\hline 1690 & LVL & Level \\
\hline 1691 & $\mathrm{MCP}$ & Main Coolant Pump \\
\hline 1692 & MOD & Moderator \\
\hline 1693 & MT & Moderator Tank \\
\hline 1694 & NPP & Nuclear Power Plant \\
\hline 1695 & NPSH & Net Positive Suction Head \\
\hline 1696 & NRS & Nuclear Reactor Safety \\
\hline 1697 & NA-SA & NPP Utility in Argentina \\
\hline 1698 & PCCI & Pellet Clad Chemical Interaction \\
\hline 1699 & PCMI & Pellet Clad Mechanical Interaction \\
\hline 1700 & PCT & Peak Clad Temperature \\
\hline 1701 & PHW & Phenomenological Window (also Ph.W) \\
\hline 1702 & PHWR & Pressurized Heavy Water Reactor \\
\hline 1703 & PRZ & Pressurizer \\
\hline 1704 & PS & Primary System \\
\hline 1705 & PWR & Pressurized Water Reactor \\
\hline 1706 & PWSCC & Primary Water SCC \\
\hline 1707 & QF & Quench Front \\
\hline 1708 & RCS & Reactor Coolant System \\
\hline 1709 & RIA & Reactivity Initiated Accident \\
\hline 1710 & RIH & Reactor Inlet Header \\
\hline 1711 & RNB & Return to Nucleate Boiling \\
\hline 1712 & $\mathrm{RPV}$ & Reactor Pressure Vessel \\
\hline 1713 & SCC & Stress Corrosion Cracking \\
\hline 1714 & SG & Steam Generator \\
\hline 1715 & SIP & Safety Injection Pump (see also LPIS) \\
\hline 1716 & TAF & Top of Active Fuel \\
\hline 1717 & TPCF & Two Phase Critical Flow \\
\hline 1718 & TPP & Total Power Peak (higher than FPP) \\
\hline 1719 & UP & Upper Plenum \\
\hline 1720 & USAEC & Regulatory Authority in US \\
\hline 1721 & USNRC & Regulatory Authority in US \\
\hline 1722 & $\mathrm{~V} \& \mathrm{~V}$ & Verification and Validation \\
\hline 1723 & WWII & Second World War \\
\hline
\end{tabular}


Adorni M., Del Nevo A., D' Auria F., Mazzantini O., 2011, A Procedure to Address the Fuel Rod Failures during LB-LOCA Transient in Atucha-2 NPP, J. Science and Technology of Nuclear Installations, Article ID 929358, ISBN 1687-6075, doi 10.1155/2011/929358, pages 1-7

Aksan N., D’Auria F., Groeneveld D., Kirillov P., Saha D., Badulescu A., Cleveland J., (Lead Authors), 2001, Thermo-hydraulic Relationships for Advanced Water Cooled Reactors", IAEA TECDOC 1203, April, Vienna (A), ISSN 1011-4289, pp 1-344

Aksan S. N., 2017, Target phenomena in nuclear thermal-hydraulics, Book 'Thermal Hydraulics in Water-Cooled Nuclear Reactors', [F. D'Auria, Editor], Chapter 15, Elsevier, Woodhead Publishing, ISBN 9780081006627, pp 245-356

Aksan N., D'Auria F., Glaeser H., 2018, Thermal-hydraulic phenomena for water cooled nuclear reactors, Nuclear Engineering and Design, 330, pp 166-186

Ammirabile L., Walker S.P., 2014, Dynamic ballooning analysis of a generic PWR fuel assembly using the multi-rod coupled MATARE code, Nuclear Engineering and Design, 268, 24-34

Ashley R., El-Shanawany M., Eltawila F., D'Auria F., 1998, Good practices for user effect reduction, OECD/NEA/CSNI report NEA/CSNI/R(98)22, Paris, France

Azam M.S., Niu F., Wang D., Zhuo W., 2018, Experimental and CFD analysis of the effects of debris deposition across the fuel assemblies, Nuclear Engineering and Design, 332, 238-251

Baum M. R., 1984, Break opening times for axial ruptures of a gas-pressurized pipe, Nuclear Engineering and Design, 77, 161-167

Bhandari S., Leroux J.C., 1993, Evaluation of crack opening times and leakage areas for longitudinal cracks in a pressurized pipe Part II. Application of proposed model and fracture dynamics, Nuclear Engineering and Design, 142, 21-25

Bianco A., Vitanza C., Seidl M., Wensauer A., Faber W., Macián-Juan R., 2015, Experimental investigation on the causes for pellet fragmentation under LOCA conditions, Nuclear Materials, 465, 260-267

Bonelli A., Siefken L., Mazzantini O., Allison C., 2014, Summary of Severe Accident Assessment for Atucha 2 Nuclear Power Plant using RELAP5/SCDAPSIM Mod3.6 , 10 $10^{\text {th }}$ Int. Top. Meet. on Nuclear Thermal-Hydraulics, Operation and Safety (NUTHOS-10), NUTHOS10-1128, Dec. 14-18, Okinawa, Japan

Bonuccelli M., D'Auria F., Debrecin N., Galassi G.M., 1993, A methodology for the qualification of thermal-hydraulic codes nodalizations, Int. Top. Meet. on Nuclear Reactor Thermal-Hydraulics (NURETH-6), Grenoble, France

Bourga R., Moore P., Janin Y-J., Wang B., Sharples J., 2015, Leak-before-break: Global perspectives and procedures, Int. J. of Pressure Vessels and Piping, 129-130, 43-49

Bousbia Salah A., Vedovi J., D’Auria F., Ivanov K., Galassi G.M., 2004, Analysis of the Peach Bottom Turbine Trip 2 Experiment by coupled Relap5-Parcs three dimensional codes, Nuclear Science and Engineering, 148, 337-353

Brankov V. V., 2017, Modelling of fuel fragmentation, relocation and dispersal during Loss-of-Coolant Accident in Light Water Reactor, PHD These No 8018, École Polytechnique Fédérale de Lausanne (CH)

Brittain I., Aksan N, 1990, OECD-LOFT Large Break LOCA Experiments Phenomenology and Computer Code Analyses, AEA-TRS-1003, PSI Report 72, Wurenlingen / Villigen, (CH)

Celata G. P., Cumo M., D’Annibale F., Farello G. E., 1986, Two-phase flow models in unbounded two-phase critical flow, Nuclear Engineering and Design, 97, 211-222 
Chatzikyriakou D., Walker S.P., Hewitt G. F., 2010, The contribution of non-wetting droplets to direct cooling of the fuel during PWR post-LOCA reflood, Nuclear Engineering and Design, 240, 3108-3114

Chun M-H., Yu S-O., 2000, Effect of steam condensation on countercurrent flow limiting in nearly horizontal two-phase flow, Nuclear Engineering and Design, 196, 201-217

Collier J.G., 1975, Two Phase Flow and Heat Transfer in Water Cooled Nuclear Reactors, Lecture Series, Dartmouth College, New Hampshire, USA

Damerell P. S., Simons J. W. (Eds.), 1993, Reactor Safety Issues Resolved by the 2D/3D Program, MPR Associates, Inc., GRS-101, ISBN 3-923875-51-7, Sept.

D'Auria F., Vigni P., 1981, Fluid-dynamic Analysis of Steam-Water Flows from a Pressure Vessel, Workshop on Jet Impingement and Pipe Whip, June 29 - July 1, Genova (I)

D'Auria F., Vigni P., 1989, Evaluation of Fluid-dynamic Loads on RPV Internals during Blowdown, 10 $0^{\text {th }}$ SMIRT Int. Conf., Aug. 14-18, Anaheim (CA, USA)

D'Auria F., Debrecin N., Galassi G.M., 1995, Outline of the uncertainty methodology based on accuracy extrapolation (UMAE), Nuclear Technology 109, 1

D'Auria F., Galassi G.M., 1998, Code validation and uncertainties in system thermalhydraulics, Progress Nuclear Energy, 33 (1/2), 175-216

D'Auria F., Giannotti W., 2000, Development of Code with capability of Internal Assessment of Uncertainty, Nuclear Technology, 131, 1, 159-196,

D'Auria F., Mazzantini O., Cherubini M., Giannotti W., Parisi C., Moretti F., Melideo D., Del Nevo A., Galassi G.M., Araneo D., Terzuoli F., Adorni M., Muellner N., Petruzzi A., Lazzerini D., Santoro R., Bousbia-Salah A., 2008, DEGB LBLOCA (2 X 100\% Break in CL) in Atucha-2 NPP, University of Pisa Report, DIMNP NT 628(08) rev.1, Pisa (I), March - Delivered to NA-SA, Buenos Aires (Arg), pp 1-259

D'Auria F., Mazzantini O., 2009, The Best-Estimate Plus Uncertainty (BEPU) Challenge in the Licensing of Current Generation of Reactors, Int. Conf. on Opportunities and Challenges for Water Cooled Reactors in the $21^{\text {st }}$ Century, IAEA, Oct. 27-30, Vienna (A)

D'Auria F., Camargo C., Mazzantini O., 2012, The Best Estimate Plus Uncertainty (BEPU) approach in licensing of current nuclear reactors, Nuclear Engineering and Design, 248, 317-328

D'Auria F., Galassi G. M., 2017, Applications of SYS TH codes to nuclear reactors designs and accident analysis, Book 'Thermal Hydraulics in Water-Cooled Nuclear Reactors', [F. D'Auria, Editor], Chapter 15, Elsevier, Woodhead Publishing, ISBN 9780081006627, pp 951-1098

D'Auria F., Lanfredini M., 2018, Introducing V\&V\&C in nuclear thermal-hydraulics, ASME Verification and Validation Symposium (VVS2018-9321), May 16-18, Minneapolis (Mn, US)

D'Auria F., 2018, BEPU status and perspectives, Invited at ANS Best Estimate plus Uncertainty Int. Conf. (BEPU2018), May 13-18, Lucca (I), PL10

D'Auria F., Debrecin N., Glaeser H., 2018, New Safety Barrier for current and future nuclear reactors, Invited at V Int. Scientific and Technical Conf. <Innovative Design and Technologies of Nuclear Power>, V ISTC NIKIET, Oct. 2-5, Moscow (Ru), ISBN 978-5-98706-120-6

D'Auria F., Debrecin N., Glaeser H., 2019, The need for an additional technological safety barrier for current and future NPP, Invited at Int. Conf. on Nuclear Power Plants, Structures, Risk \& Decommissioning (NUPP2019), June 10-11, London (UK)

Deendarlianto, Höhne T., Lucas D., Vierow K., 2012, Gas-liquid countercurrent two-phase flow in a PWR hot leg: A comprehensive research review, Nuclear Engineering and Design, 243, 214- 233 
Edwards A.R., O'Brien T.P., 1970, Studies of phenomena connected with the depressurization of water reactors, Journal of the British Nuclear Energy Society, 9, 125-135

Faucher E., Heradc J-M., Barret M., Toulemonde C., 2000, Computation of Flashing Flows In Variable Cross-Section Ducts, Int. J. of Computational Fluid Dynamics,13, 4, 365-391

Galetti M.R., D'Auria F., 2004, Technical and regulatory concerns in the use of best estimate methodologies in LBLOCA analysis licensing process, International Meeting On Best-Estimate Methods in Nuclear Installation Safety Analysis (BE-2004) IX, Washington D.C. (US), Nov. 14-18, ISBN 089448-681-0

Glaeser H., Karwat H., 1993, The contribution of UPTF experiments to resolve some scale-up uncertainties in countercurrent two phase flow, Nuclear Engineering and Design, 145

Gonzales-Gonzales R., Petruzzi A., D’ Auria F., Mazzantini O., 2014, Identification of limiting case between DBA and SBDBA (CL break area sensitivity): A new model for the boron injection system, Nuclear Engineering and Design, 275, 1-10

Groeneveld D.C., Leung L.K.H., Kirillov P.L., Bobkov V.P., Smogalev I.P., Vinogradov V.N., Huang X.C., Royer E., 1996, The 1995 look-up table for critical heat flux in tubes, Nuclear Engineering and Design, 163, 1-23

GRNSPG, 2010, <Atucha-II> FSAR Chapter 15, Section 15.0: Introduction to the Accident Analyses, University of Pisa, GRNSPG, RL 700(10), rev. 3, Pisa (I), pp 1-2300, October

Hamouda O., Weaver D. S., Riznic J. R., 2018, Transient two-phase blowdown: Experiments and analysis, International Journal of Multiphase Flow, 104, 307-321

Heckmann K., Sievers J., 2018, Leak-before-break analyses of PWR and BWR piping concerning size effects, Nuclear Engineering and Design, 326, 383-391

Hewitt G.F., Delhaye J.M., Zuber N. (Eds.), 1992, Post-Dryout Heat Transfer, CRC Press, Boca Raton, FL, USA

Hosford S.B., Mattu R., Meyer R.O., Throm E.D., Tinkler C.G., 1981, Asymmetric Blowdown Loads on PWR Primary Systems, USNRC NUREG/0609, Washington (DC, US), pp 1-88

IAEA, 2000, Safety of Nuclear Power Plants: design, requirements, NS-R-1, Vienna, Austria.

IAEA, 2002, [Authors: Allison C., Balabanov E., D’Auria F., Jankowski M., Mišák J. Salvatores S., Snell V.], Accident analysis for nuclear power plants, IAEA Safety Reports Series No. 23, ISSN 1020-6450; ISBN 92-0-115602-2, Vienna, Austria, pp 1-129

IAEA, 2007, Use and Development of Coupled Computer Codes for the Analysis of Accidents at Nuclear Power Plants, TECDOC 1539 [plus supporting CD], Vienna (A)

IAEA, 2008, [Authors: D’Auria F., Glaeser H., Lee S., Mišák J., Modro M., Schultz R.R.], Best Estimate Safety Analysis for Nuclear Power Plants: Uncertainty Evaluation, IAEA Safety Report Series, SRS No 52, Vienna (A), 2008, pp 1-211, ISSN 1020-6450

Jo J. C., Jeong J. J., Yun B. J., Moody F. J., 2018, Numerical prediction of a flashing flow of saturated water at high pressure, Nuclear Engineering and Technology, 50, 1173-1183

Kang D. G., 2016, Analysis of LBLOCA using best estimate plus uncertainties for three-loop nuclear power plant power uprate, Annals of Nuclear Energy, 90, 318-330

Kastanya D., Boyle S., Hopwood J., Park J. H., 2013, The impact of power coefficient of reactivity on CANDU-6 reactors, Nuclear Engineering and Technology, 45, 5, 573-580

Kendoush A. A., 1989, Measurement of neutron induced nucleation, Nuclear Engineering and Design, 110, 349-360 
Kim B. J., Kim J., Kim K., Bae S.W., Moon S-K., 2017, Effects of fuel relocation on reflood in a partially-blocked

Kim K.T., 2011, The effect of fuel rod oxidation on PCMI-induced fuel failure, J. of Nuclear Materials, 418, 249_ 260

Krieg R., Schlechtendahl E.G., Scholl K.H., 1977, Design of the HDR experimental program on blowdown loading and dynamic response of PWR-vessel internals, Nuclear Engineering and Design, 43, 2, 419-435

Krieg R., Dolensky B., Granda A., 1982, Core support columns in the upper plenum of a Pressurized Water Reactor under blowdown loading II. Three dimensional analysis, calculation of deformation and stresses, Nuclear Engineering and Design, 73, 35-44

Kurihara R., Ueda S., Miyazono S., 1987, Experimental and analytical studies of pipe whip tests, Nuclear Engineering and Design, 103, 253-265

Lazarte A. I., Ferreri J. C., 2012, Natural Circulation Characterization of the CNA-II PHWR based on Flow Maps using RELAP5. In: 9th International Topical Meeting on Nuclear Thermal-Hydraulics, Operation and Safety (NUTHOS-9), N9P0037, Kaohsiung, Taiwan, Sept. 9-13

Lee S., Hassan Y.A., Abdulsattar S.S., Vaghetto R., 2014, Experimental study of head loss through an LOCA-generated fibrous debris bed deposited on a sump strainer for Generic Safety Issue 191, Progress in Nuclear Energy, 74, 166-175

Leyse R.H., 2007, letter to Ms. Annette L. Vietti Cook, Secretary USNRC, Rulemaking and Adjudications Staff, Public Comment on PRM-50-84: PRM-50-84 and MELLLA+, July 27

Lochon H., Daude F., Galon P., Hérard J.M., 2017, Computation of fast depressurization of water using a two-fluid model: revisiting Bilicki modelling of mass transfer, Computers and Fluids, 156, pp.162-174.

Mahmoodi R., Zolfaghari A., Minuchehr A., 2019, Simulation of pressure waves propagation following LOCA in piping systems using Laplace Transform Finite Volume, Annals of Nuclear Energy, 124, 164-171

Mascari F., Vella G., Woods B. G., Welter K., D'Auria F., 2012, Analysis of primary/containment coupling phenomena characterizing the MASLWR design during a SBLOCA scenario, INTECH Book 'Nuclear Power Plants', edited by S.H. Chang, ISBN 978-953-51-0408-7, Chapt. 8, pp 203-233

Mazzantini O., D'Auria F., Petruzzi A., 2018, Full BEPU application for Chapter 15 of Atucha-2 NPP, ANS Best Estimate plus Uncertainty Int. Conf. (BEPU2018), May 13-18, Lucca (I), PL07

Moretti F., Terzuoli F., D'Auria F., Mazzantini O., 2018, Instrumentation for full-scale Boron Injection Test Facility to support Atucha-2 NPP licensing, Nuclear Engineering and Design, 336, 154-162

Muellner N., Petruzzi A., Camargo C., Galetti M. R., D'Auria F., 2008, A proposal for performing Atucha-II accident analysis for licensing purposes, A report prepared by DIMNP under the $2^{\text {nd }}$ NASA-UniPi Agreement to support a formal submittal of NA-SA to ARN, University of Pisa report, 2008-rev.1, July, pp 1-182

Nigmatulin B. I., Soplenkov K. I., Blinkov V. N., 1987, Critical steady state blowdown of flashing water through tubes, Nuclear Engineering and Design, 99, 85-92

Noori-Kalkhoran O., Shirani A. S., Ahangari R., 2016, Simulation of Containment Pressurization in a Large Break-Loss of Coolant Accident Using Single-Cell and Multicell Models and CONTAIN Code, Nuclear Engineering and Technology, 48, 1140-1153

Nouri-Borujerdi A., Ghazani A. S, 2018, A non-equilibrium relaxation model for fast depressurization of pipelines, Annals of Nuclear Energy, 111, 1-11 

Yadigaroglu G., Holmstrom H.L.O.], Thermo-hydraulics of Emergency Core Cooling in Light Water Reactors-A

OECD/NEA/CSNI, 1999, [Authors: Karwat H., Bardelay J., Hashimoto T., Koroll G. W., Krause M., L'Heriteau J-P., Lundstrom P., Notafranesco A., Royl P., Schwinges B., Tezuka H., Tills J., Royen J.], State-of-the-Art Report (SOAR) on containment thermalhydraulics and hydrogen distribution, CSNI/R(1999)16, Paris (F)

OECD/NEA/CSNI, 2003, Proceedings of the Joint CNRA/CSNI Workshop on "Re-defining the LBLOCA: technical bases and its implications" <held in Zurich, June 23-24, 2003>, NEA/CSNI (2003)17 - Vol 1 pp 1-107, Vol 2 pp 1-87, Paris (F)

OECD/NEA, 2004, [Authors: D’Auria F. (Project Coordinator), Bousbia Salah A., Galassi G.M., Vedovi J., Reventos F., Cuadra A., Gago J.L., Sjoberg A., Yitbarek M., Sandervag O., Garis N., Anhert C., Aragones J.M., Verdù G., Mirò R., Hadek J., Macek J., Ivanov K., Rizwan-Uddin, Sartori E., Rindelhardt U., Rohde U., Frid V., Panayotov D., Neutronics/Thermal-hydraulics Coupling in LWR Technology - CRISSUE-S WP2: State-of-the-Art Report, OECD/NEA Report No 5436, ISBN 92-64-02084-5, Paris (F), Vol. II, pp 1- 293

OECD/NEA, 2009, Nuclear Fuel Behavior in Loss-of-coolant Accident (LOCA) Conditions, NEA No. 6846, pp 1-369, ISBN 978-92-64-99091-3

OECD/NEA/CSNI, 2017, [(Lead Authors) Bestion D., D'Auria F. (Ed.), Lien P., Nakamura H., (Contributors) Austregesilo H., Skorek T., Bae B.U., Choi K.Y., Kim K.D., Moon S. K., Martinez-Quiroga V., Reventos F., Mascari F., Schollenberger S., Umminger K., Reyes J.N., Rohatgi U.S. Wang W., Zaki T.], Scaling in system thermal-Hydraulics applications to Nuclear Reactor safety and design: a State-of-the-Art-Report, NEA/ CSNI/R(2016)14, JT03411050, Paris, March, pp 1-402

Park B. G., Park J. W., Kim C. H., 2011, Experimental study of debris head loss through a pressurized water reactor recirculation sump screen after LOCA, Nuclear Engineering and Design,241, 7, 2462-2469

Pecchia M., Parisi C., D’Auria F., Mazzantini O., 2009, Atucha-2 PHWR Monte Carlo MCNP5 and KENO-VI Models Development and Application, Int. Conf. on Mathematics, Computational Methods and Reactor Physics (M\&C), Saratoga Springs, (NY, US), May 3-7

Pecchia M., Parisi C., D'Auria F., Mazzantini O., 2015, Application of MCNP for predicting power excursion during LOCA in Atucha-2 PHWR, J. Annals of Nuclear Energy, 85, pp 271-278

Petruzzi A., D'Auria F., 2005, Relap5/mod3.2 post-test analysis and CIAU uncertainty evaluation of LOFT experiment L2-5, Int. Top. Meet. on Nuclear Reactor Thermal-Hydraulics (NURETH-11), Avignon (F), Oct. 2-6

Petruzzi A., D'Auria F., 2006, The Internal Assessment of Uncertainty, CIAU and CIAU-TN: Features and key Applications, ANS-CNS Top. Meet. On Reactor Physics - PHYSOR, Vancouver (BC, Canada), Sept. 10-14

Petruzzi A., Cherubini M., Lanfredini M., D’Auria F., Mazzantini O., 2016, The BEPU Evaluation Model with RELAP5-3D for the Licensing of the Atucha-II NPP, Nuclear Technology, 193, pp 113-160

Pontillon Y., Ravel S., Parrat D., Ferroud-Plattet M. P., Guérin Y., 2002, Fission gas release under fast transient and LOCA conditions: analytical devices implemented at CEA, Tech. Meet $<$ Fuel behavior under transient and LOCA conditions $>$, Halden (Norway), 10-14 Sept. 2001, IAEA TECDOC 1320, Vienna (A)

Popov N. K., Snell V. G., 2012, Safety and Licensing Aspects of Power Reactor Reactivity Coefficients, $20^{\text {th }}$ Int. Conf. on Nuclear Engineering and the ASME 2012 Power Conference, ICONE20-POWER2012-55243, Anaheim, (Ca, USA), July 30-Aug.3, 221-230; doi:10.1115/, ISBN: 978-0-7918-4498-4

Prosek A., Mavko B., D’ Auria F., 2004, Quantitative analysis of RD-14M large LOCA test B9401 calculations, IJS Report IJS-DP-8819, Ljubljana (Slo), Jan.

Queral C., Montero-Mayorga J., Gonzales-Cadelo J., Jimenez G., 2015, AP-1000 large break LOCA BEPU analysis with Trace code, Annals Nuclear Energy, 85, 576-589 
Ranjan R., Banerjee S., Singh R. K., Banerji P., 2014, Local impact effects on concrete target due to missile: An empirical and numerical approach, Annals of Nuclear Energy, 68, 262-275

Ransom V.H., Wang W., Ishii M., 1998, Use of an ideal scaled model for scaling evaluation, J. Nuclear Engineering and Design, 186

Raynaud P. A. C., 2012, Fuel Fragmentation, Relocation, and Dispersal during the Loss-of-Coolant Accident, USNRC NUREG 2121, March, Washington (D.C., US), pp 1-127

Reid S.R., Wang B., Aleyaasin M., 2011, Structural modelling and testing of failed high energy pipe runs: 2D and 3D pipe whip, Int. J. of Pressure Vessels and Piping, 88, 189-197

RELAP5/MOD3, 1998, Code manual volume I: code structure, system models and solution procedure, NUREG/CR-5535, USNRC, Washington, DC, USA

Reventos F., Perez M., Batet L., Pericas R. (Coordinators), Toth I., Bazin P., De Crecy A., Borisov S., Glaeser H., Skorek T., Joucla J., Probst P., Ui A., Chung B., Oh D., Kyncl M., Pernica R., Manera A., D'Auria F., Petruzzi A., Del Nevo A., 2008, Simulation of a LBLOCA in Zion Nuclear Power Plant - BEMUSE Phase IV Report, OECD/NEA/CSNI/ R(2008)6 vol 1, JT03256246, Paris (F)

Rohatgi U.S., Glaeser H., 2019, Counter Current Flow Limitation (CCFL), this Special Issue [MDPI. Fluids]

Rozzia D., Del Nevo A., Adorni M., D'Auria F., 2012, Modeling of BWR Inter-Ramp Project experiments by means of TRANSURANUS code, Annals of Nuclear Energy, 50, 238-250

Sartoris C., Taisne A., Petit M., Barré F., Marchand O., 2010, A consistent approach to assess safety criteria for reactivity initiated accidents, Nuclear Engineering and Design, 240, 57-70

Shiozawa S., Saito S., Yanagihara S., 1982, Zircaloy-U02 and -Water Reactions and Cladding Temperature Estimation for Rapidly-Heated Fuel Rods under an RIA Condition, J. of Nuclear Science and Technology, 19, 5, 368-383

Svanholm K., Breghi M.P., D’ Auria F., Ianiri R., 1995, Halden Reactors IFA-511.2 and IFA-54X: Experimental Series under Adverse Core Cooling Conditions, Experimental Thermal and Fluid Science, 11, 77-100

Thadani A, Laaksonen J., 2003, Workshop Summary “Re-defining the LBLOCA: technical bases and its implications", June 23-24, Zurich (CH), NEA/CSNI(2003)17, Paris (F), Vol I, pp 15-17

Ullah Amin S. A., Bang Y. S., Lee J. S., 2017, Assessment of post-LOCA long term cooling considering the in-vessel downstream effect, Annals of Nuclear Energy, 110, 63-72

Urbanic V.F., Heidrick T. R., 1978, High-temperature oxidation of zircaloy-2 and zircaloy-4 in steam, J. of Nuclear Materials, 75, 2, 251-261

USAEC, 1971, Interim Acceptance Criteria (IAC) for ECCS, USAEC, Washington, DC, USA

USNRC, 1978, Standard Format and Content of Safety Analysis Report for Nuclear Power Plants - LWR Edition, USNRC Regulatory Guide 1.70, Washington, DC, USA

USNRC, 2005, Transient and accident analysis methods, RG 1.203, USNRC, Washington, DC, USA

USNRC, 2007, NUREG-0800: Standard Review Plan Section 4.2: Fuel System Design, Appendix B-Interim Acceptance Criteria and Guidance for the Reactivity Initiated Accidents, USNRC, NUREG 0800, Washington DC, USA 
USNRC, 2018, Regulatory Guide 1.224, Preliminary Draft (Draft was issued as DG-1263, dated March 2014),

Valette M., Pouvreau J., Bestion D., Emonot P., 2011, Revisiting large break LOCA with the CATHARE-3 three-field model, Nuclear Engineering and Design, 241, 4487-4496

Vigni P., D'Auria F., Rosa U., 1978, Blowdown experiments from a pressure vessel with internal structures, (in Italian), University of Pisa Report, IIN - RL 317(78), Pisa (I), Dec. 1978, pp 1-65

Vigni P., D'Auria F., 1979, Unsteady Two-Phase Jet Forces (in Italian), J. Ingegneria Nucleare, 10, 23-32

Wolf L., 1982, Experimental results of coupled fluid-structure interactions during blowdown of the HDR-vessel and comparisons with pre-and post-test predictions, Nuclear Engineering and Design, 70, 3, 269-308

Yano T., Miyazaki N., Isozaki T., 1982, Transient analysis of blowdown thrust force under PWR LOCA, Nuclear Engineering and Design, 75, 157-168

Ylonen A., 2008, Large break blowdown test facility study, Master thesis at University of Lappeenranta, Lappeenranta (Finland) 